Aus Der Klinik fÜr Unfallchirurgie, Plastische- Und

WIEDERHERSTELLUNGSCHIRURGIE

(Prof. Dr. med. Wolfgang Lehmann)

DER Medizinischen FakUltäT DER UniversitäT GÖttingen

\title{
Der Einfluss von Strontiumranelat Auf Die Muskulatur Der osteopenen RatTe
}

\author{
INAUGURAL-DISSERTATION \\ ZUR ERLangung Des Doktorgrades \\ DER Medizinischen FAKUltät \\ Der Georg-August-Universität zu Göttingen \\ VORGELEGT VON
}

Benjamin Leopold Harlass

AUS

EINBECK

GÖTTINGEN 2019 
Dekan: Prof. Dr. rer. nat. Heyo K. Kroemer Referent: Prof. Dr. med. Stephan Sehmisch Ko-Referent: Prof. Dr. med. Wolfgang Wuttke Drittreferent: Prof. Dr. med. Martin Oppermann Datum der mündlichen Prüfung: 29.10.2019 
Hiermit erkläre, ich die Dissertation mit dem Titel "Der Einfluss von Strontiumranelat auf die Muskulatur der osteopenen Ratte"

eigenständig angefertigt und keine anderen als die von mir angegebenen Hilfsmittel verwendet zu haben.

Westerstede den 31.03.2019

Benjamin Leopold Harlass 


\section{Inhaltsverzeichnis}

$\begin{array}{ll}\text { Abkürzungsverzeichnis } & 3\end{array}$

1 Einleitung 5

$1.1 \quad$ Fragestellung der Dissertation . . . . . . . . . . . . . . . . . . . 5

1.2 Die Ratte als Modell für Sarkopenie und Osteoporose . . . . . . . . . . . . . 6

1.2.1 Morphologische Veränderungen der sarkopenen Muskulatur bei Mensch und Ratte . . . . . . . . . . . . . . . . . . . . . 7

1.2.2 Vorstellung der zu untersuchenden Parameter . . . . . . . . . . . . . 8

1.3 Sarkopenie . . . . . . . . . . . . . . . . . . . . . . . . . . . . . . 10

1.3.1 Differenzierung zwischen Skelett- und Herzmuskulatur sowie glatter Muskulatur ............................ 11

1.3.2 Aufbau der quergestreiften Muskulatur . . . . . . . . . . . . . . 11

1.3 .3 Epidemiologie . . . . . . . . . . . . . . . . . . . . . . . 13

1.3 .4 Formen der Sarkopenie . . . . . . . . . . . . . . . . . . . . . . . 13

1.3.5 Diagnostik . . . . . . . . . . . . . . . . . . . 13

1.3.6 Pathogenese der Sarkopenie . . . . . . . . . . . . . . . . . . . . . 14

1.3.7 Therapie der Sarkopenie . . . . . . . . . . . . . . . . . . 15

1.3.8 Wechselwirkung zwischen Knochen und Muskeln . . . . . . . . . . . . 16

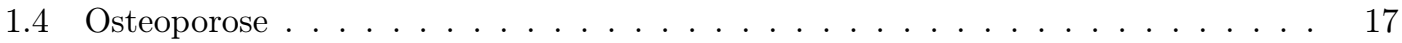

1.4 .1 Definition . . . . . . . . . . . . . . . . . . 17

1.4 .2 Epidemiologie . . . . . . . . . . . . . . . . . . . . . 18

1.4 .3 Formen . . . . . . . . . . . . . . . . . . . . . 18

1.4 .4 Diagnostik . . . . . . . . . . . . . . . . . . . . 21

1.4.5 Laborchemische Tests . . . . . . . . . . . . . . . . . . . . 23

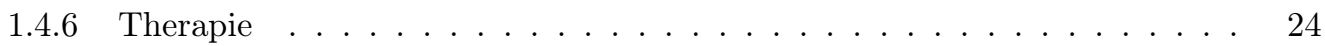

1.5 Strontiumranelat . . . . . . . . . . . . . . . . . . . . . . . . 29

2 Material und Methoden 32

2.1 Versuchsübersicht . . . . . . . . . . . . . . . . . . . . . . . . . . . 32

2.1.1 Versuchstierhaltung . . . . . . . . . . . . . . . . . . . . 33

2.1 .2 Ovarektomie . . . . . . . . . . . . . . . . . . . . 33

2.1 .3 Osteotomie . . . . . . . . . . . . . . . . . . 34

2.1 .4 Strontiumranelat . . . . . . . . . . . . . . . . . . . 34

2.1.5 Muskelpräparation . . . . . . . . . . . . . . . . . . 34

2.2 Schneiden der Muskulatur . . . . . . . . . . . . . . . . . . . . . . . . . 34

2.3 Färbungen . . . . . . . . . . . . . . . . . . . . . . . 35

2.3.1 Amylase-Periodic acid-Schiff reaction für Kapillarfärbung (nach Horak 1988) 35

2.3 .2 Glykogenfärbung . . . . . . . . . . . . . . . . . . . . . 37

2.4 Auswertungen der Färbungen . . . . . . . . . . . . . . . . . . . . . . . . . 40

2.4.1 Auswertung Kapillar-Färbung . . . . . . . . . . . . . . . . . . . . . 40

2.4 .2 Auswertung ATPase-Färbung . . . . . . . . . . . . . . . . . . 43

2.4 .3 Statistik . . . . . . . . . . . . . . . . . . . 46 
3 Ergebnisse

3.1 Uterusgewichte der Tiere am Tag der Obduktion . . . . . . . . . . . . . . . . . 47

3.2 Gewichtsentwicklung der Tiere im Verlauf . . . . . . . . . . . . . . . . . 48

3.3 Futteraufnahme der Tiere im Verlauf . . . . . . . . . . . . . . . . . . . . . 49

3.4 Ergebnisse der Kapillar-Färbung . . . . . . . . . . . . . . . . . . . . 50

3.4 .1 M. gastrocnemius . . . . . . . . . . . . . . . . . . . . 50

3.4 .2 M. longissimus . . . . . . . . . . . . . . . . . . 53

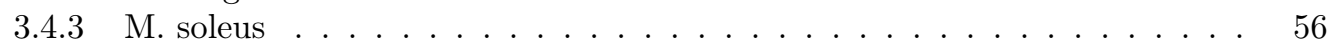

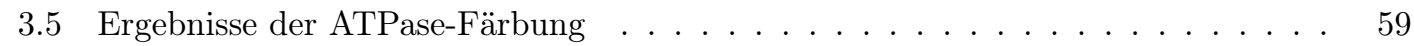

3.5 .1 M. gastrocnemius . . . . . . . . . . . . . . . . . . . 59

$3.5 .2 \quad$ M. longissimus . . . . . . . . . . . . . . . . . . . . 62

3.5.3 M. soleus . . . . . . . . . . . . . . . . . . . . . . 69

$3.6 \quad$ Zusammenfassung der signifikanten Ergebnisse _ . . . . . . . . . . . . . . . . 70

4 Diskussion $\quad \mathbf{7 1}$

4.1 Die ovarektomierte Ratte als Tiermodell . . . . . . . . . . . . . . . . . . . . . . 72

4.2 Diskussion der Ergebnisse der Kapillar-Färbung . . . . . . . . . . . . . . . . . . 73

4.3 Diskussion der Ergebnisse der ATPase-Färbung . . . . . . . . . . . . . 75

$\begin{array}{lll}5 & \text { Schlussfolgerung } & 77\end{array}$

$\begin{array}{ll}\text { Abbildungsverzeichnis } & \mathbf{7 9}\end{array}$

$\begin{array}{lr}\text { Tabellenverzeichnis } & \mathbf{8 0}\end{array}$

6 Literaturverzeichnis $\quad 83$ 


\section{Abkürzungsverzeichnis}

ALM Appendicular Lean Mass

Amylase-PAS-Färbung Amylase-Periodic acid-Schiff reaction-Färbung

ANOVA Analysis of Variance

ATP Adenosintriphosphat

ATPase Adenosintriphosphatase

BMC Bone Mineral Content

BMD Bone Mineral Density

BMI Body Mass Index

BSG Blutsenkungsgeschwindigkeit

COPD Chronic Obstructive Pulmonal Disease

CRPS Complex Regional Pain Syndrome

CT Computertomographie

dest. destilliert

DVO Dachverband Osteologie

DXA Dual-Röntgen-Absorptiometrie

EWGSOP European Working Group on Sarcopenia in Older People

Fa. Firma

FIT Fracture Intervention Trial

FLEX Fracture Intervention Trial Long-Term Extension

FNIHSP The Foundation for the National Institutes of Health Sarcopenia Project

Gamma-GT Gamma-glutamyl transpeptidase

Horizon PFT Health Outcomes and Reduced Incidence with Zoledronic acid Once yearly Pivotal Fracture Trial

IWGS International Working Group on Sarcopenia

KG Körpergewicht

kg Kilogramm 
Inhaltsverzeichnis

LW Lendenwirbel

M. Musculus

MALEO Male Osteoporosis

MORE Trial Multiple Outcomes of Raloxifene Evaluation Trial

MRT Magnetresonantomographie

PROOF prevent recurrence of osteoporotic fractures study

PTH Parathormon

QCT quantitative Computertomographie

RANKL Receptor Activator of NF-KappaB Ligand

SERM Selective Estrogen Receptor Modulator

TSH Thyroid-stimulating hormone

WHO World Health Organization

SD Standardabweichung

SOTI Spinal Osteoporosis Therapeutic Intervention

TROPOS Treatment of Peripheral Osteoporosis

[- ]Dimensionslose Größe 


\section{Einleitung}

\subsection{Fragestellung der Dissertation}

Sarkopenie ist eine altersbedingte Erkrankung, bei der es zu einer Verminderung der Muskelmasse und der Muskelkraft kommt, die sich häufig parallel zu einer Osteoporose entwickelt. Bereits im Wolffschen Gesetz wurde postuliert, dass sich der Knochen in seiner Mikrostruktur den auf ihn wirkenden Belastungen anpasst (Wolff 2010). Einfache biomechanische Überlegungen zeigen, dass die Hauptbelastung des Knochens sich über den Zug der Muskulatur an den Apophysen ergibt (Özkaya et al. 2012). Muskel und Knochen bilden eine funktionelle Einheit, die sich auch als endokrin-aktive Gewebe gegenseitig beeinflussen (Kaji 2013), im englischen Sprachraum hat sich dafür der Begriff functional muscle-bone-unit etabliert (Schoenau 2005).

Die enge Verbindung wird unter anderem dadurch deutlich, dass sich Griffkraft als surrogate Parameter für eine mögliche Osteoporose eignet (Sahin et al. 2002).

Es ist daher sinnvoll beide Krankheitsbilder gemeinsam zu betrachten. Strontiumranelat ist in Deutschland- trotz des erhöhten Risikos von tiefen Beinvenenthrombosen und dem gehäuften Auftreten von kardiovaskulären Ereignissen- als Medikament zur Osteoporosetherapie bei Kontraindikationen für andere Osteoporosemedikamente zugelassen. Von Strontiumranelat ist bekannt, dass es als einziges aktuell zugelassenes Medikament sowohl den Abbau von Knochen hemmt als auch die Proliferation von Osteoblasten stimuliert (Bonnelye et al. 2008).

Über die Wirkung von Strontiumranelat auf die Muskulatur ist hingegen wenig bekannt. Ziel dieser Arbeit ist es zu evaluieren, ob die Gabe von Strontiumranelat bei der osteopenen Ratte einen messbaren Einfluss auf die Muskulatur hat. Hierzu wird den Versuchstieren in definierten Versuchsgruppen für eine gewisse Periode Strontiumranelat mit dem Futter verabreicht. Nach dem Tod der Tiere werden der M. soleus, M. longissimus und M. gastrocnemius per Mikrotom geschnitten, gefärbt und histologisch untersucht. Neben der Größe der einzelnen Muskellzellen und der Anzahl der Kapillaren wird auch das Verhältnis von oxidativen zu glykolytischen Muskelzellen untersucht. 


\subsection{Die Ratte als Modell für Sarkopenie und Osteoporose}

Ratten sind etablierte Tiermodelle für das Altern (Mitchell et al. 2015) und zeigen dem Menschen ähnliche Veränderungen im Alter (Yorke et al. 2017), wozu auch die Entwicklung einer Sarkopenie gehört (Altun et al. 2010). Das Alter von Ratten lässt sich nicht linear mit dem menschlichen Alter korrelieren, je nach Entwicklungsabschnitt zeigen sich unterschiedliche Alterungsraten. Die Ratte ist nach circa sechs Wochen geschlechtsreif, mit etwa sieben bis acht Monaten in Hinblick auf das Sozialverhalten erwachsen, das Skelettwachstum ist zwischen dem siebten und achtem Lebensmonat abgeschlossen, während die reproduktive Seneszenz zwischen dem 15 bis 20 Lebensmonat beginnt. Mit Beginn der Menopause gelten die Ratten als alt (Sengupta 2013) und mit steigendem Alter wird auch die Ausprägung der Sarkopenie stärker. Das mediane Überleben für Ratten, die als Haustiere gehalten werden, liegt bei 23 Monaten, während das von Fischer-344Ratten bei etwa 26 Monaten liegt (Yorke et al. 2017). Entsprechend der großen Variabilität in Bezug auf die Frage, wann eine Ratte als alt gilt, finden sich in der Literatur auch große Schwankungsbreiten ab welchen Alter mit den Untersuchungen zur Sarkopenie begonnen wird. In der zitierten Literatur finden sich Schwankungen des Versuchstieralters zu Beginn der Versuche von 18 (Pannérec et al. 2016) bis 30 Monaten (Altun et al. 2010).

Die ovarektomierte Ratte ist ein etabliertes Modell zum Studium der Osteoporose, sodass die Food and Drug Administration (FDA) die ovarektomierte Ratte als Tiermodell für Osteoporosemedikamente empfiehlt (Thompson et al. 1995).

Die Sprague-Dawley Ratten sind etwa mit 12 Wochen geschlechtsreif und erreichen auch in diesem Alter die peak bone mass bezogen auf den kompletten Körper (Sengupta et al. 2005), auch wenn das longitudinale Wachstum der Knochen sich bis zum 15 bis 21 Lebensmonat fortsetzt (Lelovas et al. 2008). Trotz des weiteren Längenwachstums des Knochens zeigen die Ratten nach einer Ovarektomie einen Verlust an Knochensubstanz aufgrund des Östrogenmangels (Leitner et al. 2009), wobei sich die Ausprägung des Substanzverlustes je nach Knochen und auch in der zeitlichen Dynamik unterscheidet (Wronski et al. 1989). Das Skelettwachstum der Ratte ist stark vom Alter abhängig, man unterscheidet zwischen dem vollentwickelten Skelett zwischen dem dritten und sechsten Lebensmonat und alten Skelett ab dem sechsten Lebensmonat. Nach einer deutlichen Abschwächung vom dritten bis zum sechsten Lebensmonat ist es nach dem sechsten 


\section{Einleitung}

Lebensmonat vernachlässigbar (Kalu 1991). In diesem Versuch wurden Sprague-Dawley Ratten als Tiermodell benutzt.

\subsubsection{Morphologische Veränderungen der sarkopenen Muskulatur bei Mensch und Ratte}

Beschriebene Veränderungen in der Morphologie der Muskulatur bei sarkopenen Menschen sind ein verminderter Querschnitt der Typ-II-Muskelfasern (Martel et al. 2006; Verdijk et al. 2007; Frontera et al. 2008), eine Reduktion der Satellitenzellen in den Typ-II-Muskelfasern sowie eine verminderte Vaskularisierung der Typ-II-Muskelfasern (Verdijk et al. 2007; Nederveen et al. 2016). Im Gegensatz dazu ist der Typ-I-Muskelfaserquerschnitt größtenteils bis in das hohe Alter konstant (Verdijk et al. 2007; Snijders et al. 2009). Bezüglich einer verminderten Muskelfaseranzahl gibt es in der Literatur widersprüchliche Angaben. Während die Muskelatrophie in einer Studie rein auf die Hypotrophie der Typ II-Muskelfasern zurückgeführt wird (Nilwik et al. 2013), wird in anderen Studien neben der Hypotrophie der Typ-II-Muskelfasern auch eine Reduktion der Muskelfaseranzahl beschrieben (Lexell et al. 1983; Lexell et al. 1988).

Die morphologischen Veränderungen bei der sarkopenen Ratte sind denen des Menschen vergleichbar (Ballak et al. 2014). Der Hauptverlust an Muskelmasse findet wie beim Menschen an den unteren Extremitäten statt (Ibebunjo et al. 2013), wobei ebenfalls am stärksten die TypII-Muskelfasern betroffen sind (Pannérec et al. 2016). Bei der sarkopenen Ratte kommt es auch zu einer tatsächlichen Muskelfaseratrophie und die Muskulatur der sarkopenen Ratte zeigt auch in der Funktion dem sarkopenen Menschen analoge Einschränkungen. Interessanterweise ist die Muskulatur der Ratten an den vorderen Extremitäten analog zu den oberen Extremitäten des Menschen von der Sarkopenie ausgenommen, was auf Unterschiede in der nervalen Innervation der Muskulatur zurückgeführt wurde (Pannérec et al. 2016).

Die Ursache für den Verlust von Muskelmasse ist ein Missverhältnis aus Synthese und Abbau der Muskulatur. Das geringere Ansprechen der Proteinbiosynthese im Muskel auf anabole Stimuli wie freie Aminosäuren wird als anabole Resistenz bezeichnet. Neben der verminderten Synthese kommt es zu einem gesteigerten Abbau der Muskulatur, dies ist möglicherweise auf eine verstärkte Expression des Ubiquitin-Proteasom-Signalweges zurückzuführen (Altun et al. 2010). In welchem 
Anteil die verminderte Synthese bzw. der verstärkte Abbau zur Sarkopenie beiträgt ist noch nicht abschließend geklärt.

\subsubsection{Vorstellung der zu untersuchenden Parameter}

\section{M. gastrocnemius und $M$. soleus}

Der M. gastrocnemius und der M. soleus bilden zusammen den M. tricpes surae. Der M. gastrocnemius entspringt mit beiden Köpfen an der Rückseite der Femurkondylen und bildet nach Verschmelzung beider Muskelbäuche eine Endsehne, die mit der Endsehne des M. soleus verschmilzt und dann die Achillessehne bildet, die am Calcaneus inseriert. Der M. Soleus entspringt im proximalen Drittel von Fibula und Tibia und liegt ventral vom M. gastrocnemius, der Soleus inseriert etwas weiter distal. Ihre Hauptfunktion ist beim Menschen wie bei der Ratte die Plantarflexion und Supination des Fußes. Der M. gastrocnemius kann bei fixiertem Sprunggelenk als zweigelenkiger Muskel ein Heranziehen der Ferse an das Gesäß unterstützen (Drenckhahn 2008). Beim M. soleus überwiegen die Typ-I-Muskelfasern, auch wenn, wie bei jedem Skelettmuskel, eine gewissen Plastizität in Bezug auf die prozentuale Verteilung der Muskelfasern besteht (Kugelberg 1976; Tasić-Dimov und Dimov 2007), unter funktionellen Aspekten wird dies mit einem Überwiegen der Haltearbeit des M. soleus gedeutet. Beim M. gastrocnemius in der Ratte überwiegen die Typ-II-Muskelfasern, wobei sich auch hier der Typus, abhängig von der Belastung, ändern kann (Hong et al. 2013). Als Muskeln der unteren Extremität sind beide von der Sarkopenie betroffen.

\section{M.longissimus}

Der M. longissimus dorsi ist Teil des lateralen Trakts der autochthonen Rückenmuskulatur und bildet mit dem M. Iliocostalis das Sakrospinale System. Er reicht vom Os sacrum bis zum temporale. Lateral liegt der M. iliocostalis, der mit M. longissimus eine gemeinsame Ursprungssehne hat. Zusammen mit dem M. semispinalis werden die zwei Muskeln auch als Erector spinae bezeichnet. Funktionell dient der M. longissimus der Seitneigung und Streckung der Wirbelsäule, in aufrechter oder vorgebeugter Haltung ist er der maßgebliche Haltemuskel gegen die Schwerkraft (Drenckhahn 2008). Beim Longissimus dorsi überwiegen im Tiermodell die Typ-II-Muskelfasern 


\section{Einleitung}

(Khan et al. 2013; Flisinski et al. 2014; Hyytiäinen et al. 2014). Als Rückenmuskel ist er von der Sarkopenie weniger betroffen als die Muskulatur der unteren Extremitäten.

\section{Muskelfaserquerschnitt}

Die Kraft, die ein Muskel entwickeln kann, hängt vom physiologischen Querschnitt des Muskels ab, diese ergibt sich theoretisch als senkrechter Schnitt zu allen Muskelfasern. Je größer der Muskelquerschnitt, umso größer ist die theoretische Kraftentwicklung. Da beim Muskel nie alle Muskelfasern exakt gleich verlaufen und auch nicht unbedingt im gleichen Winkel inserieren, handelt es sich um eine Idealisierung. Bei der Sarkopenie nimmt der Querschnitt aller Muskelfasern, allerdings insbesondere der Typ-II-Muskelfasern, ab (Martel et al. 2006; Verdijk et al. 2007; Frontera et al. 2008; Pannérec et al. 2016).

\section{Kapillaren}

Die Kapillaren sind für die Versorgung des Muskels mit Nährstoffen, Sauerstoff und Wachstumsfaktoren essentiell. Bei der Sarkopenie beim Menschen zeigt sich eine Abnahme der Kapillardichte, insbesondere der Vaskularisierung der Typ-II-Muskelfasern, die allerdings neben dem Alter vom Trainingsstatus abhängt und bei adäquatem Training steigerbar ist (Proctor et al. 1995). Der Abstand zwischen den Kapillaren und den Satelittenzellen ist beim sarkopenen Menschen ebenfalls erhöht, dies könnte ein Grund für die verminderte Regenerationsfähigkeit bzw. die anabole Resistenz der sarkopenen Muskulatur sein (Nederveen et al. 2016). Auch unabhängig von der mikroskopisch sichtbaren Vaskularisierung der Muskulatur kommt es im Alter zu einer verminderten Perfusion der Muskulatur, die unabhängig von der verminderten Muskelmasse und möglicherweise auf eine verminderte Funktion des Endothels und der Zellatmung zurückzuführen ist (Dinenno et al. 2001). Eine höhere Anzahl an Kapillaren als Anpassung an Ausdauerbelastungen ist belegt (Brodal et al. 1977; Laughlin 1999), wobei die Anzahl der Kapillaren bis zu vierfach erhöht bei trainierten Ausdauersportlern im Vergleich zu Untrainierten sein kann (Saltin 1988), wobei eine Zunahme der Vaskulasierung von den Trainingsmodalitäten abhängig ist(Verdijk et al. 2016). Die Grundkonfiguration der Vaskularisierung hat einen Einfluss auf das Ansprechen der Typ-II-Muskelfasern auf Widerstandstraining, wobei eine hohe Vaskularisierung zu einem verbesserten Ansprechen führt (Snijders et al. 2017). Insulin übt seine anabole Wirkung ebenfalls über 


\section{Einleitung}

eine Erhöhung des Blutflusses und eine daraus folgende erhöhte Perfusion aus (Timmerman et al. 2010). Es kommt bei der Sarkopenie, ähnlich wie bei der Degeneration der Typ-II-Muskefasern, auch zu einer verminderten Absolut-Anzahl an Kapillaren (Verdijk et al. 2016; Snijders et al. 2017).

\subsection{Sarkopenie}

Sarkopenie ist definiert als eine altersbedingte Abnahme an Muskelmasse sowie Muskelkraft (Morley et al. 2001) und in der International Statistical Classification of Diseases and Related Health Problems als M62.84 als eigenständige Erkrankung anerkannt (Cao und Morley 2016). Der Begriff wurde von Rosenberg 1989 geprägt, wobei initial nur eine altersbedingte Abnahme der Muskelmasse zur Definition gehörte (Rosenberg 1997). Die Abnahme von Muskelmasse und Muskelkraft in Abhängigkeit von steigendem Lebensalter ist belegt, wobei die Muskelkraft schneller als die Muskelmasse abnimmt (Goodpaster et al. 2006). Die Muskelmasse korreliert negativ mit steigendem Lebensalter ab der dritten Lebensdekade (Janssen et al. 2000) bzw. ab dem siebenundzwanzigstens Lebensjahr (Silva et al. 2010). Männer haben absolut und relativ eine größere Muskelmasse als Frauen, wobei der Hauptunterschied in der Muskelmasse im Oberkörper liegt (Janssen et al. 2000), der Hauptverlust an Muskelmasse mit steigendem Alter findet bei beiden Geschlechtern an den unteren Extremitäten statt.

Aktuelle Kriterien zur Diagnosestellung der Sarkopenie umfassen neben dem essentiellen Verlust von Muskelmasse fakultativ den Verlust von Muskelkraft und/oder einen Verlust an körperlicher Leistungsfähigkeit. Die Muskelmasse wird dabei entweder absolut oder in Relation zur Körpergröße gemessen. Die kombinierte Muskelmasse aus Armen und Beinen wird als appendicular lean mass (ALM) bezeichnet. Die International Working Group on Sarcopenia (IWGS) definiert eine Sarkopenie als vorliegend, wenn die Ganggeschwindigkeit vermindert ist $(<1 \mathrm{~m} / \mathrm{s})$ und eine geschlechtsspezifische Verminderung der Muskelmasse (ALM Männer $\leq 7,23 \mathrm{~kg} / \mathrm{m}^{2}$, ALM Frauen $\leq 5,67 \mathrm{~kg} / \mathrm{m}^{2}$ ) vorliegt (Fielding et al. 2011). Die European Working Group on Sarcopenia in Older People (EWGSOP) hat einen Screeningalgorithmus entwickelt, wobei Ganggeschwindigkeit, Griffkraft sowie Muskelmasse gemessen werden. Zuerst wird die Ganggeschwindigkeit (pathologisch bei $\leq 0,8 \mathrm{~m} / \mathrm{s}$ ) gemessen, anschließend folgen Griffkraft (pathologisch bei 
Werten $<30 \mathrm{~kg}$ für Männer bzw. $<20 \mathrm{~kg}$ für Frauen) sowie die Muskelmasse (pathologisch bei einer ALM Männer $\leq 7,23 \mathrm{~kg} / \mathrm{m}^{2}$ bzw. Frauen $\leq 5,67 \mathrm{~kg} / \mathrm{m}^{2}$ ) (Cruz-Jentoft et al. 2010). Die The Foundation for the National Institutes of Health Sarcopenia Project (FNIHSP) definieren eine Sarkopenie als vorliegend, wenn entweder eine verminderte Muskelmasse (ALM/BMI $<0,789$ Männer, <0,512 Frauen) und eine verminderte Griffkraft ( $<26$ kg Männer, $<16$ kg Frauen) oder eine verminderte Muskelmasse und eine verminderte Ganggeschwindigkeit $(<0,8 \mathrm{~m} / \mathrm{s})$ vorliegen (Dam et al. 2014).

\subsubsection{Differenzierung zwischen Skelett- und Herzmuskulatur sowie glatter Muskulatur}

Das definierende Merkmal der Muskulatur ist die Fähigkeit zur Kontraktion. Es wird zwischen Skelett-, Herz- und glatter Muskulatur unterschieden, die alle eine unterschiedliche Mikrostruktur haben. Aufgrund der lichtmikroskopisch imponierenden Querstreifung werden Herz- und Skelettmuskulatur zur quergestreiften Muskulatur zusammengefasst, obwohl sie funktionell verschieden sind. Da sich diese Arbeit ausschließlich mit der Skelettmuskulatur beschäftigt, wird auf eine weitere Erläuterung der glatten und der Herzmuskulatur verzichtet. Die Skelettmuskulatur ist willkürlich innervierbar und findet sich am Bewegungsapparat. Sie besteht histologisch aus vielkernigen Zellen, die durch Fusion von Myoblasten entstanden sind.

\subsubsection{Aufbau der quergestreiften Muskulatur}

Laut Drenckhahn (2008) besteht ein Muskel aus einer Vielzahl von Muskelfasern, die von einer Bindegewebshülle umgeben sind, und den sehnigen Verbindungen des Muskels, die den Muskel entweder mit dem Skelett oder anderen Strukturen verbinden. Außen ist der Muskel von einer Faszie aus straffem Bindegewebe umgeben. Die unter der Faszie liegende Hülle aus lockerem Bindegewebe heißt Epimysium. Vom Epimysium strahlen bindegewebige Septen in den Muskel ein, die dann Perimysium genannt werden. Im Perimysium verlaufen die Leitungsbahnen und die Ausläufer der Sehnen (Lüllmann-Rauch und Paulsen 2012). Einzelne Muskelfasern sind von Endomysium umgeben. In diesem verlaufen geschlängelt die Kapillaren um die Längenveränderung des Muskels ausgleichen zu können. Die Reißfestigkeit eines Muskels wird maßgeblich durch 


\section{Einleitung}

das umgebende Bindegewebe bestimmt. Die eigentliche Muskelzelle, auch Muskelfaser genannt, ist eine vielkernige Riesenzelle, die mehrere Zentimeter lang sein kann und deren Durchmesser sich im Bereich von 10- $100 \mu \mathrm{m}$ befindet. Die meisten Muskelfasern sind Zuckungsfasern, u. a. in den Muskelspindeln kommen jedoch auch Tonusfasern vor. Während Zuckungsfasern auf den Reiz der innervierenden Nervenzelle nach dem Alles-oder-Nichts-Prinzip reagieren, können Tonusfasern sich abgestuft verkürzen. Unter den Zuckungsfasern unterscheidet man je nach der überwiegenden Form der Energiegewinnung drei Fasertypen. Der Typ 1, aufgrund des hohen Myoglobingehalts rot gefärbt, arbeitet überwiegend oxidativ und ermüdet langsam. Der Typ 2B arbeitet überwiegend glykolytisch und ermüdet schnell. Der Typ 2A stellt den Intermediärtyp dar. Bei der verwendeten ATPase-Färbung sind Fasern vom Typ 1 dunkel angefärbt, während die 2B-Fasern hell imponieren (Lüllmann-Rauch und Paulsen 2012). Mehrere von Perimysium umhüllte Muskelfasern bilden ein Primärbündel. Gruppen von Primärbündeln werden als Sekundärbündel bezeichnet. Die Kraft, die ein Muskel entwickeln kann, ist abhängig vom physiologischen Querschnitt des Muskels. Dieser wird senkrecht zu allen Muskelfasern gemessen. Falls der Muskel gefiedert ist, ist nur die senkrecht in Zugrichtung wirkende Kraftkomponente zu berücksichtigen. Für die absolute Kraft ist des Weiteren der Sehnenverlauf zu berücksichtigen.

\section{Myoblasten}

Die Myoblasten sind die mitotisch aktiven Vorläuferzellen, die durch Fusion zunächst Myotuben bilden. Mehrere Myotuben bilden die ersten quergestreiften Myofibrillen und eine Basalmembran, in die potentiell teilungsfähige Myoblasten mit eingeschlossen werden. Mehrere Myotuben lagern sich aneinander und bilden die Muskelfasern. Die eingeschlossenen Myoblasten bilden während der Reifung der Myotuben weitere Zellkerne. Die Muskelfaser selbst hat die Fähigkeit zur Mitose verloren, im Falle des Muskelwachstums stellen somit auch die Myoblasten die benötigten Zellkerne zur Verfügung. Die eingeschlossenen Myoblasten werden aufgrund ihrer Lage auch als Statellitenzellen bezeichnet (Lüllmann-Rauch und Paulsen 2012). 


\subsubsection{Epidemiologie}

Je nach zugrunde liegender Definition der Sarkopenie ergeben sich unterschiedliche Zahlen bezüglich der Prävalenz. Legt man die drei oben genannten Beispielsdefinitionen zugrunde, so ergeben sich unterschiedliche Zahlen, wie oft eine Sarkopenie vorliegt, jedoch besteht eine gute Übereinstimmung, wann eine Sarkopenie nicht vorliegt (Dam et al. 2014). Je nach zugrunde liegender Studie ist nach den EWGSOP-Kritierien bei selbständig lebenden alten Menschen von einer Prävalenz von 1-29\% (bis zu $30 \%$ bei Frauen) von 14-33\% (bis $68 \%$ bei Männern) bei Pflegeheimbewohnern und von bis zu 10\% bei Patienten in einem Akutkrankenhaus auszugehen (Cruz-Jentoft et al. 2014). Aufgrund der demographischen Entwicklung ist von einer zunehmenden Prävalenz in Zukunft auszugehen.

\subsubsection{Formen der Sarkopenie}

Die Sarkopenie wird anhand der Ätiologie in primäre und sekundäre Sarkopenie eingeteilt. Eine primäre Sarkopenie liegt vor, wenn die Sarkopenie allein durch den Alterungsprozess bedingt ist. Gibt es eine andere Ursache, so liegt eine sekundäre Sarkopenie vor.

\subsubsection{Diagnostik}

Entsprechend den oben genannten Definitionen ist eine Messung der Muskelmasse, Muskelkraft sowie der physischen Leistungsfähigkeit zur Diagnosestellung der Sarkopenie notwendig. Die Messung der Muskelmasse mittels bildgebender Verfahren ist beispielsweise über eine Computertomographie (CT) sowie Magnetresonanztomographie (MRT) oder eine Dualröntgenabsorptiometrie (DXA) möglich. CT und MRT weisen dabei die höchste Präzision, allerdings auch die höchsten Kosten sowie eine limitierte Verfügbarkeit auf, sie stellten damit den Goldstandard für wissenschaftliche Studien dar. Beim CT besteht zudem eine erhöhte Strahlenbelastung. Die DXA wird entsprechend als praktikables Verfahren von der EWGSOP empfohlen (Cruz-Jentoft et al. 2010). Die Messung der Körpermasse über elektrischen Widerstand (Bioimpedanzanalyse) sowie die Messung des körpereigenen Kaliums werden als nicht-bildgebende Messmethoden empfohlen (Cruz-Jentoft et al. 2010). Sowohl von der EWGSOP und der IWGS wird als Parameter 
für die Gesamtmuskelkraft die Griffkraft gemessen, wobei zur Messung auf ein Dynamometer zurückgegriffen wird (Cruz-Jentoft et al. 2010, Fielding et al. 2011).

Die Griffkraft korreliert nicht nur mit der Muskelkraft im gesamten Körper, sondern ist auch ein Prädiktor für erkrankungsspezifische sowie absolute Mortalität (Rantanen et al. 2003). Je nach Studie gibt es eine ausgeprägte oder weniger ausgeprägte Korrelation der Griffkraft mit der Quadricepsstärke (Chan et al. 2014). Problematisch ist, dass es keine eindeutige Vorschrift zur Durchführung der Griffkraftmessung gibt (Sousa-Santos und Amaral 2017).

Weitere Methoden zur Messung der Muskelkraft umfassen die Knieflexion-/Extensionskraft sowie die exspiratorische Messung des Atemstroms. Beide Methoden sind aber aufgrund des apparativen Aufwandes bzw. als alleiniger Parameter für die Gesamtmuskelkraft nicht geeignet (Cruz-Jentoft et al. 2010). Zur Messung der körperlichen Leistungsfähigkeit stehen unterschiedliche Testverfahren zur Verfügung. In allen drei oben genannten Klassifikationen reicht aber zur Feststellung einer verminderten körperlichen Leistungsfähigkeit bereits eine verminderte Ganggeschwindigkeit aus. (Cruz-Jentoft et al. 2010, Fielding et al. 2011, Dam et al. 2014)

\subsubsection{Pathogenese der Sarkopenie}

Die Muskulatur unterliegt wie das restliche Körpergewebe einem natürlichen Alterungsprozess. Es kommt neben einem Verlust an Muskelmasse zu einer Abnahme der Typ-2-Muskelfasern, zusätzlich kommt es zu einer verminderten Innervationsdichte der Muskelfasern sowie einem Verlust an Satellitenzellen. Auch nimmt die Menge an elastischen Fasern ab, und es kommt zu einer vermehrten Fetteinlagerung in den Muskel. Des Weiteren zeigen sich Störungen in den Mitochondrien sowie dem sarkoplasmatischem Retikulum. Zusätzlich kommt es im Alter zu vermehrten inflammatorischen Reaktionen sowie einer Abnahme des Testosteronspiegels. Allerdings führt die physiologische Alterung nicht zwangsläufig zu einer Sarkopenie. Die Sarkopenie ist eine multifaktorielle Erkrankung, bei der neben der Zellalterung externe Faktoren wie körperliche Aktivität, Ernährung sowie psychosoziale Faktoren eine Rolle spielen. Hauptverantwortlich für Muskelhypotrophie ist die körperliche Inaktivität, so kommt es bei jungen Menschen bereits nach einer kurzen Immobilisierungsdauer von fünf Tagen zu einem massivem Verlust an Muskelmasse (Wall et al. 2014). 
Bei alten Menschen ist die körperliche Aktivität vermindert, bereits moderate Muskelaufbautrainingsprogramme gelten als die effizienteste Therapie der Sarkopenie (Tieland et al. 2017). Bei alten Menschen liegt zusätzlich oft ein kataboler Ernährungszustand vor, der zu einer weiteren Abnahme der Muskelmasse führt, dieser Zustand wird als Altersanorexie bezeichnet (Morley 2012). Zusätzlich spielen Selbstwirksamkeit sowie die psychische Resilienz eine wichtige Rolle bei der Entstehung der Sarkopenie (Tieland et al. 2017).

\subsubsection{Therapie der Sarkopenie}

Die Konstellation einer Sarkopenie kann mannigfaltige Ursachen haben. Liegt eine sekundäre Sarkopenie vor, so steht die Behandlung der Grunderkrankung im Vordergrund. Da der Verlust der Muskelmasse neben dem Alterungsprozess hauptsächlich durch körperliche Inaktivtät bedingt ist, lassen sich durch ein progressives Widerstandstraining sowohl die Muskelmasse als auch die Kraft sowie die körperliche Leistungsfähigkeit insgesamt steigern. Dies führt zu einer verbesserten neuromuskulären Koordination, sodass sowohl die Koordination als auch das Gleichgewicht verbessert werden, was wiederum eine geringe Anzahl an Stürzen bedingt (Sayer et al. 2013). Eine ausreichende Versorgung mit Proteinen bzw. Aminosäuren ist aufgrund der häufigen Mangelernährung im Alter ebenfalls notwendig. Im Alter ist darüber hinaus die anabolen Reaktion bei Aufnahme von verzweigtkettigen Aminosäuren weniger ausgeprägt, sodass sich eine Aufnahme von bis zu 1,5 g Protein pro Kilogramm Körpergewicht empfiehlt (Sayer et al. 2013; Tieland et al.2017).

Möglicherweise hat auch ein Vitamin-Mangel einen negativen Effekt auf die Muskulatur, wobei die Ursache dafür noch nicht abschließend geklärt ist, ebenso sind die Vorzüge einer antioxidantienreichen Ernährung noch nicht abschließend geklärt (Sayer et al. 2013). Eine pharmakologische Therapie der Sarkopenie existiert bisher nicht, auch wenn die anabole Wirkung einer Hormonsubstitution mit Testosteron und oder Somatropin unbestritten ist, so existieren bisher keine entsprechende therapeutische Empfehlungen (Giannoulis et al. 2012). 


\subsubsection{Wechselwirkung zwischen Knochen und Muskeln}

Ähnlich wie bei Knochen unterliegt die Muskulatur sehr dynamischen Veränderungen. Auf einen adäquaten, regelmäßigen, verstärkten Reiz wie beispielsweise regelmäßiges körperliches Training reagiert der Muskel mit Wachstum, auf Inaktivität mit Hypotrophie. Des Weiteren kann sich, je nach Belastung, auch der überwiegende Fasertyp des Muskels ändern. Der Stoffwechsel der Muskulatur beeinflusst den gesamten Stoffwechsel des Körpers, zusätzlich dient die Muskulatur dem Organismus als Proteinreservoir bei katabolen Ernährungszuständen.

Um 1900 stelle Julius Wolff das sogenannte Wolffsche Gesetz auf, in dem postuliert wurde, dass sich der Knochen je nach Beanspruchung verändern kann. Im Utah Paradigm of Skeletal Physiology wurde als Hauptfaktor für die Änderung der Knochenstruktur die Verformung des Knochens aufgrund von Belastungen identifiziert. Diese Idee führte zur Formulierung der Mechanostat-Theorie (Frost 2001). Die Hauptbelastungen auf einen Knochen resultieren aus den von der Skelettmuskulatur ausgeübten Kräften (Schiessl et al. 1998).

Somit kann man Knochen und Muskulatur nicht getrennt betrachten, sondern muss sie als eine funktionelle Einheit sehen. Im Alter tritt eine Veränderung der Körperzusammensetzung auf, insbesondere bei postmenopausalen Frauen nehmen die Gesamtkörpermasse und insbesondere auch die Muskelmasse ab, wobei der Wegfall des Östrogens als regulierender Faktor eine wichtige Rolle spielt (Aloia et al. 1991). Ein erniedrigter Östrogenspiegel bei Ratten sorgte in vergangen Studien für eine bei Gabe von Östrogenen reversible Vergrößerung der einzelnen Muskelfasern (McCormick et al. 2004), und in weiteren Studien konnte gezeigt werden, dass ein erniedrigter Östrogenspiegel mit einer verminderten Angiogenese assoziiert ist (Matsubara et al. 2012). Ebenso wird der Muskelfasertypus von Östrogen beeinflusst, so finden sich bei Frauen im Vergleich zu Männern ein erhöhter Anteil von Typ-1 und Typ-2a-Fasern und eine stärkere Vaskularisierung der Muskulatur (Haizlip et al. 2015)

Bei postmenopausalen Frauen ist der sinkende Östrogenspiegel mit einer verminderten fettfreien Körpermasse sowie einem erhöhten Verletzungsrisiko assoziiert, wobei Östrogensubstitution die erhöhte fettfreie Körpermasse nur bedingt beeinflussen kann (Bea et al. 2011), die reduzierte Muskelmasse bedingt ein erhöhtes Osteoporoserisiko, ebenso nimmt die Wahrscheinlichkeit für Stürze zu, welche ein Hauptgrund für das Auftreten von osteoporotischen Frakturen sind (Kim 


\section{Einleitung}

et al. 2014). Die Verminderung der Muskelmasse und der Muskelkraft im Alter als eigenständige Krankheit werden unter dem Begriff Sarkopenie subsummiert (Clynes et al. 2015).

Als gesichertes Wissen gilt die Assoziation einer hohen Muskelmasse sowie Muskelkraft mit einer erhöhten Knochendichte sowie eine verminderte Muskelmasse und Muskelkraft mit Osteoporose (He et al. 2015).

\subsection{Osteoporose}

\subsubsection{Definition}

Osteoporose ist definiert als eine systemische Skeletterkrankung, für die eine Verminderung der Knochendichte sowie eine Verschlechterung der Knochenqualität konstituierend sind, daraus resultiert eine gesteigerte Vulnerabilität des Knochens mit einer erhöhten Frakturgefährdung. Die Knochendichte ergibt sich maßgeblich durch den Kalziumgehalt des Knochens und hat die Dimension Masse pro Fläche oder Volumen, die Knochenqualität wird maßgeblich durch die Trabekelstrukur des Knoches bestimmt. Die häufigsten Prädilektionsstellen für Osteoporose-bedingte Frakturen sind die Wirbelkörper, die Hüfte, die Rippen sowie das Handgelenk. Alle diese Frakturen sind mit einer erhöhten Mortalität und einer eingeschränkten Lebensqualität verbunden, wobei insbesondere die am häufigsten auftretenden Wirbelkörperfrakturen zu chronischen Schmerzen führen können (NIH Consensus Development Panel on Osteoporosis Prevention 2001). Von den genannten Frakturen führen Hüftfrakturen zu den stärksten Einschränkungen im Alltagsleben und sind mit einer altersangepassten Erhöhung der Mortalität um bis zu 20\% assoziiert (Cummings und Melton 2002). In der klinischen Praxis wird Osteoporose über eine verminderte Knochendichte definiert. Dazu wird der Knochenmineralgehalt per DXA-Knochendichtemessung an der Lendenwirbelsäule und am proximalen Femur bestimmt und mit einem Referenzkollektiv verglichen. Zur Bildung des Referenzkollektives wurden 20- 29-jährige Frauen herangezogen. Die Abweichung wird in Standardabweichung angegeben, dieser Wert wird als T-Score bezeichnet. Eine normaler Knochen liegt bei einer Abweichung der Knochendichte von weniger als 1 Standardabweichung (SD) und eine Osteopenie bei einer Abweichung von mehr als 1 und weniger als 2,5 SD vor. Bei einer Abweichung von mehr als -2,5 SD liegt eine Osteoporose vor, bei dem Auf- 


\section{Einleitung}

treten von mindestens einer Fraktur als Folge der Osteoporose wird die Osteoporose als manifest bezeichnet. Es existieren für Männer und Frauen getrennte Referenzkollektive, somit variiert die Aussagekraft, je nachdem, ob für die Bestimmung des T- Score bei einem männlichen Patienten ein weibliches oder männliches Referenzkollektiv herangezogen wurde.

\subsubsection{Epidemiologie}

Die Anzahl der weltweit von Osteoporose betroffenen Menschen wird auf etwa 200 Millionen geschätzt. In Deutschland wurde die Anzahl der von Osteoporose betroffenen Patienten auf 7,8 Millionen in der Altersgruppe der über-50-Jährigen angegeben, was einer Prävalenz von etwa $26 \%$ entspricht. Es zeigte sich eine klare Altersabhängigkeit mit einer deutlichen Zunahme im Alter und eine deutliche Geschlechterdiskrepanz, wobei $83 \%$ der Betroffenen Frauen sind (Häussler et al. 2007). Aufgrund der weltweiten demografischen Entwicklung ist von einer steigenden Prävalenz auszugehen. Die Anzahl der Osteoporose-bedingten Frakturen in der gesamten EU im Jahr 2003 wird auf knapp 3,8 Millionen taxiert (Häussler et al. 2007), für die USA wird von 1,5 Millionen Frakturen pro Jahr bedingt durch Osteoporose ausgegangen (Riggs und Melton 1995). Die sozioökonomischen Kosten in der EU werden auf 27 Milliarden Euro mit einer prognostizierten Verdopplung bis zum Jahr 2050 bemessen (Kanis und Johnell 2005).

\subsubsection{Formen}

Es gibt viele verschiedene Möglichkeiten der Einteilung der Osteoporose. Hier wird nur auf die Einteilung anhand der Lokalisation und der Ätiopathogenese eingegangen, da diese klinisch die größte Relevanz besitzen. Eine Einteilung nach betroffenen Skelettarealen ist sinnvoll, da sich je nach Ursache der Osteoporose charakteristische Befallsmuster ergeben. Für die eigentliche Therapie ist dann die Ursache der Osteoporose entscheidend. 


\section{Einleitung}

\section{Einteilung nach Lokalisation}

Je nach betroffenen Anteilen des Skelettes unterscheidet man eine lokalisierte Osteoporose von einer generalisierten. Die häufigste Form der Osteoporose ist die generalisierte Form, die stets ein symmetrisches Befallsmuster zeigt. Für eine lokalisierte Osteoporose kann es diverse Ursachen geben, einige Beispiele ohne Anspruch auf Vollständigkeit sind der folgenden Tabelle zu entnehmen (Tab. 1.1).

Tabelle 1.1: Ursachen der lokalisierten Osteoporose

\begin{tabular}{cl}
\hline Krankheit & Ursache \\
\hline Inaktivitätsosteoporose an Extremitäten & Immobilisation beispielsweise bedingt \\
durch eine Parese \\
Complex Regional Pain Syndrome (CRPS) & Meistens posttraumatisch \\
Knochenmarködem- Syndrom & Unklare Ätiolgie \\
Gorham- Syndrom & Unklare Ätiologie \\
Andere osteolytische Syndrome & Infektiös, traumatisch, neoplastisch, \\
& metabolisch, vaskulär, genetisch, ange- \\
& boren \\
\hline
\end{tabular}

\section{Einteilung nach der Ätiologie}

Hier wird prinzipiell zwischen einer primären und einer sekundären Osteoporose unterschieden. Obwohl über die Pathophysiologie der postmenopausalen und senilen Osteoporse vieles inzwischen bekannt ist, werden diese unter dem Begriff der primären Osteoporose subsummiert. Die sekundäre Osteoporose ist stets Folge einer anderen Grundkrankheit. Auch wenn sekundäre Osteoporosen insgesamt selten sind, führen sie häufig zu Frakturen (Bartl 2011). Die folgende Tabelle listet exemplarisch Grundkrankheiten, die zu einer sekundären Osteoporose führen können, auf (Tab. 1.2). 


\section{Einleitung}

Tabelle 1.2: Ursachen der sekundären Osteoporose

\begin{tabular}{|c|c|}
\hline Ursache & Krankheit \\
\hline \multirow{9}{*}{ Hämatologisch/ myelogen } & Hypogonadismus, Hyperthyreose, Hy- \\
\hline & perparathyreoidismus, Morbus Cus- \\
\hline & hing, Diabetes mellitus \\
\hline & Multiples Myelom, Polyzythämia ve- \\
\hline & ra, chronisch myeloische Leukämie, ge- \\
\hline & steigerte Erythropoese bei angeborener \\
\hline & Hämolyse, Morbus Gaucher, Lympho- \\
\hline & me, Leukämien, systemische Mastozy- \\
\hline & tose \\
\hline Onkologisch & Metastasen unklarer Ätiologie \\
\hline \multirow[t]{4}{*}{ Hepatisch/ gastroenterologisch/ alimentär } & Malabsorptionssyndrome, $\quad$ Morbus \\
\hline & Crohn, Pankreasinsuffizienz, primär \\
\hline & biliäre Zirrhose, Z.n. Billroth I und II, \\
\hline & Dünndarmresektion \\
\hline Nephrologisch & Chronische Niereninsuffizienz \\
\hline Kardiologisch/pulmonologisch & Asthma bronchiale, Z.n. Herzklappen- \\
\hline & operationen \\
\hline \multirow[t]{3}{*}{ Medikamentös/ toxisch } & Glukokortikoide, Antikoagulanzien, \\
\hline & Antiepileptika, Aluminium, Cadmium, \\
\hline & Arsen \\
\hline Genetisch & Reduzierte Peak Bone Mass \\
\hline
\end{tabular}




\section{Risikofaktoren}

Der Hauptrisikofaktor für die Entwicklung einer Osteoporose ist das Lebensalter. Geschlecht, familiäre Vorbelastung, atraumatische Wirbelkörperfraktur, periphere Fraktur nach dem 50. Lebensjahr, proximale Femurfrakturen bei den Eltern, multiple Stürze, Raucheranamnese, Immobilität sowie Untergewicht sind weitere Risikofaktoren.

\subsubsection{Diagnostik}

Die Leitlinie des Dachverbandes Osteologie (DVO) hält eine Basisdiagnostik prinzipiell bei Frauen ab dem 70. Lebensjahr sowie bei Männern ab dem 80. Lebensjahr für empfehlenswert, sofern der Nachweis einer Osteoporose bei diesen Patienten therapeutische Konsequenzen impliziert. Das gleiche gilt bereits ab dem 60. Lebensjahr bei Männern sowie bei postmenopausalen Frauen bei dem Vorliegen von niedrigtraumatischen Frakturen, im Falle einer therapeutischen Konsequenz bei erhöhtem Frakturrisiko sowie bei Patienten mit erhöhtem Frakturrisiko. Ein erhöhtes Frakturrisiko ist laut DVO dann gegeben, wenn das Risiko für eine Wirbelkörperfraktur oder eine Femurfraktur in den nächsten 10 Jahren 20\% oder mehr laut dem DVO-Risikomodell von 2006 beträgt. Bei der dazwischenliegenden Gruppe, also Männern ab dem 70. Lebensjahr sowie bei Frauen ab dem 60. Lebensjahr, ist die Indikation für eine Basisdiagnostik großzügig zu stellen. So begründen die im Folgenden genannten Risikofaktoren Untergewicht, Rauchen und/oder das Vorliegen einer COPD, Immobilität, Herzinsuffizienz, Dauertherapie mit Protonenpumpeninhibitioren oder dauerhaft hochdosierte inhalative Glukokortikoideinnahme, Herzinsuffizienz, Immobilität, proximale Femurfraktur bei Vater oder Mutter, multiple intrinsische Stürze oder erhöhte Sturzneigung, Therapie mit Glitazonen, Diabetes mellitus Typ 2, Hyperthyreose oder subklinischer Hyperthyreose, sofern persistierend, Aromatasehemmertherapie, Hormonablative Therapie oder Hypogonadismus beim Mann, Spondylitis ankylosans, Depression / Antidepressivaeinnahme bereits die Durchführung einer Basisdiagnostik. Bei Patientenkollektiven, bei denen aufgrund einer Grunderkrankung das Frakturrisiko oder der V.a. auf eine sekundäre Osteoporose besteht, ist eine Diagnostik frühzeitig anzustreben.

Die empfohlene Basisdiagnostik besteht aus Anamnese, körperlicher Untersuchung, einer laborchemischen Untersuchung und einer DXA-Knochendichtemessung. Weitere bildgebende Dia- 


\section{Einleitung}

gnostik ist fakultativ, sie sollte aber unter anderem bei dem klinischen Verdacht auf Frakturen erfolgen.

\section{Anamnese und körperliche Untersuchung}

Wichtige Bestandteile der Anamnese sind die Erfassung der Frakturriskofaktoren sowie zu eruieren, ob Anhalte für das Vorliegen einer sekundären Osteoporose bestehen. Eine ausführliche Medikamentenanamnese in Bezug auf sturzbegünstigende Medikamente sowie zur Frage einer möglichen Substitution von Kalzium und Vitamin D ist sinnvoll. Des Weiteren sollte in Bezug auf das Vorliegen von weiteren Vorerkrankungen festgestellt werden, ob diese Kontraindikationen für eine mögliche geplante medikamentöse Therapie darstellen. Zusätzlich sollte bei bereits manifesten Frakturen eine genaue Erfassung der Schmerzlokalisation sowie der Schmerzintensität zur Planung der weiteren analgetischen Therapie erfolgen.

In der körperlichen Untersuchung liegt der Fokus auf direkten oder indirekten Zeichen der Osteoporose. Neben der obligaten Erfassung der Körpergröße und des Körpergewichts sind Veränderung der Statik und Haltung zu dokumentieren. Klopfschmerzhaftigkeit der Processus spinosus, Bewegungseinschränkungen der Wirbelsäule, paravertebraler Hartspann sind klinische Zeichen für das Vorliegen einer Wirbelkörperfraktur. Des Weiteren wird von der DVO ab dem 70. Lebenjahr empfohlen den Timed-up and go- sowie den Chair rising-Test in Kombination mit dem Tandemstand durchzuführen.

\section{Osteodensometrie}

Die Durchführung der Osteodensometrie erfolgt zur Feststellung, ob eine Osteoporose gemäß der WHO-Definition vorliegt. Sie ist zur Therapieplanung, Therapieevaluation und Verlaufskontrolle unverzichtbar und erlaubt die Diagnosestellung vor dem Auftreten von Frakturen. Es gibt mehrere Verfahren zur Messung der Knochendichte, die DXA-Messung ist der Standard.

DXA Die Dual-Röntgen-Absorptiometrie (englisch dual-x-ray-absorptiometry) ist das von der DVO empfohlene Standardverfahren zur Knochendichtemessung. Da das Vorliegen einer Osteoporose gemäß WHO-Kriterien auf einer verminderten Knochendichte in der DXA-Messung basiert, ist die Diagnosestellung sowie die weitere Therapieplanung von dem Ergebnis der Messung 
abhängig. Erfasst werden der Knochenmineralgehalt (BMC) mit der Dimension Gramm sowie die Knochenmineraldichte (Bone mineral density) mit den Dimension $\mathrm{g} / \mathrm{cm}^{2}$ oder $\mathrm{g} / \mathrm{cm}^{3}$. Die Methode basiert auf der in Abhängigkeit von der Energie der Röntgenstrahlung unterschiedlichen Schwächung der Strahlung beim Durchtritt durch Gewebe. Es werden zwei Strahlenquellen unterschiedlicher Energie verwendet, anschließend lässt sich anhand der Unterschiede der Schwächung Rückschlüsse auf die Gewebedichte ziehen. Es können Fett-, Muskulatur- sowie Skelettgewebe unterschieden werden. Untersucht werden der proximale Femur und die Wirbel LW 1 bis LW 4, wobei mindestens zwei Wirbelköper beurteilbar sein müssen. Der mittlere T-Score wird erhoben und mit den korrespondierenden Werten der entsprechenden, geschlechterspezifischen Normkollektiven verglichen.

\section{Computertomografie QCT und Quantitative Ultraschallmessung (Quantitative ultrasound,}

QUS) Da die DXA die empfohlene Standardmethode ist, werden die oben genannten Verfahren im Regelfall ergänzend eingesetzt. Die quantitative Ultraschallmessung hat Bedeutung als Screeningtest bei Hochrisikopatienten, bei denen die Durchführung einer DXA-Messung erschwert ist. Die QCT-Messung kann, falls eine DXA-Messung nicht durchführbar oder verwertbar ist, als Alternative durchgeführt werden. Das Röntgenbild der Wirbelsäule hat Bedeutung in der Frage nach bereits vorliegenden Frakturen oder zur Abklärung einer sekundären Osteoporse.

\subsubsection{Laborchemische Tests}

Da sich bei der primären Osteoporose die im Routinelabor erfassten Parameter üblicherweise im normwertigen Bereich befinden, dient das Labor primär dem Ausschluss einer sekundären Osteoporose. Des Weiteren lässt sich bezüglich der Therapie eruieren, ob aufgrund einer eingeschränkten Nierenfunktion die Notwendigkeit für eine Dosisanpassung bzw. eine Kontraindikation für gewisse Wirkstoffgruppen besteht. Laut DVO sollte das Routinelabor Serum-Kalzium, Serum-Phosphat, die alkalische Phosphatase, Gamma-GT, Kreatinin-Clearance, Blutsenkungsgeschwindigkeit(BSG)/ C-reaktives Protein, kleines Blutbild sowie Thyroid-stimulating hormone (TSH) umfassen. Die Testung des Testosteronspiegels bei Männern und die Bestimmung von 25Hydroxy-Vitamin D3 sowie die Knochenresorptionsparamter bleiben Einzelfällen vorbehalten. 


\section{Einleitung}

\subsubsection{Therapie}

Die Therapie der Osteoporose hat das Ziel, die Knochendichte und Qualität zu steigern, das Frakturriskio zu reduzieren und den Knochenstoffwechsel zu optimieren. Die Indikation für eine medikamentöse Therapie besteht in Abhängigkeit vom Grad der Verminderung der Knochendichte sowie spezifischer Risikokonstellationen. Die Maßnahmen lassen sich in Basismaßnahmen sowie die spezifische medikamentöse Therapie unterteilen.

\section{Allgemeinmaßnahmen}

Besteht der Verdacht auf eine sekundäre Osteoporose oder sollte eine solche vorliegen, so ist zunächst die umfassende Diagnostik bzw. die Optimierung der Therapie der Grunderkrankung anzustreben. Zu den empfohlenen Allgemeinmaßnahmen zur Frakturrisikoreduktion zählt die regelmäßige körperliche Aktivität in altersangepasster Intensität. Dauerhafte Immobilisierung des Patienten sollte vermieden werden. Ab dem 70. Lebensjahr empfiehlt sich eine jährliche Sturzanamnese mit dem Ziel vermeidbare Sturzursachen aufzudecken und zu beseitigen. Ist bereits ein Sturz oder eine Fraktur eingetreten, so ist eine psychosoziale Betreuung des Patienten anzustreben mit dem Ziel, Ängste zu reduzieren und die Mobilität zu erhalten, eine Anbindung an eine Selbsthilfegruppe ist empfehlenswert. Osteoporose- oder sturzbegünstigende Medikamente sollten in Bezug auf das Nutzen/ Risikoverhältnis evaluiert und eine Dosisanpassung bzw. ggf. eine Therapieumstellung erfolgen. Sollte der Patient eine Glukokortikoiddauertherapie erhalten, so ist die niedrigste im Rahmen der Grunderkrankungen zulässige Dosis der Glukokortikoide anzustreben. Bei erhöhtem Frakturrisiko sollte eine Therapieumstellung bei Glitazongabe erfolgen. Eine Hyponatriämie sollte vermieden werden. Für Osteoporosepatienten, die keine spezifische medikamentöse Osteoporosetherapie erhalten, wird die Supplementierung von Vitamin D3 empfohlen, eine Kalziumsubstitution sollte nur im Falle einer mangelnden Zufuhr über die Nahrung erfolgen. Für Osteoporosepatienten, die eine antiresorptive Therapie erhalten, ist die Substitution von Kalzium und Vitamin D3 obligat. 


\section{Einleitung}

\section{Medikamentöse Therapie}

Die Indikation für eine medikamentöse Osteoporosetherapie richtet sich nach Geschlecht, Lebensalter, dem Ergebnis der DXA-Knochendichtemessung sowie weiteren Risikofaktoren. Therapieindikation in Abhängigkeit vom T-Score: Eine medikamentöse Behandlung ist gemäß DVOLeitlinien ab einem geschätzten 10-Jahresfrakturrisiko für proximale Femurfrakturen und vertrebrale Frakturen von ca. 30\% oder mehr gegeben. Die untere Tabelle zeigt in Abhängigkeit von Geschlecht, Lebensalter und T-Score, ab wann eine medikamentöse Therapie indiziert ist.

Tabelle 1.3: Therapieindikationen in Abhängigkeit vom T-Score

\begin{tabular}{ccc}
\hline T-Score & Lebensalter Mann & Lebensalter Frau \\
\hline-2.0 bis -2.5 & $>85$ & $>75$ \\
-2.5 bis -3.0 & $80-85$ & $70-75$ \\
-3.0 bis -3.5 & $75-80$ & $h 65-70$ \\
-3.5 bis -4.0 & $70-75$ & $60-65$ \\
$<-4.0$ & $60-70$ & $50-60$ \\
\hline
\end{tabular}

Die in der Tabelle genannten T-Score werden durch das Vorliegen von weiteren Risikofaktoren modifiziert. Examplarisch seien an dieser Stelle das Vorliegen eines Diabetes mellitus Typ 1 oder die orale Einnahme von Glukokortikoiden >2,5 mg und kleiner als 7,5 mg Prednisolonäquivalent täglich sowie das Vorliegen von drei und mehr niedrigtrauamtischen Frakturen in den letzten 10 Jahren als Einzelfallentscheidung genannt, diese führen zu einer Anhebung des T-Score-Schwellenwerts um +1 . Liegen weitere Risikofaktoren vor, so wird die Schwelle für den Beginn einer medikamentöse Therapie weiter herabgesetzt.

Therapieindikation beim Vorliegen von Frakturen Liegen bildmorphologisch bzw. klinisch typisch osteoporotische proximale Femur- und oder Wirbelkörperfrakturen vor, so kann abhängig von der klinischen Gesamtsituation auf eine DXA-Messung verzichtet werden. Bei dem Vorliegen einer niedrigtraumatischen proximalen Femurfraktur oder multiplen niedrigtraumatischen Wirbelkörperfrakturen, deren Ätiologie wahrscheinlich auf eine Osteoporose zurückzuführen ist, in Verbindung mit einem verminderten DXA T-Score kleiner als -2, in Einzelfällen auch höher, 


\section{Einleitung}

besteht eine Indikation zur medikamentösen Osteoporosetherapie. Liegen singuläre niedrigtraumatische Wirbelkörperfrakturen in Verbindung mit einem verminderten DXA T-Score kleiner als -2 -in Einzelfällen auch höher- vor, besteht ebenfalls eine Indikation zur medikamentösen Therapie.

Hormonersatztherapie Der Begriff der Hormonersatztherapie ist nicht eindeutig definiert, so verstehen einige Autoren darunter die Gabe einer Östrogen-Gestagenkombination, andere verstehen bereits eine alleinige Gabe von Östrogenen als Hormonersatztherapie. Da die reduzierte endogene Östrogenproduktion der Hauptgrund für den Verlust an Knochenmasse nach der Menopause ist, ist es aus pathophysiologischer Sicht einleuchtend, Östrogene zu substituieren. In der bis dato größten Studie der Women's Health Initiative Study von 2003 wurden 16.000 postmenopausale Patienten auf zwei Studienarme verteilt und wurden entweder mit einer Östrogen/ Gestagenkombination oder einem Placebo behandelt. Es zeigten sich bei der mit Östrogen/ Gestagenkombination behandelten Gruppe eine Risikoreduktion von vetrebralen, nichtvertebralen und Oberschenkelhalsfrakturen. Die Studie wurde allerdings nach 5,3 Jahren aufgrund des vermehrten Auftretens von Mammakarzinomen abgebrochen. Zusätzlich zeigte sich der Behandlungsgruppe die Risiken für Schlaganfälle, Herzinfarkte sowie Thrombosen erhöht (Writing Group for the Women's Health Initiative Investigators 2002). Die DVO-Leitlinie von 2014 empfiehlt die Gabe von Östrogenen bei postmenopausalen Frauen mit hohem Frakturrisiko unter Berücksichtung der Risken, sofern Kontraindikation für andere Arzneimittel bestehen.

Selektive Östrogenrezeptormodulatoren Die selektiven Östrogenrezeptormodulatoren (SERM) sind Substanzen, die ja nach vorliegendem Östrogenrezeptor agonistisch, antagonistisch oder ohne Wirkung sind. Die Östrogenrezeptoren Alpha und Beta, an die die SERMs binden, sind unterschiedlich im Gewebe verteilt. Sie kommen im Gehirn, Uterus, Knochen, den Brüsten, den Ovarien sowie in der Leber vor. Es können inzwischen mehrere Generationen von SERMs unterschieden werden. Als Beispielsubstanzen sind Tamoxifen als Vertreter der ersten Generation, Raloxifen als Vertreter der zweiten Generation sowie Lasofoxifen und Bazedoxifen zu nennen. Tamoxifen wird, trotz osteoprotektiver Wirkung (Powles et al. 1996), aktuell zur adjuvanten Therapie nach Primärbehandlung des Mammakarzinoms sowie bei metastasiertem 


\section{Einleitung}

Mammakarzinom eingesetzt. Bei Patientinnen mit Mammcarcinom und Osteoporose, reduziert es die Inzidenz von osteoporotischen Frakturen, insbesondere Schenkelhalsfrakturen (Tzeng et al. 2015). Die antiosteoporotische Wirkung von Raloxifen wurde unter anderem im Multiple Outcomes of Raloxifene Evaluation Trial (MORE Trial) belegt. In dieser Studie an 7705 postmenopausalen osteoporotischen Patientinnen, die über drei Jahre lief, zeigte sich eine dosisabhängige Reduktion der Inzidenz an vertrebralen Frakturen, auf nicht- vertebrale Frakturen zeigte sich kein Effekt des Medikaments (Ettinger et al. 1999). In der Nachfolgestudie, dem CORE (Contiunuing Outcomes Relevant to Evista) Trial, zeigte sich neben den antiosteoporotischen Effekten auch eine verminderte Inzidenz von invasivem Brustkrebs (Martino et al. 2004). Die SERMs stellen eine Alternative zu den Bisphosphonaten in der Osteoporosetherapie dar.

Parathormon (Teriparatid) Bei Parathormon (PTH) handelt es sich um ein im Menschen physiologisch vorkommenes Hormon, welches der Aufrechterhaltung der Kalziumhomöostase dient. Bei einem Abfall der Serumkalziumkonzentration wird es vemehrt sezerniert und fördert die osteoklastische Knochenresorbtion und damit ein Ansteigen des Serumkalziums. Zusätzlich wurde gezeigt, dass PTH bei pulsatiler Gabe sowohl die Knochendichte als auch den Knochenumbau erhöht und den Knochenverlust reduziert. (Dempster et al. 1993). Gebildet wird es in der Nebenschilddrüse. Parathormon ist ein Polypeptid, bestehend aus 84 Aminosäuren, wobei der biologisch aktive Teil aus den Aminosäuren 1-34 des N-terminalen Endes des Polypeptids besteht (Neer et al. 2001). Teriparatid ist die rekombinante Form des biologisch aktiven Teils. Für die Osteoporosetherapie wird es in den DVO Leitlinien von 2014 empfohlen, allerdings beträgt die maximale Therapiedauer 24 Monate.

Kalzitonin Bei Kalzitonin besteht die antiosteoporotische Wirkung in der Inhibition der Osteoklasten. Es kann subkutan oder per Nasenspray appliziert werden. In der Prevent Recurrence of Osteoporotic Fractures Study (PROOF-Studie) wurde gezeigt, dass eine nasale Gabe von Kalzitionin das absolute Risiko einer vertebralen, osteoporotischen Fraktur um 33\% im Vergleich zur Placebogruppe reduzieren kann, allerdings zeigte sich kein Effekt auf nicht- vertebrale Frakturen (Chesnut et al. 2000). Kalzitonin wird nicht retiniert und kann deshalb bei Schwangeren 


\section{Einleitung}

und Kindern zur Osteoporosetherapie eingesetzt werden, eine weitere Anwendung besteht bei Knochenschmerzen im Rahmen einer vertebralen Berstungsfraktur (Bartl 2010).

Bisphosphonate Bei den Bisphosphonaten handelt es sich um antiresorptive Substanzen, die den Knochenabbau über eine Hemmung der Osteoklastenfunktion reduzieren. Des Weiteren hemmen sie in unterschiedlichen Abstufungen die Farnesylphosphatase und haben unterschiedliche Affinitäten für die Hydroxylappatitbindungsstellen auf der Knochenoberfläche (Russell et al. 2008). Für die Therapie der postmenopausalen Osteoporose sind unter anderem Alendronat, Risedronat und Zolendronat in Deutschland zugelassen. Insgesamt handelt es sich bei Bisphosphonanten um die am häufigsten eingesetzten antiosteoporotischen Medikamente. Für Alendronat wurde die Wirksamkeit unter anderem im Rahmen des Fracture Intervention Trial (FIT) belegt. Es wurden 3658 an Osteoporose erkrankte Frauen in die Studie eingeschlossen. Die Frauen hatten entweder eine präexistente Wirbelfraktur oder hatten einen T-Score kleiner als $-2,5 \mathrm{im}$ Bereich des Oberschenkelhalses, aber keine Wirbelfraktur. Es konnte in den gepoolten Daten eine Reduktion des relativen Risikos auf 0,47, bezogen auf proximale Femurfrakturen, 0,52, bezogen auf radiologisch vorliegende Wirbelfrakturen, 0,55 auf klinisch evidente Wirbelfrakturen und für sämtliche Frakturen auf 0,70 erzielt werden. Eine Risikoreduktion ließ sich bereits nach 12 Monaten nachweisen (Black et al. 2000).

In der Follow-up-Studie Fracture Intervention Trial Long-Term Extension (FLEX) wurden 1099, bereits für fünf Jahre mit Alendronat behandelte, postmenopausale Frauen entweder weiter mit Alendronat oder einem Placebo für weitere fünf Jahre behandelt (Black et al. 2006). Es zeigte sich für die Patientinnen, die die Einnahme von Alendronat fortsetzten, ein vermindertes absolutes Risiko für symptomatische Wirbelkörperfrakturen von 2,4\%, verglichen mit 5,3\% in der Placebogruppe, was einer relativen Risikoreduktion von 55\% entspricht. Bezüglich dem Auftreten von unerwünschten Nebenwirkungen zeigte sich kein Unterschied zwischen den Patientinnen, die Alendronat für fünf Jahre und denen, die Alendronat für zehn Jahre erhielten (Bone et al. 2004). In der Health Outcomes and Reduced Incidence with Zoledronic acid Once yearly Pivotal Fracture Trial (Horizon PFT) wurden 3889 postmenopausale Frauen mit einem Durchschnittsalter von 73 mit einem T-Score kleiner als -2,5 am Schenkelhals oder einem T-Score von -1,5 oder kleiner bei dem Vorliegen einer Wirbelkörperfraktur eingeschlossen. 


\section{Einleitung}

Die Patientinnen erhielten entweder 5 mg Zolendronat oder ein Placebo intravenös zum Start der Studie, nach zwölf und nach vierundzwanzig Monaten.

Der Beobachtungszeitraum betrug sechsundreißig Monate. Es zeigte sich eine relative Risikoreduktion von $70 \%$, bezogen auf das radiologische Vorliegen einer Wirbelfraktur bei einem absoluten Risiko von 3.3\% in der Zolendronsäuregruppe gegen $10.9 \%$ in der Placebogruppe sowie ein reduziertes relatives Risiko für proximale Femurfrakturen von 41\%, bezogen auf ein absolutes Risiko von 1,4\% in der Zolendronsäuregruppe gegen 2,5\% in der Placebogruppe.

Das Risiko von anderen Frakturen zeigte sich ebenfalls signifikant reduziert. Sowohl die Knochendichte als auch die Knochenmetabolismusmarker zeigten sich verbessert (Black et al. 2007). In der Follow- up Studie wurden die bisher mit Zolendronat behandelten Patientinnen randomisiert auf eine Gruppe, die Zolendronat für weitere drei Jahre erhielt, und eine Placebogruppe aufgeteilt. Nach sechs Jahren Behandlungsdauer zeigte sich das relative Risiko für das radiologische Vorliegen einer Wirbelfraktur reduziert (Black et al. 2012). Die Wirksamkeit von Risedronat zur Reduktion von vertebralen Frakturen wurde für den Zeitraum von fünf Jahren in der Erweiterung der ursprünglich auf drei Jahre geplanten Vertebral Efficacy with Risedronate Therapy Multinational (VERT-MN)-Studie gezeigt (Sorensen et al. 2003). Als Hauptnebenwirkung der prinzipiell gut veträglichen Medikamente sind schockartige Reaktionen bei der intravenösen Gabe sowie gastrointenstinale Beschwerden bei der oralen Gabe zu nennen (Black et al. 2007; Bobba et al. 2006). Bei der Langzeitgabe von Bisphosphonaten sind das gehäufte Auftreten von Kiefernekrosen (Pazianas et al. 2007) sowie das Risiko von atypischen Femurfrakturen (Saita et al. 2015) als Komplikationen beschrieben.

\subsection{Strontiumranelat}

Strontium ist wie Kalzium ein Element aus der Familie der Erdalkalimetalle und folglich in Bezug auf die chemischen Eigenschaften ähnlich. Strontium hat einen dualen Wirkmechanismus, es bewirkt sowohl eine gesteigerte Proliferation der Osteoblasten als auch eine verminderte Differenzierung der Osteoklasten, damit einhergehend ist sowohl eine vermehrte Aktivität der Osteoblasten als auch eine verminderte Aktivität der Osteoklasten (Bonnelye et al. 2008). In zwei großen prospektiven klinischen Studien wurde die Wirksamkeit von Strontiumranelat belegt. In der Spi- 


\section{Einleitung}

nal Osteoporosis Therapeutic Intervention- Studie (SOTI) (Meunier und Reginster 2003) wurden 1649 über 50 Jahre alte Frauen, seit mindestens fünf Jahren postmenopausal, mit mindestens einer osteoporotischen Wirbelkörperfraktur in der Vorgeschichte, mit 2 g/Tag Strontiumranelat oder einem Placebo für vier Jahre behandelt. Alle der Patientinnen nahmen bereits Kalzium und Vitamin D ein. Bereits nach einem Jahr zeigte sich bei den mit Strontiumranelat behandelten Patientinnen eine Reduktion des allgemeinen Frakturrisikos von 49\%. Nach drei Jahren zeigte sich eine Reduktion des absoluten Risikos eine neue Wirbelkörperfraktur zu erleiden von $41 \%$ (Meunier et al. 2004).

Nach Ablauf der vier Jahre wurden die Patientinnen, die Strontiumranelat erhalten hatten, entweder weiterbehandelt oder bekamen ein Placebo für ein Jahr, während alle Patientinnen aus der Placebogruppe nun Strontiumranelat für ein Jahr erhielten. In den Folgeuntersuchung zeigte sich, dass sowohl das Risiko für Wirbelköperfrakturen als auch das allgemeine Frakturrisiko erniedrigt blieb (Meunier et al. 2009) Die Knochenmasse nahm in der Gruppe, die Strontiumranelat für fünf Jahre erhielt, konstant zu, während sie in der Gruppe, die Strontiumranelat für vier Jahre erhielt, nach dem Umsetzen auf ein Placebo abnahm. Während sich die SOTI- Studie primär mit Wirbelkörperfrakturen beschäftigte, lag der Fokus der Treatment of Peripheral Osteoporosis-Studie (TROPOS-Studie) (Meunier und Reginster 2003) auf der Wirksamkeit auf periphere Frakturen, die Verhinderung von Wirbelkörperfrakturen stellte einen zweiten Endpunkt dar. Die Studie ging über einen Zeitraum von fünf Jahren. Initial wurden 5091 weibliche Probanden mit Osteoporose und einem Alter über 74 Jahren oder zwischen 70-74 Jahre alt mit einem zusätzlichen Risikofaktur für Frakturen in die Studie eingeschlossen; 2714 Probanden schlossen die Studie ab.

Nach drei Jahren zeigte sich, dass das relative Risiko von Nicht- Wirbelkörper-Frakturen um 16\% und Hüft-, Becken- , Handgelenks- , Sakrum- , Rippen- , Sternum- , Klavikula- und Humerusfrakturen um 19\% im Vergleich zur Placebogruppe reduziert war. In der Hochrisikiogruppe war die relative Risikoreduktion für Hüftfrakturen sogar 36\% (Reginster et al. 2005, Reginster et al. 2008).

In der Male Osteoporosis-Studie (MALEO- Studie), in der die Wirksamkeit von Strontiumranelat für die Behandlung der Osteoporose bei Männern untersucht werden sollte, zeigte sich eine Erhöhung des Risikos für Myokardinfarkte (Kaufman et al. 2013). 2013 wurde von der Eu- 


\section{Einleitung}

ropäischen Arzneimittelkommission aufgrund der relativen Risikoerhöhung für Myokardinfarkte und venöse Thrombembolien die restriktive Verwendung von Strontiumranelat empfohlen. Diese Empfehlung basiert auf gepoolten Daten mehrerer großer Placebo-kontrollierter Studien. Die Originaldaten sind nicht öffentlich zugänglich und weder in der Auswertung von TROPOS noch von SOTI findet sich eine Erwähnung eines erhöhten Risikos für eine der genannten Komplikationen (Bolland und Rey 2014). Die Fachinformation von Strontiumranelat empfiehlt eine Risikoabwägung und ein Absetzen beim Auftreten einer venösen Thrombembolie. Strontiumranelat wird in den aktuellen Leitlinien der Deutschen Gesellschaft für Osteologie für die Behandlung der schweren Osteoporose bei postmenopausalen Frauen sowie erwachsenen Männern mit hohem Frakturrisiko empfohlen, sofern ein anderes Osteoporosemittel nicht zur Behandlung in Betracht kommt. Im letzten Rote-Hand-Brief vom März 2014 werden als Kontraindikationen für die Therapie mit Strontiumranelat klinisch gesicherte, aktuell bestehende oder vorausgegangene ischämische Herzkrankheit, periphere arterielle Verschlusskrankheit und/oder zerebrovaskuläre Erkrankung oder eine unkontrollierte arterielle Hypertonie genannt. 


\section{Material und Methoden}

\subsection{Versuchsübersicht}

Das Versuchskollektiv bestand aus 60 weiblichen Versuchstieren der Gattung Sprague Dawley. Diese wurden zu Versuchsbeginn zufällig auf fünf Gruppen mit jeweils zwölf Tieren verteilt (siehe Tabelle: Verteilung der Versuchstiere). Im Alter von drei Monaten wurden die Tiere der Gruppen zwei bis fünf ovarektomiert, während Gruppe eins Sham-operiert wurde. Acht Wochen später wurden alle Versuchstiere beidseitig an den Tibiametaphysen transversal osteotomiert und osteosynthetisch mit Titanplatten und Schrauben versorgt. Um den Ablauf der Knochenheilung post mortem zu beurteilen, wurden den Versuchstieren während des Versuches an bestimmten Tagen je einer der vier fluorochromen Farbstoffe subkutan appliziert. Xylenolorange am Tag 13 nach Osteotomie (90 mg/kg KG), Calceingrün am Tag 18 (10 mg/kg KG), Alazarincomplexon am Tag 24 und 26 (30 mg/kg KG) und Tetrazyklin am Tag 36 (25 mg/kg KG). Fünf Wochen post-Osteotomie wurden die Ratten durch Dekapitation getötet und die zu untersuchenden Knochen sowie das Muskelgewebe wurden gewonnen(siehe Tabelle: Überblick Versuchsablauf). Fünf Tiere verstarben frühzeitig, bei drei Tieren war der Erfolg der Ovarektomie fraglich, so dass das Kollektiv noch 52 Tiere umfasste.

Tabelle 2.1: Verteilung der Versuchstiere

\begin{tabular}{cccc}
\hline Gruppennummer & Tiernummer & Käfig & Behandlung \\
\hline 1 & $1-12$ & $1-3$ & non-ovx \\
2 & $13-24$ & $4-6$ & ovx \\
3 & $25-36$ & $7-9$ & ovx, SR nach Osteo \\
4 & $37-48$ & $10-12$ & ovx, SR vor Osteo \\
5 & $49-60$ & $13-15$ & ovx, SR vor u. nach Osteo \\
\hline
\end{tabular}


Tabelle 2.2: Versuchsablauf

\begin{tabular}{cc}
\hline Zeit & Was wurde gemacht \\
\hline Versuchsbeginn & Ovarektomie und Sham-OP \\
Nach acht Wochen & Osteotomie und Osteosynthese \\
Nach 13 Wochen & Dekapitation \\
\hline
\end{tabular}

\subsubsection{Versuchstierhaltung}

Die 60 weiblichen Ratten der Gattung Sprague Dawley der Firma Harlan Laboratories, Indianapolis, wurden in Gruppen von zwei bis vier Tieren über die gesamte Versuchsdauer in der Zentralen Tierexperimentellen Einrichtung der Universitätsmedizin Göttingen gehalten. Ein Tausch der Käfige des Typs Makrolon(CIV erfolgte jeden dritten Tag. Wasser und Futter wurden ohne Beschränkungen bereitgestellt, bei den Versuchstieren der Gruppe vier wurde nach der Ovarektomie und bis zur Osteotomie Strontiumranelat in der Dosierung $625 \mathrm{mg} / \mathrm{kg}$ KG dem Futter beigemischt, bei der Gruppe drei nach der Osteotomie bis zum Versuchsende und bei der Gruppe fünf vom Tag der Ovarektomie bis zum Versuchsende. Die Umweltbedingungen wurden konstant gehalten; die Raumtemperatur betrug $20^{\circ} \mathrm{C}$, die relative Luftfeuchtigkeit $55 \%$ und die Tag- bzw. Nachtintervalle 12 Stunden. Die Ovarektomien sowie die Osteotomien erfolgten unter Aufsicht von Herrn Prof. Dr. med. Semisch und Frau Dr. rer. nat. Komrakova. Die Genehmigung für die durchgeführten Tierversuche erfolgte durch das Niedersächsische Landesamt für Verbraucherschutz und Lebensmittelsicherheit unter dem Aktenzeichen 33.9-42502-04-11/0560, gefördert wurde das Projekt von der Elsbeth-Bonhoff-Stiftung.

\subsubsection{Ovarektomie}

Im Alter von drei Monaten wurde bei 48 Ratten, Gruppe zwei bis fünf, die Ovarektomie durchgeführt während die zwölf Ratten der Gruppe eins SHAM-operiert wurden. Nach der Narkose der Versuchstiere mit Ketamin $(90 \mathrm{mg} / \mathrm{kg} \mathrm{KG})$ und Xylazin $(7,5 \mathrm{mg} / \mathrm{kg} \mathrm{KG})$ wurde das Abdomen rasiert, desinfiziert, median laparotomiert und das Peritoneum eröffnet. Nach Aufsuchen des Uterus wurden die Tubae uterina mittels Faden legiert und die Ovarien abgesetzt. Die Bauchdeckenmuskulatur wurde per chirurgischen Faden verschlossen und der Hautschnitt mittels Hautklammern versorgt. 


\subsubsection{Osteotomie}

Um den Einfluss von Strontiumranelat auf die Knochenheilung evaluieren zu können, erfolgte acht Wochen nach Ovarektomie die bilaterale transversale Osteotomie der Tibiametaphyse und die osteosynthetische Versorgung mit Titanplatten und Schrauben.

\subsubsection{Strontiumranelat}

Die Gruppen drei bis fünf erhielten zeitweise Strontiumranelat in der Dosierung $625 \mathrm{mg} / \mathrm{kg}$ KG/Tag im Futter. Die Gruppe vier erhielt das Strontiumranelat nach der Ovarektomie und prophylaktisch bis zur Osteotomie, Gruppe drei im Anschluss an die Osteotomie und Gruppe fünf sowohl prä- als auch post-Osteotomie.

\subsubsection{Muskelpräparation}

Dreizehn Wochen nach Ovarektomie erfolgte in $\mathrm{CO}_{2}$-Narkose die Dekapitation der Versuchstiere. Im Anschluss wurde die dorsale Haut am Unterschenkel vom Fuß bis zum Übergang zum Femur vertikal inzidiert und der Musculus gastrocnemius sowie der Musculus soleus an dem Origo an den Femurkondylen sowie an der Insertio am Os calcaneus abgesetzt. Dorsal des Musculus gastrocnemius konnte per anatomischer Pinzette dann der M. soleus abgezogen werden. Von dorsal wurden im mittleren Drittel der Tiere Fell und Haut vertikal inzidiert und der M. longissimus in seinem Verlauf dargestellt und ein etwa $2 \mathrm{~cm}$ langes und $1 \mathrm{~cm}$ dickes Muskelstück herausgelöst. Die so gewonnene Muskulatur wurde sofort in flüssigem Stickstoff bei $-180{ }^{\circ} \mathrm{C}$ schockgefrostet und danach in Aluminumfolie verpackt und wieder in flüssigem Stickstoff gelagert. Die ständige Lagerung erfolgte dann in einer Kühltruhe bei $-80{ }^{\circ} \mathrm{C}$ bzw. $-71{ }^{\circ} \mathrm{C}$. Der Transport zum Gefriermikrotom in dem Tierzuchtinstitut der Agrarwissenschaftlichen Fakultät erfolgte unter Sicherstellung der Kühlung.

\subsection{Schneiden der Muskulatur}

Die zu bearbeitenden Proben wurden der Kühltruhe entnommen und im Gefriermikrotom bei $-22{ }^{\circ} \mathrm{C}$ zwischengelagert. Der zu schneidene Muskel wurde dann in gewünschter Lage mit einem 
Tropfen destilliertem Wasser auf dem Haltekörper des Mikrotoms fixiert, wobei die Temperatur des Haltekörper $-20{ }^{\circ} \mathrm{C}$ betrug. Anschließend wurde der Trägerkörper mit dem fixierten Muskel schrittweise an die Mikrotomklinge herangeführt, die Dicke des Muskelschnittes betrug dabei 12 $\mu \mathrm{m}$. Die Schnitte wurden auf einen Adhäsionsobjektträger aufgebracht und die Güte des Schnittes lichtmikroskopisch beurteilt. Wenn der Muskel nicht möglichst rechtwinkelig getroffen wurde, erschienen die Zellen stark langgezogen, und es erfolgte eine Korrektur des Winkels zwischen Probe und Mikrotomklinge.

Es wurden auf je zwei Objektträger pro Muskel vier bis fünf Schnitte aufgebracht. Anschließend wurden die Objektträger bei Raumtemperatur 1 Stunde getrocknet und wieder bei $-61{ }^{\circ} \mathrm{C}$ gelagert. Als Mikrotom diente das Modell CM 1900 der Firma Leica, als Objektträger wurde das Modell SuperfrostCoplus der Firma Gerhard Menzel GmbH benutzt.

\subsection{Färbungen}

Je einer der zwei pro Muskel gewonnenen Objektträger wurde nach dem Kapillar-Färbungs- bzw. Adenosintriphospatase-Färbungsschema (ATPase-Färbungsschema) gefärbt. Vorher wurden die Proben etwa 15 Minuten angetaut und nach Abschluss der entsprechenden Färbungen mittels Kleber und Objektträgerdeckgläschen der Firma Gerhard Menzel GmbH versiegelt.

\subsubsection{Amylase-Periodic acid-Schiff reaction für Kapillarfärbung (nach Horak 1988)}

Das Kapillarfärbungsschema erfolgte orientiert an der Amylase-Periodic acid-Schiff reactionFärbung (PAS-Färbung)(Andersen 1975). Es folgt eine Aufzählung der einzelnen Schritte.

1. Fixierung der Proben für 1 Stunde bei $4{ }^{\circ} \mathrm{C}$, anschließend Lagerung für 10 Minuten bei Raumtemperatur

2. Zehnfache Spülung mit destilliertem Wasser

3. Inkubation für 25 Minuten bei $37^{\circ} \mathrm{C}$ in Alpha- Amylaselösung

4. Zehnfache Spülung mit destilliertem Wasser. 
5. Inkubation für $30 \mathrm{~min}$ in $1 \%$ iger Perjodsäure

6. Zehnfache Spülung mit destilliertem Wasser.

7. Inkubation für 25 Minuten in Schiff's Reagenz

8. Inkubation für $30 \mathrm{~min}$ in $\mathrm{SO}_{2}$-Wasser

9. Spülung für 10 min unter fließendem Leitungswasser

10. Inkubation für $3 \mathrm{~min}$ in destilliertem Wasser

\section{Verwendete Substanzen}

\section{Fixierungslösung}

1. Ethanol, Firma (Fa.) Merck $129 \mathrm{ml}$

2. Chloroform, Fa. Merck $1.0244524 \mathrm{ml}$

3. Essigsäure, Fa. Merck $638.1 \mathrm{ml}$

\section{Amylaselösung}

1. Amylase Fa. Sigma $555 \mathrm{mg}$

2. destilliertes Wasser $180 \mathrm{ml}$

\section{Perjodsäure}

1. Perjodsäure, Fa. Roth 3257.1 1,8 g

2. destilliertes Wasser $180 \mathrm{ml}$

\section{Schiff's Reagenz}

1. Schiff's Reagenz, Fa. Roth 


\section{$\mathrm{SO}_{2}$ - Wasser}

1. destilliertes (dest.) Wasser $600 \mathrm{ml}$

2. Kaliumdisulfidlsg $\mathrm{K}_{2} \mathrm{~S}_{2} \mathrm{O}_{5}, 10 \%$ igFa. Merck $505730 \mathrm{ml}$

3. HCL, 1N, Fa. Merck $1.0905730 \mathrm{ml}$

\subsubsection{Glykogenfärbung}

Die Färbung der Muskelfasertypen ATPase-/Diaphorase erfolgte modifiziert nach Horak (Horák 1983). Eine detaillierte Auflistung der Färbeschritte folgt.

1. Fixierung nach Meier bei $\mathrm{pH}$ 6,3-6,6 für $1 \mathrm{~min}$

2. Zweimalige Spülung in destilliertem Wasser für jeweils 5 Minuten

3. Diaphoraseinkubation für 60 Minuten bei $37^{\circ} \mathrm{C}$

4. Spülung in destilliertem Wasser für 15 Minuten

5. Saure Vorinkubation für 15 Minuten

6. Inbukation in Tris- $\mathrm{CaCl}_{2}$-Lösung bei $\mathrm{pH} 7.8$ für 2 Minuten

7. Inkubation in ATPase- Lösung bei pH 9.4 für 30 Minuten bei $37^{\circ} \mathrm{C}$

8. Dreimalige Spülung mit $\mathrm{CaCl}_{2}$ - Waschlösung für jeweils 30 sek

9. Inkubation für 2 Minuten in Kobaltchloridlösung

10. Dreimalige Spülung mit destilliertem Wasser für je 45 sek

11. Inkubation für 2 Minuten in Ammoniumsulfidlösung unter Sicherstellung der Abluft

12. Spülung für 10 Minuten unter fließendem Leitungswasser

13. Spülung für 5 Minuten mit destilliertem Wasser 


\section{Phosphatpuffer $(0,1 \mathrm{M}, \mathrm{pH} 7,4)$}

1. Lösung 1: 0,1 M prim. Natriumphosphat 18,8 g $\mathrm{NaH}_{2} \mathrm{PO}_{4}$ x $\mathrm{H}_{2} \mathrm{O}$ oder 15,6 g $\mathrm{NaH}_{2} \mathrm{PO}_{4}$ x $2 \mathrm{H}_{2} \mathrm{O}$ mit Aqua dest. auf 11 auffüllen (Fa. Merck 6346)

2. Lösung 2: 0,1 M sek. Natriumphosphat 35,82 g $\mathrm{NaHPO}_{4} \times 12 \mathrm{H}_{2} \mathrm{O}$ mit Aqua dest. auf 11 auffüllen (Fa. Merck 6346)

3. 15,9 ml Lösung 1 plus 84,1 ml Lösung 2 ergibt den Ansatz

\section{Nitro-BT-Stammlösung}

1. Nitro-BT (Nitro-blaues Tetrazoliumchlorid (Konz. $1 \mathrm{mg} / \mathrm{ml}$ )) $40 \mathrm{mg}$ (Fa. Roth)

2. destilliertes Wasser $40 \mathrm{ml}$

\section{$\mathrm{CaCl}_{2}$-Stammlösung (Sigma-Aldrich Laborchemikalien $\mathrm{GmbH}$ )}

1. $4,99 \mathrm{~g} \mathrm{CaCl} 2(\mathrm{M}=111 \mathrm{~g} / \mathrm{mol})$ mit Aqua dest. auf $250 \mathrm{ml}$ auffüllen.

\section{$\mathrm{CaCl}_{2}$-Waschlösung (Sigma-Aldrich Laborchemikalien GmbH)}

1. $7,5 \mathrm{~g} \mathrm{CaCl} l_{2}(\mathrm{M}=111 \mathrm{~g} / \mathrm{mol})$ mit Aqua dest. auf $1 \mathrm{l}$ auffüllen.

\section{Glycin-Stammlösung (pH-Wert auf 9,4 einstellen) (AppliChem GmbH)}

1. $7,51 \mathrm{~g}$ Glycin $(98 \%, \mathrm{M}=75,07 \mathrm{~g} / \mathrm{mol})$ mit Aqua dest. auf $250 \mathrm{ml}$ auffüllen.

\section{Glycinpuffer (pH-Wert auf 9,4 einstellen) (AppliChem GmbH)}

1. $125 \mathrm{ml}$ Glycin-Stammlösung

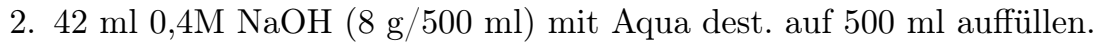

\section{Ammoniumsulfid-Lösung (Herstellung unter dem Abzug)}

1. $0,2 \mathrm{ml}$ Ammoniumsulfid (Fa. Merck)

2. $150 \mathrm{ml}$ Aqua dest. 


\section{Kobaltchlorid-Lösung}

1. $3 \mathrm{~g}$ Kobaltchlorid $\left(\mathrm{CoCl}_{2} \times 6 \mathrm{H}_{2} \mathrm{O}\right)$ (AppliChem $\left.\mathrm{GmbH}\right)$

2. $150 \mathrm{ml}$ Aqua dest.

ATPase-Inkubationslösung (Lagerung bei $37^{\circ} \mathrm{C}$, pH-Wert 9,4)

1. $555 \mathrm{mg} \mathrm{KCl}(\mathrm{M}=75 \mathrm{~g} / \mathrm{mol})$

2. $228 \mathrm{mg} \operatorname{ATP}(\mathrm{M}=551,2 \mathrm{~g} / \mathrm{mol})$ (Carl Roth $\mathrm{GmbH} \&$ Co. $\mathrm{KG})$

3. $135 \mathrm{ml}$ Glycinpuffer

4. $15 \mathrm{ml} \mathrm{CaCl}_{2}$-Stammlösung

\section{Tris- $\mathrm{CaCl}_{2}$-Lösung (pH-Wert 7,8)}

1. $1,82 \mathrm{~g}$ Tris (Tris-(hydroxymethyl)-aminomethan $99,9 \%, \mathrm{M}=121,14 \mathrm{~g} / \mathrm{mol}$ ) (Carl Roth GmbH \& Co. KG)

2. $15 \mathrm{ml} \mathrm{CaCl} 2$-Stammlösung

3. $135 \mathrm{ml}$ Aqua dest.

\section{saure Vorinkubationslösung (pH-Wert 4,2)}

1. $15 \mathrm{ml} \mathrm{CaCl}_{2}$-Stammlösung

2. $0,6 \mathrm{ml}$ konzentrierte Essigsäure (Eisessig)

3. $135 \mathrm{ml}$ Aqua dest.

\section{Diaphorase-Inkubationslösung (gekühlte Lagerung)}

1. 20 mg NADH-Dinatriumsalz (AppliChem GmbH)

2. $3,2 \mathrm{ml}$ Phosphatpuffer $(0,1 \mathrm{M} ; \mathrm{pH} 7,4)$

3. $4 \mathrm{ml}$ Nitro-BT (Carl Roth GmbH \& Co. KG)

4. $4,8 \mathrm{ml}$ Aqua dest. 


\section{Fixierlösung nach Meier $(\mathrm{pH}$ 6,3-6,6)}

1. 1,5 g Paraformaldehyd (Carl Roth GmbH \& Co. KG)

2. 3 g $\mathrm{CaCl}_{2}$ (-6-Hydrat) (Sigma-Aldrich Laborchemikalien $\mathrm{GmbH}$ )

3. 9 g Saccharose oder Dextran (AppliChem GmbH)

4. $150 \mathrm{ml}$ Aqua dest.

\subsection{Auswertungen der Färbungen}

Die Auswertung der gefärbten Muskelschnitte erfolgte mittels eines Mikroskops Modell Eclipse E6000 in Verbindung mit einer Kamera DS-Fi2 und dem Softwarepaket NIS- Elements 4.0, alle Komponenten vom Hersteller Nikon. Unter dem Lichtmikroskop wurde unter zehnfacher Vergrößerung ein adäquat gefärbter Muskelausschnitt aufgesucht und mittels der an das Lichtmikroskop angeschlossenen Kamera fotografiert. Das Bild konnte dann an dem an der Kamera angeschlossenen PC in der Software NIS-Elements 4.0 ausgewertet werden.

\subsubsection{Auswertung Kapillar-Färbung}

Zur Auswertung der Kapillar-Färbung diente ein unter zehnfacher Vergrößerung aufgenommenes Foto eines adäquat angefärbten Querschnitts des entsprechenden Muskels. Hier musste darauf geachtet werden, dass das zu untersuchende Muskelfaserbündel möglichst senkrecht geschnitten wurde, was an der Form der Muskelfasern erkennbar ist, und das die Kapillaren gut sichtbar angefärbt waren. Per Software wurde ein Rechteck mit einem Flächeninhalt von 0,985 $\mathrm{mm}^{2}$ auf das Bild projiziert, es erfolgte dann innerhalb dieses Rechtecks die Auszählung der Anzahl an Kapillaren und der Anzahl an Muskelfasern. Während sich die Muskelfasern als große, unterschiedlich stark angefärbte polygonale Strukturen darstellen, sind die Kapillaren kleinere, dunklere angefärbte Strukturen bei denen meistens ein Lumen erkennbar ist, die sich zwischen den Muskelfasern befinden. Zum Auszählen der deutlich kleineren Kapillaren wurde mittels Zoom gearbeitet. Das Verhältnis wurde als Quotient aus der Anzahl Kapillaren und der Anzahl an Muskelfasern gebildet, was die Software automatisch errechnete. Zur Selbstüberprüfung und Standardisierung wurden zu Beginn des Auszählens je drei zufällig ausgewählte Abschnitte aus dem Muskel 


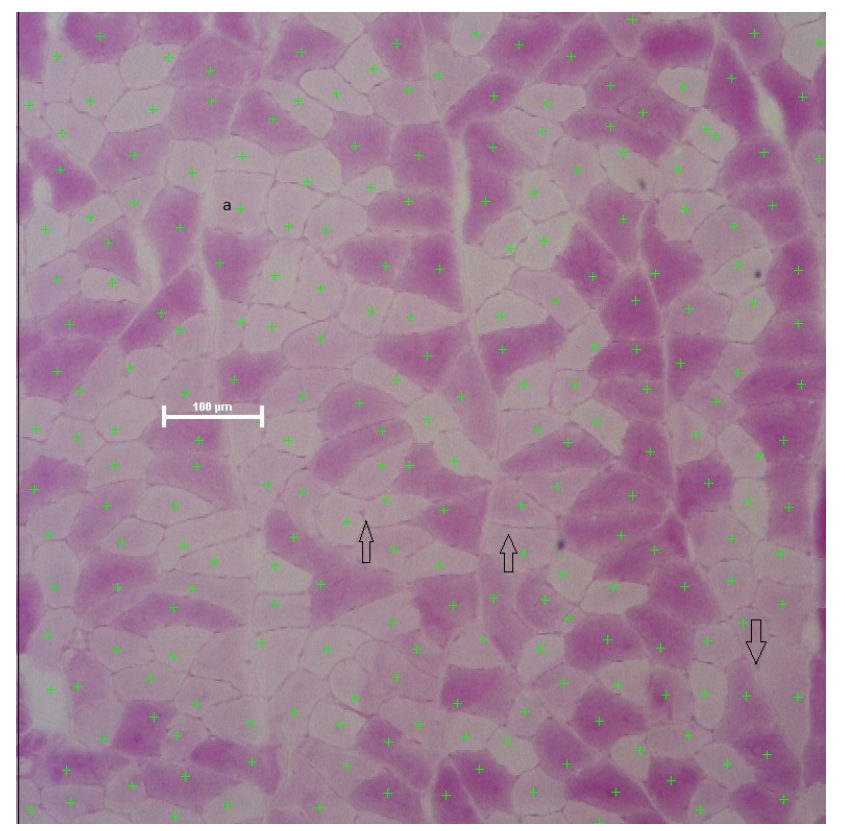

Abbildung 2.1: M.gastrocnemius Kapillar-Färbung (a: Anschnitt einer Muskelfaser, Pfeile: Anschnitt einer Kapillare)

ausgezählt, wobei keine Abweichung über 5\% in der Anzahl der Kapillaren bzw. Muskelzellen zugelassen wurde. Bei der Auswertung war dem Untersucher nicht bekannt, zu welcher Versuchstiergruppe die einzelnen Präparate gehörten. Die Auszählungen erfolgten durch den Autor. 


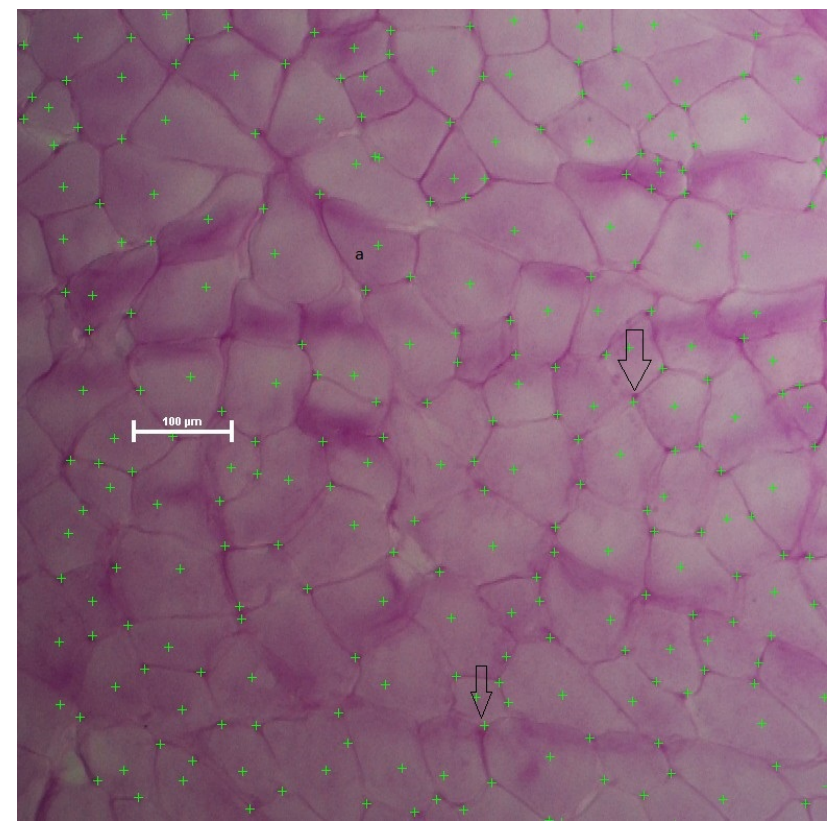

Abbildung 2.2: M.longissimus KapillarFärbung

(a: Anschnitt einer Muskelfaser, Pfeile: Anschnitt einer Kapillare)

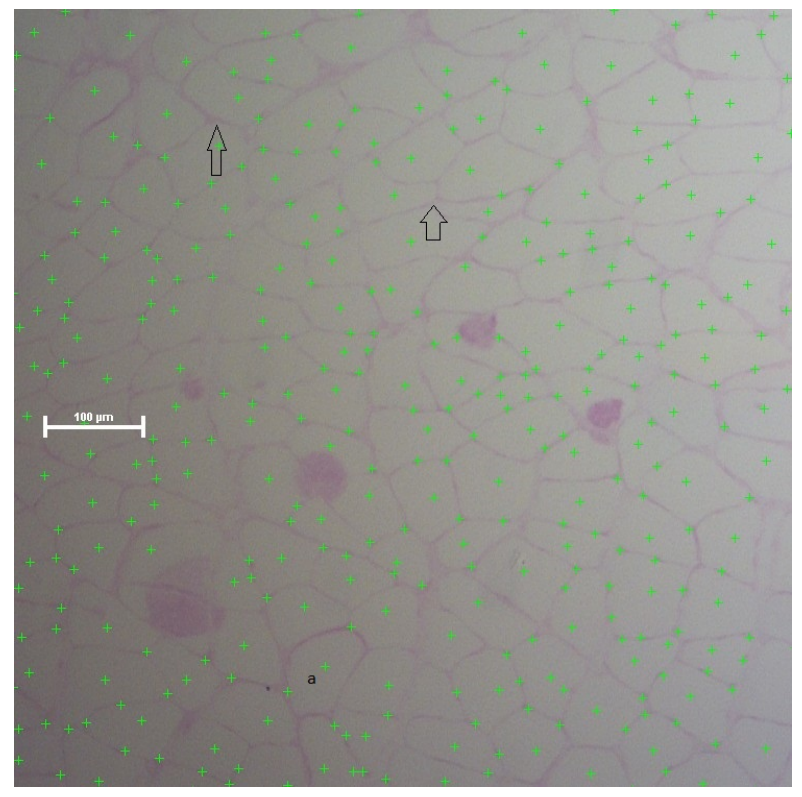

Abbildung 2.3: M.soleus

KapillarFärbung (a: Anschnitt einer Muskelfaser, Pfeile: Anschnitt einer Kapillare) 


\subsubsection{Auswertung ATPase-Färbung}

Auch die Auswertung der ATP-Färbung erfolgten nachdem unter Vergrößerung ein adäquat angefärbter und möglichst senkrecht getroffener Ausschnitt fotografiert wurde. Innerhalb dieses Ausschnittes wurden drei Regions Of Interest (ROIs) identifiziert und innerhalb dieser ROIs wurden die Umfänge von je 30 glykolytischen und 30 oxidativen Muskelfasern per Maus umfahren und die korrespondierenden Flächeninhalte per Software automatisch berechnet. Die oxidativen Muskelfasern (Slow twitch oxidative STO) stellten sich aufgrund der Färbung als sehr dunkel dar, während die glykolytischen Fasern (fast twitch glycolytic FTG) sehr hell imponieren. Der Intermediärtyp zeigt sich entsprechend auch im Farbspektrum zwischen beiden angesiedelt. Beim M. gastrocnemius wurden zusätzlich das Größenverhältnis als Quotient aus dem Flächeninhalt der oxidativen und der glykolytischen Fasern bestimmt. Beim M. longissimus wurden in einem Aussschnitt von $0.95 \mathrm{~mm}$ die Anzahl an oxidativen und an glykolytischen Fasern bestimmt und der Quotient aus beiden gebildet. Da bei dem M. soleus nicht sinnvoll zwischen den beiden Muskelfasertypen unterschieden werden kann, wurden pro Schnitt nur 30 Zellen ausgezählt. Die Auszählung erfolgte durch den Autor. 


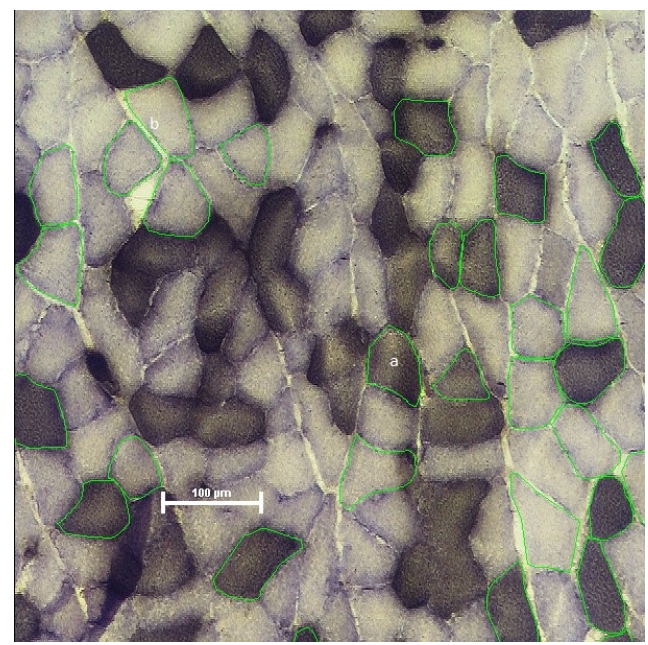

Abbildung 2.4: M.

gastrocnemius

ATPase-Färbung

(a: Anschnitt einer oxidativen Faser, b: Anschnitt einer glykolytischen Faser)

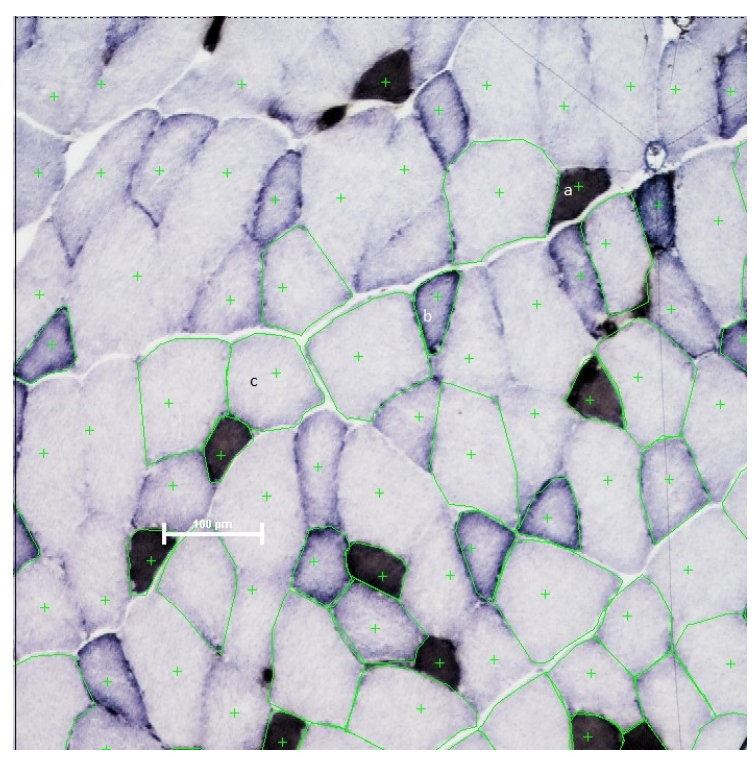

Abbildung 2.5: M. longissimus-ATPaseFärbung

(a: Anschnitt einer oxidativen Faser, b: Anschnitt einer glykolytischen Faser) 


\section{Material und Methoden}

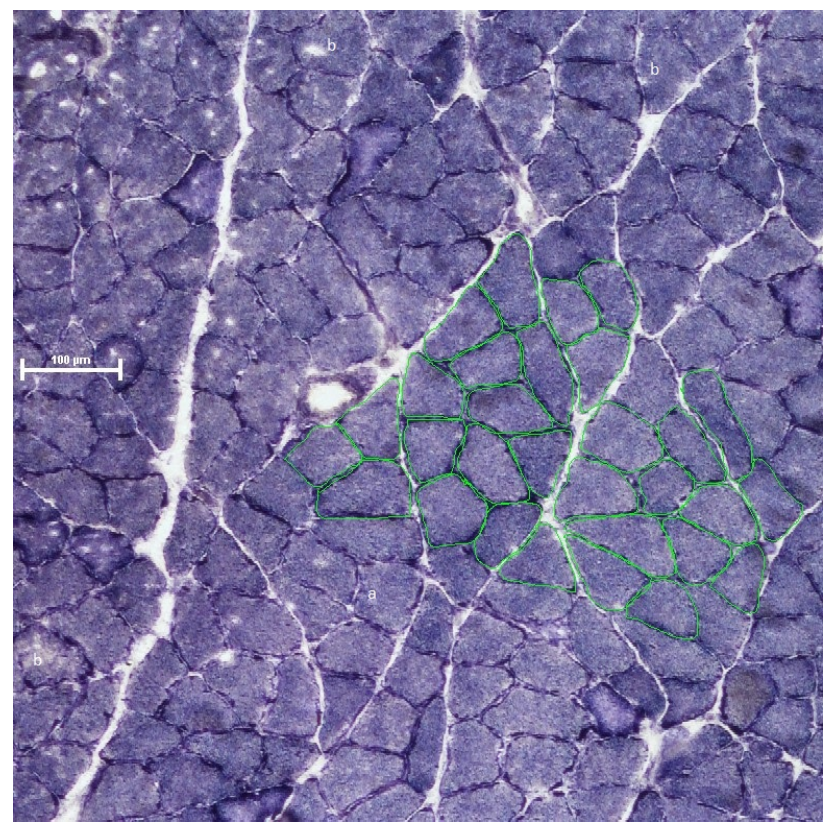

Abbildung 2.6: M. soleus-ATPaseFärbung (a: Anschnitt einer Muskelfaser, b: Anschnitt einer durch die Kryokonservierung zerstörten Faser) 


\subsubsection{Statistik}

Die statistische Auswertung der Ergebnisse wurde mit dem Programm GraphPad Prism (Version 5, GraphPad Software Inc., San Diego, USA) durchgeführt. Für die zu untersuchenden Parameter der einzelnen Gruppen wurden zunächst Mittelwert, Minimum und Maximum, Standardabweichung und Standardfehler errechnet. Eine Untersuchung auf signifikante Unterschiede wurde mittels one-way ANOVA und anschließendem Tukey-Kramer post-hoc- Test durchgeführt. Als Signifikanzniveau wurde $\alpha \leq 0,05$ gewählt. 


\section{Ergebnisse}

Die Daten zur Gewichtsentwicklung, den Uterusgewichten und zur Futteraufnahme wurden bereits im Rahmen einer anderen Dissertation der Arbeitsgruppe veröffentlicht: Weidemann (2014), ebenso wurden Ergebnisse in einem Paper veröffentlicht (Saul et al. 2017).

\subsection{Uterusgewichte der Tiere am Tag der Obduktion}

Tabelle 3.1: Uterusgewichte der Tiere [g]

\begin{tabular}{|c|c|c|c|c|c|}
\hline non-ovx & ovx & $\begin{array}{l}\text { SR nach Os- } \\
\text { teo }\end{array}$ & SR vor Osteo & $\begin{array}{l}\text { SR vor } \\
\text { nach Osteo }\end{array}$ & \\
\hline Uterusgewicht & $\begin{array}{l}0,64 \pm 0,21 \\
\sim \sim\end{array}$ & $\begin{array}{l}0,13 \pm 0,03 \\
\#\end{array}$ & $\begin{array}{l}0,13 \pm 0,03 \\
\#\end{array}$ & $\begin{array}{l}0,14 \pm 0,02 \\
\#\end{array}$ & $\begin{array}{l}0,12 \pm 0,02 \\
\#\end{array}$ \\
\hline
\end{tabular}

Die Uterusgewichte der nicht- ovarektomierten Tiere zeigen sich gegenüber den ovarektomierten Tieren signifikant erhöht (Tabelle 3.1). 
3 Ergebnisse

\subsection{Gewichtsentwicklung der Tiere im Verlauf}

Tabelle 3.2: Gewichtsentwicklung der Versuchstiere im Verlauf [g]

\begin{tabular}{|c|c|c|c|c|c|}
\hline Woche & non-ovx & ovx & $\begin{array}{l}\text { SR nach Os- } \\
\text { teo }\end{array}$ & SR vor Osteo & $\begin{array}{l}\text { SR vor u. } \\
\text { nach Osteo }\end{array}$ \\
\hline 0 & $261 \pm 8$ & $270 \pm 11$ & $264 \pm 13$ & $255 \pm 24$ & $270 \pm 9$ \\
\hline 1 & $273 \pm 9$ & $283 \pm 8$ & $279 \pm 14$ & $280 \pm 9$ & $276 \pm 13$ \\
\hline 2 & $285 \pm 7^{\sim} \sim$ & $314 \pm 10 \#$ & $317 \pm 19 \#$ & $313 \pm 11 \#$ & $310 \pm 14 \#$ \\
\hline 3 & $294 \pm 9^{\sim} \sim$ & $338 \pm 19 \#$ & $345 \pm 25 \#$ & $340 \pm 12 \#$ & $336 \pm 16 \#$ \\
\hline 4 & $303 \pm 13^{\sim} \sim$ & $353 \pm 21 \#$ & $364 \pm 28 \#$ & $355 \pm 15 \#$ & $352 \pm 17 \#$ \\
\hline 5 & $306 \pm 8^{\sim} \sim$ & $353 \pm 24 \#$ & $368 \pm 31 \#$ & $355 \pm 20 \#$ & $352 \pm 17 \#$ \\
\hline 6 & $314 \pm 9^{\sim} \sim$ & $365 \pm 25 \#$ & $383 \pm 34 \#$ & $364 \pm 19 \#$ & $364 \pm 18 \#$ \\
\hline 7 & $314 \pm 11^{\sim} \sim$ & $369 \pm 28 \#$ & $389 \pm 37 \#$ & $370 \pm 21 \#$ & $371 \pm 22 \#$ \\
\hline 8 & $315 \pm 12^{\sim} \sim$ & $366 \pm 26 \#$ & $392 \pm 39 \#$ & $368 \pm 22 \#$ & $368 \pm 25 \#$ \\
\hline 9 & $312 \pm 12^{\sim} \sim$ & $355 \pm 26 \#$ & $374 \pm 53 \#$ & $354 \pm 21 \#$ & $360 \pm 26 \#$ \\
\hline 10 & $306 \pm 14^{\sim} \sim$ & $360 \pm 26 \#$ & $386 \pm 46 \#$ & $356 \pm 23 \#$ & $362 \pm 26 \#$ \\
\hline 11 & $315 \pm 18^{\sim} \sim$ & $368 \pm 29 \#$ & $397 \pm 49 \#$ & $366 \pm 21 \#$ & $373 \pm 26 \#$ \\
\hline 12 & $323 \pm 17^{\sim} \sim$ & $371 \pm 28 \#$ & $403 \pm 47$ \# & $371 \pm 21 \#$ & $380 \pm 27 \#$ \\
\hline 13 & $323 \pm 16^{\sim} \sim$ & $380 \pm 29 \#$ & $410 \pm 51 \#$ & $376 \pm 22 \#$ & $381 \pm 30 \#$ \\
\hline
\end{tabular}

Alle Tiere nahmen bis einschließlich der neunten Woche an Körpergewicht zu. Nach der Osteotomie fiel das Gewicht zunächst bei allen Tieren, um anschließend wieder zu steigen. Das Körpergewicht der nicht-ovarektomierten Ratten zeigt sich konstant signifikant ab der dritten Woche, gegenüber den ovarektomierten Tieren vermindert (Tabelle 3.2). 


\subsection{Futteraufnahme der Tiere im Verlauf}

Tabelle 3.3: Futteraufnahme der Tiere im Verlauf [g]

\begin{tabular}{|c|c|c|c|c|c|}
\hline Woche & non-ovx & ovx & $\begin{array}{l}\text { SR nach Os- } \\
\text { teo }\end{array}$ & SR vor Osteo & $\begin{array}{ll}\text { SR vor u. } \\
\text { nach Osteo }\end{array}$ \\
\hline 1 & $20,20 \pm 4,96$ & $15,62 \pm 0,61$ & $13,76 \pm 1,02$ & $16,52 \pm 5,41$ & $13,38 \pm 0,82$ \\
\hline 2 & $23,79 \pm 5,85$ & $24,04 \pm 1,09$ & $26,88 \pm 0,18$ & $24,75 \pm 0,05$ & $26,40 \pm 1,98$ \\
\hline 3 & $\underset{\sim}{20,96 \pm 1,06}$ & $\begin{array}{l}26,10 \pm 1,43 \\
\#\end{array}$ & $\begin{array}{l}26,71 \pm 2,15 \\
\#\end{array}$ & $\begin{array}{l}27,33 \pm 0,47 \\
\#\end{array}$ & $\begin{array}{l}27,26 \pm 1,45 \\
\#\end{array}$ \\
\hline 4 & $22,80 \pm 4,28$ & $24,12 \pm 1,42$ & $25,89 \pm 1,39$ & $24,61 \pm 0,25$ & $25,48 \pm 1,10$ \\
\hline 5 & $23,38 \pm 2,75$ & $24,38 \pm 1,6$ & $26,12 \pm 1,19$ & $25,14 \pm 0,73$ & $24,71 \pm 0,77$ \\
\hline 6 & $22,45 \pm 2,43$ & $24,10 \pm 1,40$ & $25,26 \pm 0,66$ & $25,80 \pm 1,43$ & $23,35 \pm 0,51$ \\
\hline 7 & $21,51 \pm 1,35$ & $22,95 \pm 0,86$ & $24,32 \pm 0,37$ & $23,74 \pm 1,65$ & $24,15 \pm 1,97$ \\
\hline 8 & $21,33 \pm 0,75$ & $21,63 \pm 0,58$ & $23,16 \pm 0,47$ & $21,82 \pm 1,41$ & $23,05 \pm 1,42$ \\
\hline 9 & $14,38 \pm 0,42$ & $14,00 \pm 1,50$ & $14,72 \pm 4,88$ & $13,73 \pm 0,53$ & $13,79 \pm 0,52$ \\
\hline 10 & $19,43 \pm 1,21$ & $19,26 \pm 0,14$ & $20,05 \pm 2,33$ & $19,52 \pm 1,36$ & $19,57 \pm 0,61$ \\
\hline 11 & $19,99 \pm 1,80$ & $20,68 \pm 1,31$ & $22,31 \pm 1,88$ & $20,25 \pm 0,29$ & $20,99 \pm 0,32$ \\
\hline 12 & $20,89 \pm 1,21$ & $\underset{\sim}{18,26 \pm 1,6}$ & $\begin{array}{l}22,63 \pm 1,55 \\
\#\end{array}$ & $\underset{\sim}{19,57 \pm 1,02}$ & $22,06 \pm 1,31$ \\
\hline 13 & $24,21 \pm 1,00$ & $21,88 \pm 1,86$ & $\begin{array}{l}24,67 \pm 1,04 \\
\#\end{array}$ & $\underset{\sim}{21,02 \pm 1,00}$ & $23,75 \pm 1,10$ \\
\hline
\end{tabular}

Die Futteraufnahme aller Tiere nahm in der zweiten Woche zu, wobei der Anstieg in der Gruppe der ovarektomierten Tiere stärker ausgeprägt war. In der dritten Woche nahmen die nichtovarektomierten Tiere signifikant weniger Futter auf als die ovarektomierten. Nach der Osteotomie (Woche 9) fiel die Futteraufnahme bei allen Tieren zunächst ab, um sich im weiteren Verlauf wieder zu steigern. Eine signifikant gesteigerte Futteraufnahme fand sich in Woche zwölf in der Gruppe SR nach Osteo, verglichen mit der ovarektomierten Gruppe sowie der Gruppe, die Strontiumranelt vor der Osteotomie erhielt. Der Unterschied zur Gruppe, die Strontiumranelat vor der Osteotomie erhielt, blieb in der dreizehnten Woche bestehen (Tabelle 3.3). 


\subsection{Ergebnisse der Kapillar-Färbung}

\subsubsection{M. gastrocnemius}

\section{Kapillaranzahl}

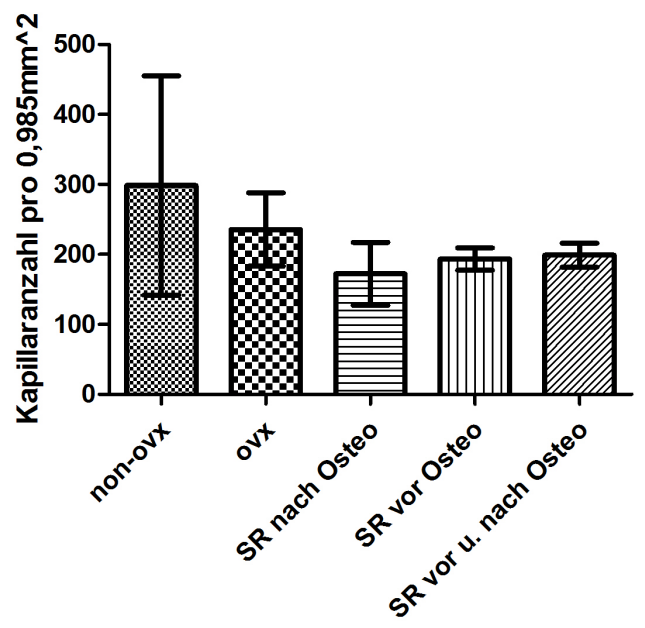
Abbildung 3.1: M. gastrocnemius- Kapillaranzahl (non-ovx: nicht ovariek- tomierte Kontrollgruppe, ovx: ovariektomierte Tiere, SR nach Osteo: Stron- tiumsubstitution nach Osteotomie, SR vor Osteo: Strontiumsubstitution vor Osteotomie, SR vor u. nach: Strontiumsubstitution vor und nach Osteotomie)

Bei der Kapillaranzahl des M. gastrocnemius zeigten sich keine signifikanten Ergebnisse. Auffällig ist die sehr hohe Schwankungsbreite der Kapillaranzahl (Abb. 3.1, Tab. 3.4).

Tabelle 3.4: M. gastrocnemius-Kapillaranzahl [1/0,985 $\left.\mathrm{mm}^{2}\right]$

\begin{tabular}{|c|c|c|c|c|c|}
\hline Gruppe & $\begin{array}{ll}\text { Anzahl } & \text { der } \\
\text { Tiere [-] } & \\
\end{array}$ & Minimum & Maximum & Mittelwert & Standardabweichung \\
\hline non-ovx & 3 & 147 & 460 & 298,7 & 156,7 \\
\hline ovx & 5 & 140 & 439 & 235,6 & 117,3 \\
\hline $\begin{array}{l}\text { SR nach Os- } \\
\text { teo }\end{array}$ & 3 & 97 & 253 & 172,3 & 78,14 \\
\hline $\mathrm{SR}$ vor Osteo & 8 & 116 & 247 & 193,4 & 45,10 \\
\hline $\begin{array}{l}\text { SR vor u. } \\
\text { nach Osteo }\end{array}$ & 7 & 134 & 270 & 199 & 45,37 \\
\hline
\end{tabular}




\section{Ergebnisse}

\section{Faseranzahl}

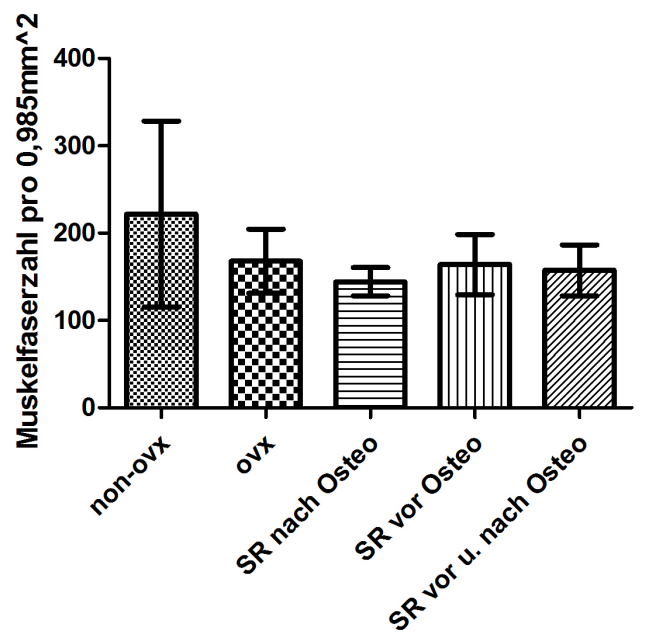
Abbildung 3.2: M. gastrocnemius-
Faseranzahl
(non-ovx: nicht ovariek- tomierte Kontrollgruppe, ovx: ovariektomierte Tiere, SR nach Osteo: Stron- tiumsubstitution nach Osteotomie, SR vor Osteo: Strontiumsubstitution vor Osteotomie, SR vor u. nach: Strontiumsubstitution vor und nach Osteotomie)

Bei der Faseranzahl des M. gastrocnemius zeigten sich keine signifikanten Abweichungen. Auch bei der Faseranzahl besteht eine hohe Schwankungsbreite (Abb. 3.2, Tab. 3.5).

Tabelle 3.5: M. gastronemius-Faseranzahl [1/0,985 $\left.\mathrm{mm}^{2}\right]$

\begin{tabular}{|c|c|c|c|c|c|}
\hline Gruppe & $\begin{array}{l}\text { Anzahl der } \\
\text { Tiere [-] }\end{array}$ & Minimum & Maximum & Mittelwert & Standardabweichung \\
\hline non-ovx & 3 & 114 & 327 & 221,7 & 106,5 \\
\hline ovx & 5 & 110 & 313 & 167,8 & 82,23 \\
\hline $\begin{array}{l}\text { SR nach Os- } \\
\text { teo }\end{array}$ & 3 & 124 & 176 & 144,3 & 27,79 \\
\hline SR vor Osteo & 8 & 114 & 214 & 164,0 & 34,46 \\
\hline $\begin{array}{l}\text { SR vor u. } \\
\text { nach Osteo }\end{array}$ & 7 & 116 & 196 & 157,4 & 29,15 \\
\hline
\end{tabular}


Ratio Anzahl Kapillaren/Anzahl Fasern

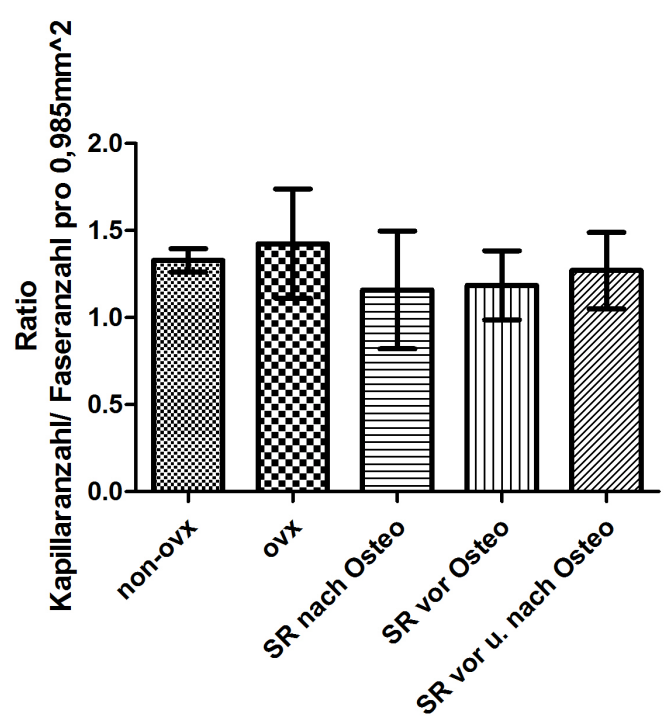

Abbildung 3.3: M. gastrocnemius Ratio Anzahl Kapillaren/ Anzahl Fasern

(non-ovx: nicht ovariektomierte Kontrollgruppe, ovx: ovariektomierte Tiere, SR nach Osteo: Strontiumsubstitution nach Osteotomie, SR vor Osteo: Strontiumsubstitution vor Osteotomie, SR vor u. nach: Strontiumsubstitution vor und nach Osteotomie)

Das Verhältnis aus Kapillaranzahl und Faseranzahl des M. gastrocnemicus zeigte keine signifikanten Abweichungen (Abb. 3.3, Tab. 3.6).

Tabelle 3.6: M. gastrocnemius Ratio Anzahl Kapillaren/Anzahl Fasern [-]

\begin{tabular}{|c|c|c|c|c|c|}
\hline Gruppe & $\begin{array}{ll}\text { Anzahl } & \text { der } \\
\text { Tiere [-] } & \end{array}$ & Minimum & Maximum & Mittelwert & Standardabweichung \\
\hline non-ovx & 3 & 1,289 & 1,407 & 1,329 & 0,06749 \\
\hline ovx & 5 & 1,000 & 1,791 & 1,425 & 0,3137 \\
\hline $\begin{array}{l}\text { SR nach Os- } \\
\text { teo }\end{array}$ & 3 & 0,7823 & 1,438 & 1,158 & 0,3383 \\
\hline SR vor Osteo & 8 & 1,018 & 1,500 & 1,186 & 0,1976 \\
\hline $\begin{array}{l}\text { SR vor u. } \\
\text { nach Osteo }\end{array}$ & 7 & 0,9796 & 1,570 & 1,270 & 0,2193 \\
\hline
\end{tabular}




\subsubsection{M. longissimus}

\section{Kapillaranzahl}

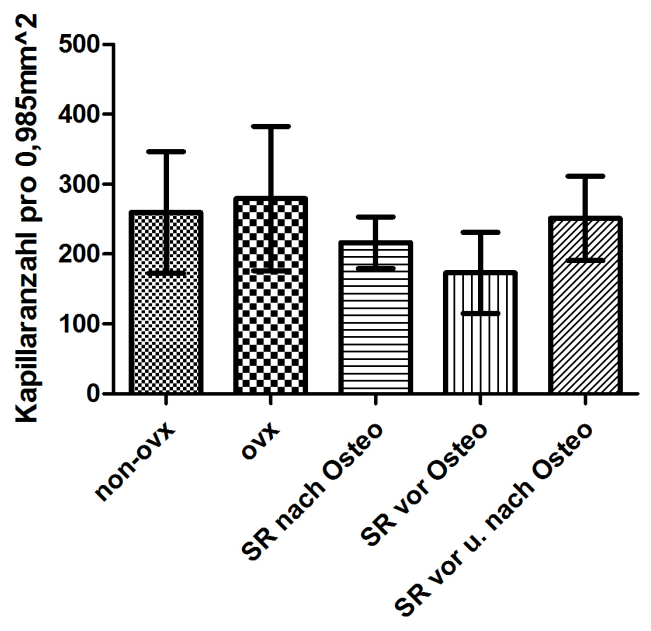

Abbildung 3.4: M. longissimusKapillaranzahl (non-ovx: nicht ovariektomierte Kontrollgruppe, ovx: ovariektomierte Tiere, SR nach Osteo: Strontiumsubstitution nach Osteotomie, SR vor Osteo: Strontiumsubstitution vor Osteotomie, SR vor u. nach: Strontiumsubstitution vor und nach Osteotomie)

Bei der Kapillaranzahl des M. longissimus zeigten sich keine signifikanten Ergebnisse (Abb.

3.4, Tab. 3.7).

Tabelle 3.7: M. longissimus-Kapillaranzahl [1/0,985 $\left.\mathrm{mm}^{2}\right]$

\begin{tabular}{|c|c|c|c|c|c|}
\hline Gruppe & $\begin{array}{ll}\text { Anzahl } & \text { der } \\
\text { Tiere [-] } & \\
\end{array}$ & Minimum & Maximum & Mittelwert & Standardabweichung \\
\hline non-ovx & 6 & 152,0 & 369,0 & 259,3 & 87,04 \\
\hline ovx & 11 & 96,00 & 432,0 & 279,3 & 103,4 \\
\hline $\begin{array}{l}\text { SR nach Os- } \\
\text { teo }\end{array}$ & 4 & 165,0 & 250,0 & 216,3 & 36,88 \\
\hline SR vor Osteo & 7 & 82,00 & 275,0 & 173,0 & 58,03 \\
\hline $\begin{array}{l}\text { SR vor u. } \\
\text { nach Osteo }\end{array}$ & 8 & 177,0 & 370,0 & 251,1 & 60,53 \\
\hline
\end{tabular}




\section{Faseranzahl}

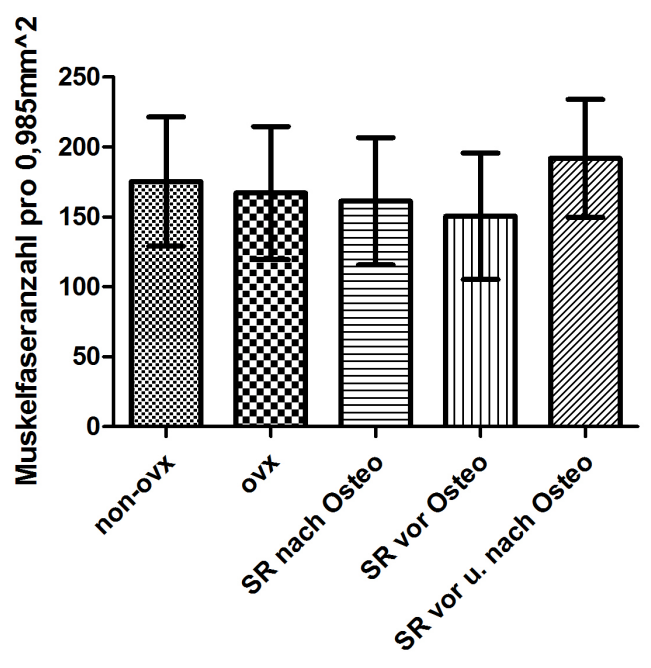

Abbildung 3.5: M. longissimusMuskelfaseranzahl (non-ovx: nicht ovariektomierte Kontrollgruppe, ovx: ovariektomierte Tiere, SR nach Osteo: Strontiumsubstitution nach Osteotomie, SR vor Osteo: Strontiumsubstitution vor Osteotomie, SR vor u. nach: Strontiumsubstitution vor und nach Osteotomie)

Bei der Faseranzahl des M. longissimus zeigten sich keine signifikanten Abweichungen (Abb.

3.5, Tab. 3.8).

Tabelle 3.8: M. longissimus-Muskelfaseranzahl $\left[1 / 0,985 \mathrm{~mm}^{2}\right]$

\begin{tabular}{|c|c|c|c|c|c|}
\hline Gruppe & $\begin{array}{ll}\text { Anzahl der } \\
\text { Tiere [-] }\end{array}$ & Minimum & Maximum & Mittelwert & Standardabweichung \\
\hline non-ovx & 6 & 108,0 & 228,0 & 175,3 & 46,22 \\
\hline ovx & 11 & 93,00 & 230,0 & 167,1 & 47,54 \\
\hline $\begin{array}{l}\text { SR nach Os- } \\
\text { teo }\end{array}$ & 4 & 114,0 & 214,0 & 161,3 & 45,57 \\
\hline SR vor Osteo & 7 & 86,00 & 222,0 & 150,6 & 45,20 \\
\hline $\begin{array}{l}\text { SR vor u. } \\
\text { nach Osteo }\end{array}$ & 8 & 130,0 & 261,0 & 191,9 & 42,17 \\
\hline
\end{tabular}


Ratio aus Anzahl Kapillaren/Anzahl Fasern

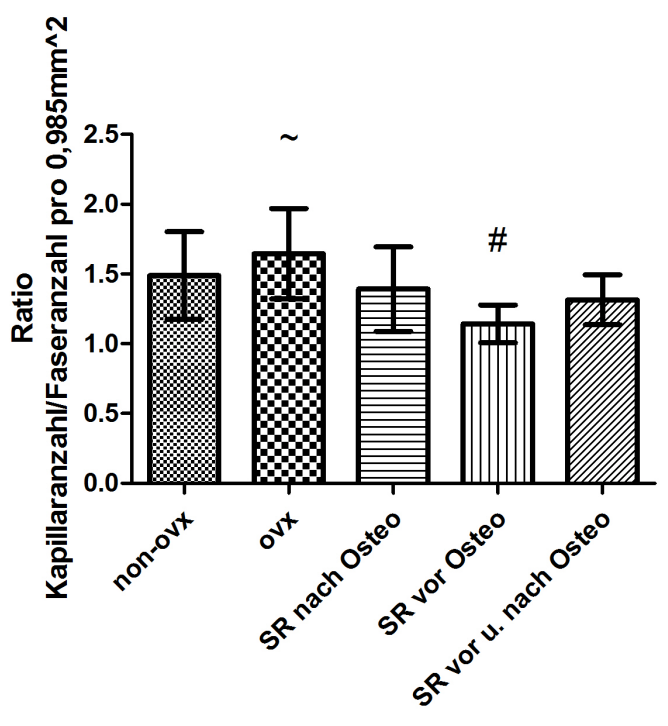

Abbildung 3.6: M. longissimus Ratio Anzahl Kapillaren/ Anzahl Fasern (non-ovx: nicht ovariektomierte Kontrollgruppe, ovx: ovariektomierte Tiere, SR nach Osteo: Strontiumsubstitution nach Osteotomie, SR vor Osteo: Strontiumsubstitution vor Osteotomie, SR vor u. nach: Strontiumsubstitution vor und nach Osteotomie, : signifikant erhöht gegen mit \# gekennzeichnete Gruppe)

Es zeigte sich die Ratio aus Kapillaren und Zellen bei der ovarektomierten Gruppe im Vergleich zur Gruppe Strontiumranelat vor der Osteotomie signifikant erhöht (Abb. 3.6, Tab. 3.9).

Tabelle 3.9: M. longissimus Ratio Anzahl Kapillaren/Anzahl Zellen [-]

\begin{tabular}{|c|c|c|c|c|c|}
\hline Gruppe & $\begin{array}{ll}\text { Anzahl der } \\
\text { Tiere [-] }\end{array}$ & Minimum & Maximum & Mittelwert & Standardabweichung \\
\hline non-ovx & 6 & 0,8824 & 1,697 & 1,488 & 0,3145 \\
\hline ovx $~ \sim$ & 11 & 1,032 & 2,126 & 1,645 & 0,3239 \\
\hline $\begin{array}{l}\text { SR nach Os- } \\
\text { teo }\end{array}$ & 4 & 1,009 & 1,746 & 1,392 & 0,3031 \\
\hline $\begin{array}{l}\text { SR vor Osteo } \\
\#\end{array}$ & 7 & 0,9535 & 1,340 & 1,143 & 0,1345 \\
\hline $\begin{array}{l}\text { SR vor u. } \\
\text { nach Osteo }\end{array}$ & 8 & 0,9725 & 1,514 & 1,316 & 0,1788 \\
\hline
\end{tabular}




\subsubsection{M. soleus}

\section{Kapillaranzahl}

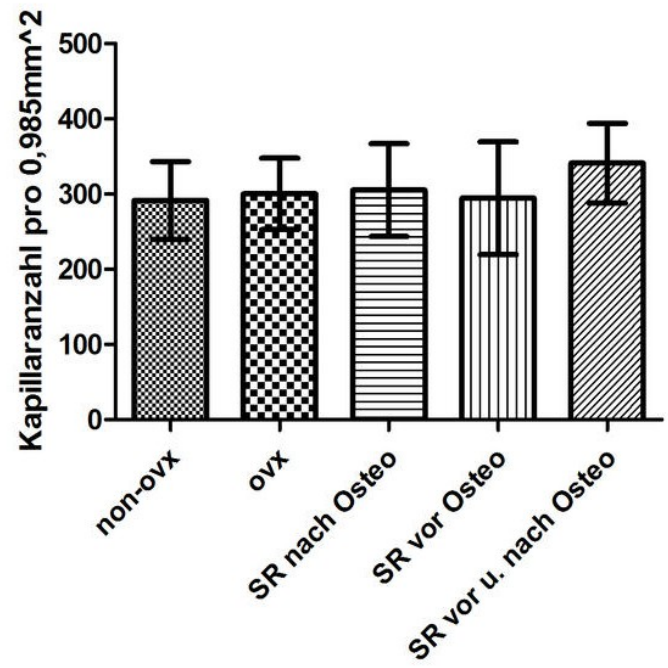

Abbildung 3.7: M. soleus Anzahl der Kapillaren

(non-ovx: nicht ovariektomierte Kontrollgruppe, ovx: ovariektomierte Tiere, SR nach Osteo: Strontiumsubstitution nach Osteotomie, SR vor Osteo: Strontiumsubstitution vor Osteotomie, SR vor u. nach: Strontiumsubstitution vor und nach Osteotomie)

Bei der Kapillaranzahl des M. soleus zeigten sich keine signifikanten Ergebnisse (Abb. 3.7, Tab. $3.10)$.

Tabelle 3.10: M. soleus-Kapillaranzahl [1/0,985 $\left.\mathrm{mm}^{2}\right]$

\begin{tabular}{|c|c|c|c|c|c|}
\hline Gruppe & $\begin{array}{ll}\text { Anzahl } & \text { der } \\
\text { Tiere [-] } & \\
\end{array}$ & Minimum & Maximum & Mittelwert & Standardabweichung \\
\hline non-ovx & 11 & 217,0 & 360,0 & 291,4 & 51,58 \\
\hline ovx & 10 & 242,0 & 405,0 & 300,2 & 47,39 \\
\hline $\begin{array}{l}\text { SR nach Os- } \\
\text { teo }\end{array}$ & 9 & 225,0 & 438,0 & 305,1 & 61,62 \\
\hline $\mathrm{SR}$ vor Osteo & 8 & 144,0 & 390,0 & 294,3 & 75,03 \\
\hline $\begin{array}{l}\text { SR vor u. } \\
\text { nach Osteo }\end{array}$ & 9 & 257,0 & 419,0 & 341,0 & 53,10 \\
\hline
\end{tabular}




\section{Faseranzahl}

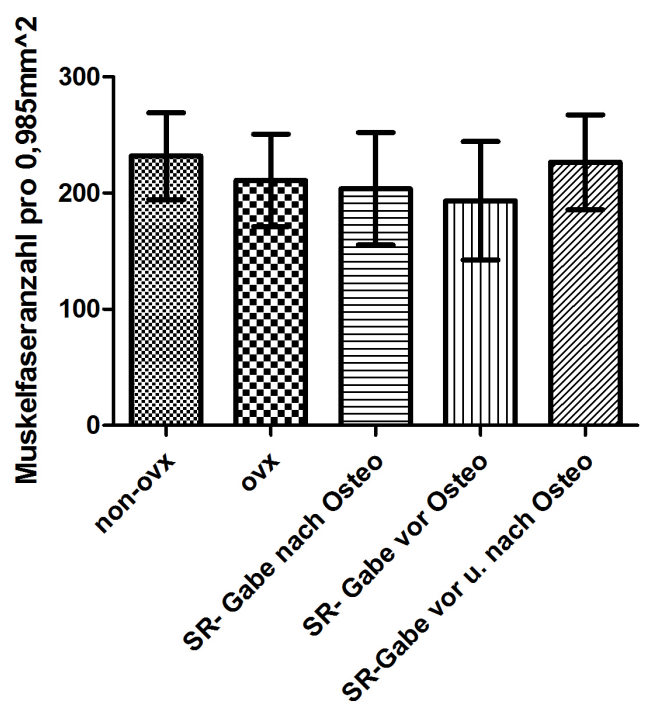

Abbildung 3.8: M. soleus-Faseranzahl (non-ovx: nicht ovariektomierte Kontrollgruppe, ovx: ovariektomierte Tiere, SR nach Osteo: Strontiumsubstitution nach Osteotomie, SR vor Osteo: Strontiumsubstitution vor Osteotomie, SR vor u. nach: Strontiumsubstitution vor und nach Osteotomie)

Bei der Faseranzahl des M. soleus zeigten sich keine signifikanten Ergebnisse (Abb. 3.8, Tab. $3.11)$.

Tabelle 3.11: M. soleus-Faseranzahl [1/0,985 $\left.\mathrm{mm}^{2}\right]$

\begin{tabular}{|c|c|c|c|c|c|}
\hline Gruppe & $\begin{array}{ll}\text { Anzahl } & \text { der } \\
\text { Tiere [-] } & \\
\end{array}$ & Minimum & Maximum & Mittelwert & Standardabweichung \\
\hline non-ovx & 11 & 174,0 & 323,0 & 231,8 & 37,34 \\
\hline ovx & 10 & 154,0 & 268,0 & 210,8 & 39,73 \\
\hline $\begin{array}{l}\text { SR nach Os- } \\
\text { teo }\end{array}$ & 9 & 133,0 & 308,0 & 203,7 & 48,39 \\
\hline SR vor Osteo & 8 & 102,0 & 268,0 & 193,4 & 51,12 \\
\hline $\begin{array}{l}\text { SR vor u. } \\
\text { nach Osteo }\end{array}$ & 9 & 182,0 & 293,0 & 226,6 & 40,88 \\
\hline
\end{tabular}




\section{Ergebnisse}

\section{Ratio Anzahl Kapillaren/Anzahl Fasern}

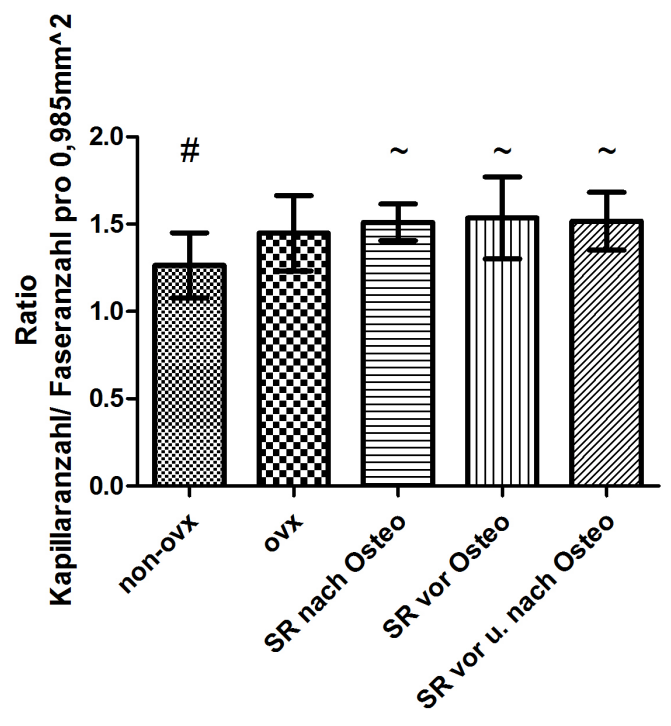

Abbildung 3.9: M. soleus Ratio Anzahl Kapillaren/ Anzahl Fasern (non-ovx: nicht ovariektomierte Kontrollgruppe, ovx: ovariektomierte Tiere, SR nach Osteo: Strontiumsubstitution nach Osteotomie, SR vor Osteo: Strontiumsubstitution vor Osteotomie, SR vor u. nach: Strontiumsubstitution vor und nach Osteotomie, ${ }^{\sim}$ : signifikant erhöht gegen mit \# gekennzeichnete Gruppe)

Es zeigte sich die Ratio aus Kapillaren und Zellen des M. soleus bei der nicht-ovarektomieren Gruppe gegen die Gruppen, die Strontiumranelat erhielten, signifikant vermindert (Abb. 3.9, Tab. 3.12).

Tabelle 3.12: M. soleus Ratio Anzahl Kapillaren/Anzahl Fasern [-]

\begin{tabular}{|c|c|c|c|c|c|}
\hline Gruppe & $\begin{array}{ll}\text { Anzahl der } & \text { diere [-] } \\
\end{array}$ & Minimum & Maximum & Mittelwert & Standardabweichung \\
\hline non-ovx \# & 11 & 1,044 & 1,515 & 1,265 & 0,1866 \\
\hline ovx & 10 & 1,085 & 1,745 & 1,448 & 0,2163 \\
\hline $\begin{array}{l}\text { SR- Gabe } \\
\text { nach Osteo }\end{array}$ & 9 & 1,389 & 1,692 & 1,511 & 0,1052 \\
\hline $\begin{array}{l}\text { SR-Gabe vor } \\
\text { Osteo }\end{array}$ & 8 & 1,252 & 1,950 & 1,536 & 0,2348 \\
\hline $\begin{array}{l}\text { SR vor u. } \\
\text { nach Osteo }\end{array}$ & 9 & 1,318 & 1,803 & 1,517 & 0,1659 \\
\hline
\end{tabular}




\subsection{Ergebnisse der ATPase-Färbung}

\subsubsection{M. gastrocnemius}

Querschnittsfläche der glykogenolytischen Fasern

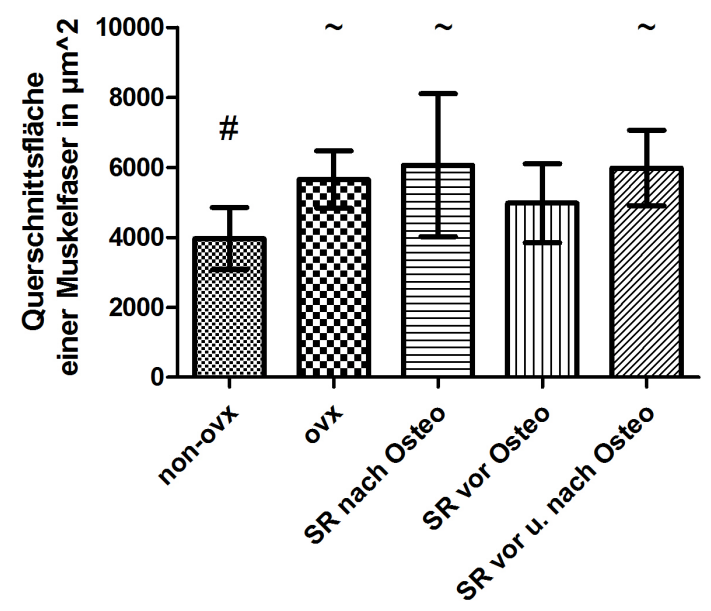

Abbildung 3.10: M. gastrocnemius Fläche der glykogenolytischen Fasern (non-ovx: nicht ovariektomierte Kontrollgruppe, ovx: ovariektomierte Tiere, SR nach Osteo: Strontiumsubstitution nach Osteotomie, SR vor Osteo: Strontiumsubstitution vor Osteotomie, $\mathrm{SR}$ vor u. nach: Strontiumsubstitution vor und nach Osteotomie, $\sim$ : signifikant erhöht gegen mit \# gekennzeichnete Gruppe)

Der Querschnitt der Muskelfaserflächen des M. gastrocnemius aller ovarektomierten Tiere, mit Ausnahme der Gruppe Strontiumranelat vor Osteotomie, zeigte sich gegenüber der nichtovarektomierten Tiere erhöht (Abb. 3.10, Tab. 3.13).

Tabelle 3.13: M. gastrocnemius Querschnittsfläche der glykogenolytischen Fasern $\left[\mu m^{2}\right]$

\begin{tabular}{|c|c|c|c|c|c|}
\hline Gruppe & $\begin{array}{ll}\text { Anzahl } & \text { der } \\
\text { Tiere [-] } & \\
\end{array}$ & Minimum & Maximum & Mittelwert & Standardabweichung \\
\hline non-ovx \# & 10 & 2445 & 5484 & 3961 & 891,5 \\
\hline ovx $^{\sim}$ & 10 & 4508 & 6820 & 5653 & 817,9 \\
\hline $\begin{array}{l}\text { SR nach Os- } \\
\text { teo }\end{array}$ & 9 & 3034 & 9312 & 6066 & 2041 \\
\hline SR vor Osteo & 10 & 3400 & 7058 & 4976 & 1129 \\
\hline $\begin{array}{l}\text { SR vor u. } \\
\text { nach Osteo }\end{array}$ & 10 & 4569 & 7338 & 5982 & 1080 \\
\hline
\end{tabular}




\section{Ergebnisse}

Querschnittsfläche der oxidativen Zellen

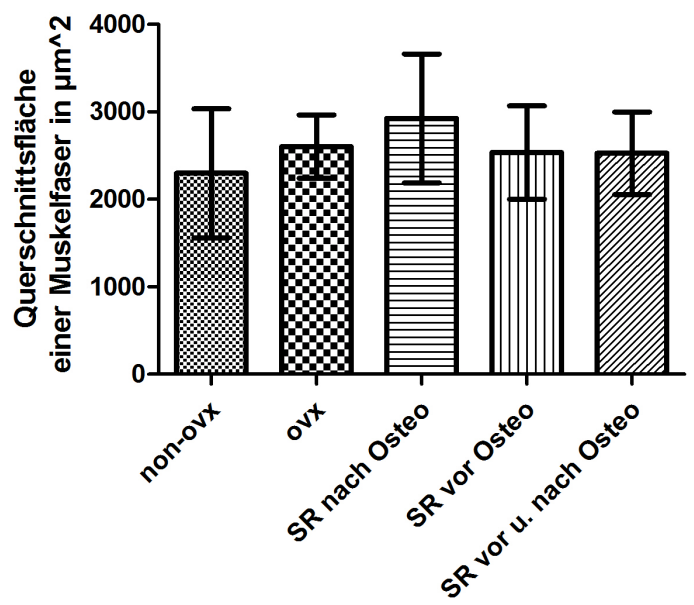

Abbildung 3.11: M. gastrocnemius Fläche der oxidativen Zellen

(non-ovx: nicht ovariektomierte Kontrollgruppe, ovx: ovariektomierte Tiere, SR nach Osteo: Strontiumsubstitution nach Osteotomie, SR vor Osteo: Strontiumsubstitution vor Osteotomie, SR vor u. nach: Strontiumsubstitution vor und nach Osteotomie)

Bei der Querschnittsfläche der oxidativen Zellen zeigten sich keine signifikanten Ergebnisse (Abb. 3.11, Tab. 3.14).

Tabelle 3.14: M. gastronemius Fläche der oxidativen Zellen $\left[\mu m^{2}\right]$

\begin{tabular}{|c|c|c|c|c|c|}
\hline Gruppe & $\begin{array}{l}\text { Anzahl der } \\
\text { Tiere [-] }\end{array}$ & Minimum & Maximum & Mittelwert & Standardabweichung \\
\hline non-ovx & 10 & 1231 & 3695 & 2298 & 737,6 \\
\hline ovx & 10 & 2064 & 3125 & 2602 & 361,1 \\
\hline $\begin{array}{l}\text { SR nach Os- } \\
\text { teo }\end{array}$ & 9 & 2034 & 4355 & 2925 & 736,9 \\
\hline SR vor Osteo & 10 & 1847 & 3595 & 2536 & 532,9 \\
\hline $\begin{array}{l}\text { SR vor u. } \\
\text { nach Osteo }\end{array}$ & 10 & 1834 & 3359 & 2527 & 473,0 \\
\hline
\end{tabular}




\section{Größenverhältnis aus oxidativen und glykogenolytischen Zellen}

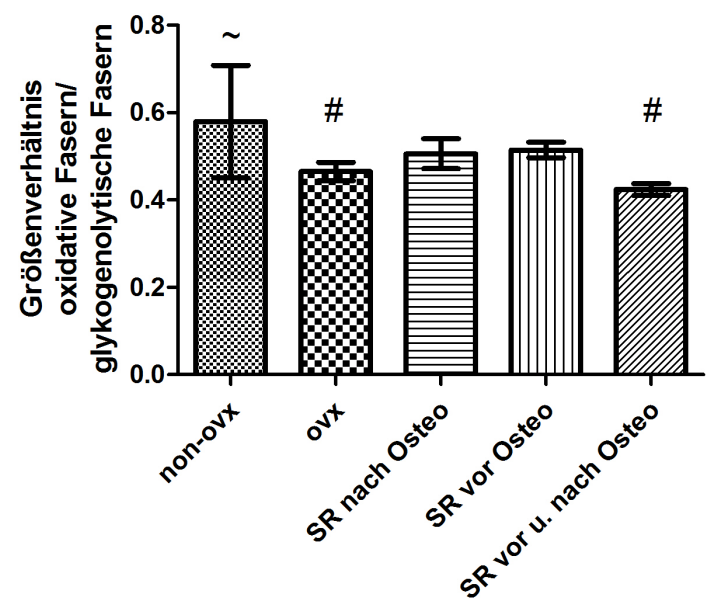

Abbildung 3.12: M. gastrocnemius Ratio Anzahl Oxidativ/ Anzahl Glykogen

(non-ovx: nicht ovariektomierte Kontrollgruppe, ovx: ovariektomierte Tiere, SR nach Osteo: Strontiumsubstitution nach Osteotomie, SR vor Osteo: Strontiumsubstitution vor Osteotomie, SR vor u. nach: Strontiumsubstitution vor und nach Osteotomie, $\sim$ : signifikant erhöht gegen mit \# gekennzeichnete Gruppe)

Es zeigte sich das Größenverhältnis aus oxidativen u. glykolytischen Zellen bei der non- ovxGruppe signifikant vergrößert gegenüber der ovx u. SR vor u. nach Osteo- Gruppen (Abb. 3.12, Tab. 3.15).

Tabelle 3.15: M. gastronemius Größenverhältnis aus oxidativen und glykogenolytischen Zellen [-]

\begin{tabular}{|c|c|c|c|c|c|}
\hline Gruppe & $\begin{array}{ll}\text { Anzahl } & \text { der } \\
\text { Tiere [-] } & \\
\end{array}$ & Minimum & Maximum & Mittelwert & Standardabweichung \\
\hline non-ovx & 10 & 0,4029 & 0,8042 & 0,5795 & 0,1289 \\
\hline ovx \# & 10 & 0,3447 & 0,5613 & 0,4651 & 0,6640 \\
\hline $\begin{array}{l}\text { SR nach Os- } \\
\text { teo }\end{array}$ & 9 & 0,3519 & 0,6704 & 0,5059 & 0,1037 \\
\hline SR vor Osteo & 10 & 0,4397 & 0,6171 & 0,5146 & 0,05545 \\
\hline $\begin{array}{l}\text { SR vor u. } \\
\text { nach Osteo } \\
\#\end{array}$ & 10 & 0,3854 & 0,5229 & 0,4240 & 0,04263 \\
\hline
\end{tabular}




\subsubsection{M. longissimus}

\section{Querschnittsfläche der glykolytischen Fasern}

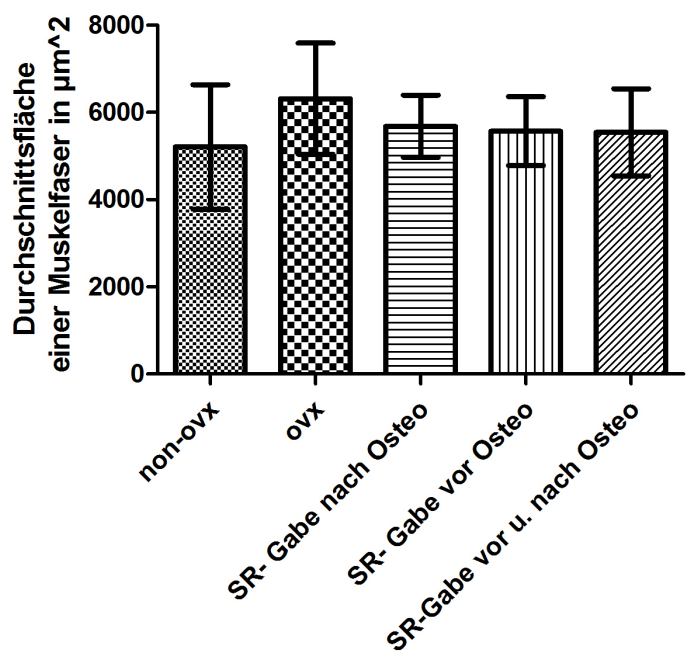

Abbildung 3.13: M. longissimus Querschnittsfläche der glykogenolytischen Fasern (non-ovx: nicht ovariektomierte Kontrollgruppe, ovx: ovariektomierte Tiere, SR nach Osteo: Strontiumsubstitution nach Osteotomie, SR vor Osteo: Strontiumsubstitution vor Osteotomie, SR vor u. nach: Strontiumsubstitution vor und nach Osteotomie)

Es zeigten sich keine signifikanten Abweichungen in der Querschnittsfläche der glykolytischen Fasern (Abb. 3.13, Tab. 3.16).

Tabelle 3.16: M. longissimus Querschnittsfläche der glykogenolytischen Fasern $\left[\mu m^{2}\right]$

\begin{tabular}{|c|c|c|c|c|c|}
\hline Gruppe & $\begin{array}{ll}\text { Anzahl } & \text { der } \\
\text { Tiere [-] } & \\
\end{array}$ & Minimum & Maximum & Mittelwert & Standardabweichung \\
\hline non-ovx & 11 & 3468 & 7998 & 5211 & 1426 \\
\hline ovx & 11 & 4847 & 9836 & 6316 & 1272 \\
\hline $\begin{array}{l}\text { SR nach Os- } \\
\text { teo }\end{array}$ & 9 & 4744 & 6799 & 5684 & 711,9 \\
\hline SR vor Osteo & 9 & 4188 & 6707 & 5573 & 787,9 \\
\hline $\begin{array}{l}\text { SR vor u. } \\
\text { nach Osteo }\end{array}$ & 9 & 4269 & 7064 & 5546 & 999,7 \\
\hline
\end{tabular}


Querschnittsfläche der oxidativen Fasern

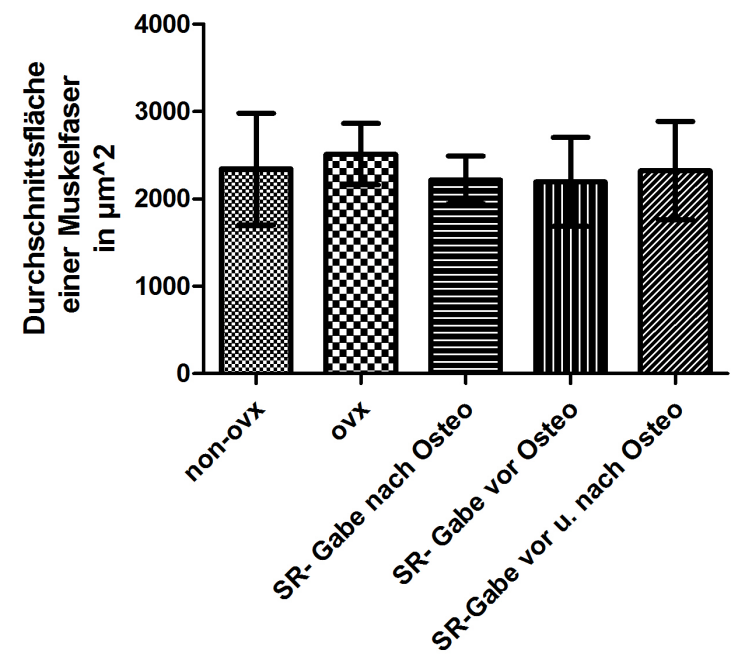

Abbildung 3.14: M. longissimus Querschnittsfläche der oxidativen Fasern

(non-ovx: nicht ovariektomierte Kontrollgruppe, ovx: ovariektomierte Tiere, SR nach Osteo: Strontiumsubstitution nach Osteotomie, SR vor Osteo: Strontiumsubstitution vor Osteotomie, SR vor u. nach: Strontiumsubstitution vor und nach Osteotomie)

Es zeigten sich keine signifikanten Abweichungen in der Querschnittsfläche der oxidativen Fasern (Abb. 3.14, Tab. 3.17).

Tabelle 3.17: M. longissimus Querschnittsfläche der oxidativen Fasern $\left[\mu m^{2}\right]$

\begin{tabular}{|c|c|c|c|c|c|}
\hline Gruppe & $\begin{array}{ll}\text { Anzahl der } \\
\text { Tiere [-] }\end{array}$ & Minimum & Maximum & Mittelwert & Standardabweichung \\
\hline non-ovx & 11 & 1367 & 3209 & 2344 & 638,7 \\
\hline ovx & 11 & 1678 & 3009 & 2513 & 352,6 \\
\hline $\begin{array}{l}\text { SR nach Os- } \\
\text { teo }\end{array}$ & 9 & 1715 & 2590 & 2220 & 271,1 \\
\hline SR vor Osteo & 9 & 1569 & 3000 & 2194 & 510,1 \\
\hline $\begin{array}{l}\text { SR vor u. } \\
\text { nach Osteo }\end{array}$ & 9 & 1683 & 3106 & 2325 & 563,0 \\
\hline
\end{tabular}




\section{Anzahl der glykolytischen Fasern}

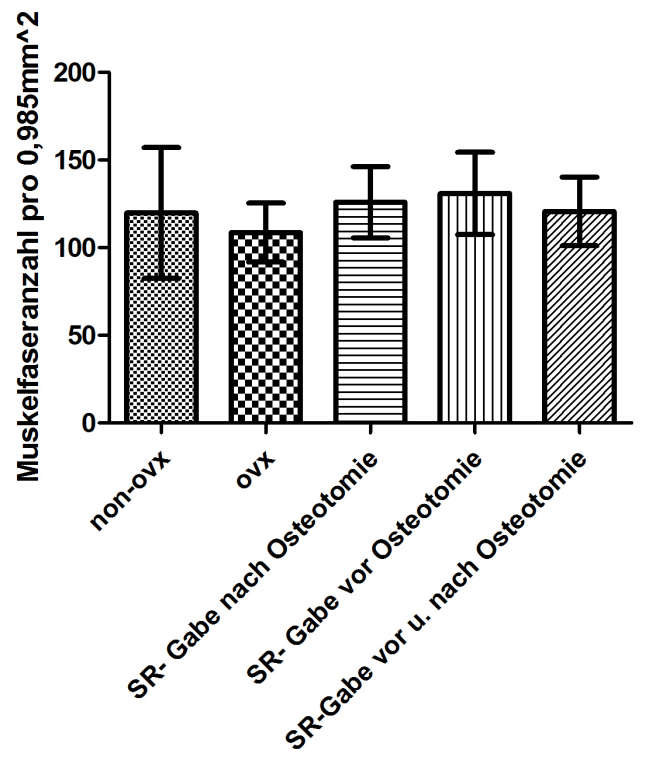
Abbildung 3.15: M. longissimus Anzahl der glykolytischen Fasern (non-ovx: nicht ovariek- tomierte Kontrollgruppe, ovx: ovariektomierte Tiere, SR nach Osteo: Stron- tiumsubstitution nach Osteotomie, SR vor Osteo: Strontiumsubstitution vor Osteotomie, SR vor u. nach: Strontiumsub- stitution vor und nach Osteotomie)

Es zeigten sich keine signifikanten Abweichungen in der Anzahl der glykolytischen Fasern (Abb. 3.15, Tab. 3.18).

Tabelle 3.18: M. longissimus Anzahl der glykogenolytischen Fasern [1/0,985 $\left.\mathrm{mm}^{2}\right]$

\begin{tabular}{|c|c|c|c|c|c|}
\hline Gruppe & $\begin{array}{ll}\text { Anzahl } & \text { der } \\
\text { Tiere [-] } & \end{array}$ & Minimum & Maximum & Mittelwert & Standardabweichung \\
\hline non-ovx & 11 & 79,0 & 198,0 & 119,78 & 37,33 \\
\hline ovx & 11 & 76,0 & 131,0 & 108,5 & 16,79 \\
\hline $\begin{array}{l}\text { SR nach Os- } \\
\text { teo }\end{array}$ & 9 & 92,0 & 161,0 & 130,9 & 23,51 \\
\hline SR vor Osteo & 9 & 101,0 & 165,0 & 125,9 & 20,31 \\
\hline $\begin{array}{l}\text { SR vor u. } \\
\text { nach Osteo }\end{array}$ & 9 & 96,0 & 156,0 & 120,7 & 19,65 \\
\hline
\end{tabular}




\section{Anzahl der oxidativen Fasern}

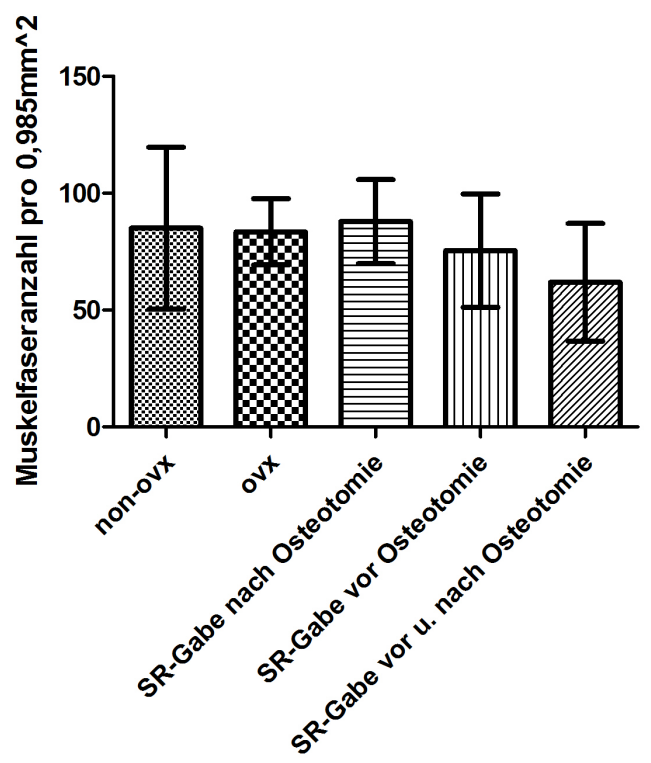

Abbildung 3.16: M. longissimus Anzahl der oxidativen Fasern

(non-ovx: nicht ovariektomierte Kontrollgruppe, ovx: ovariektomierte Tiere, SR nach Osteo: Strontiumsubstitution nach Osteotomie, SR vor Osteo: Strontiumsubstitution vor Osteotomie, SR vor u. nach: Strontiumsubstitution vor und nach Osteotomie)

Es zeigten sich keine signifikanten Abweichungen in der Zahl der oxidativen Fasern (Abb. 3.16, Tab. 3.19).

Tabelle 3.19: M. longissimus Anzahl der oxidativen Fasern [1/0,985 $\left.\mathrm{mm}^{2}\right]$

\begin{tabular}{|c|c|c|c|c|c|}
\hline Gruppe & $\begin{array}{ll}\text { Anzahl } & \text { der } \\
\text { Tiere [-] } & \end{array}$ & Minimum & Maximum & Mittelwert & Standardabweichung \\
\hline non-ovx & 11 & 32,00 & 146,0 & 85,00 & 34,67 \\
\hline ovx & 11 & 65,00 & 105,0 & 83,45 & 14,19 \\
\hline $\begin{array}{l}\text { SR nach Os- } \\
\text { teo }\end{array}$ & 9 & 68,00 & 121,0 & 87,89 & 17,91 \\
\hline SR vor Osteo & 9 & 39,00 & 110,0 & 75,44 & 24,20 \\
\hline $\begin{array}{l}\text { SR vor u. } \\
\text { nach Osteo }\end{array}$ & 9 & 35,00 & 106,0 & 61,89 & 25,19 \\
\hline
\end{tabular}




\section{Ratio aus oxidativen und glykolytischen Zellen}

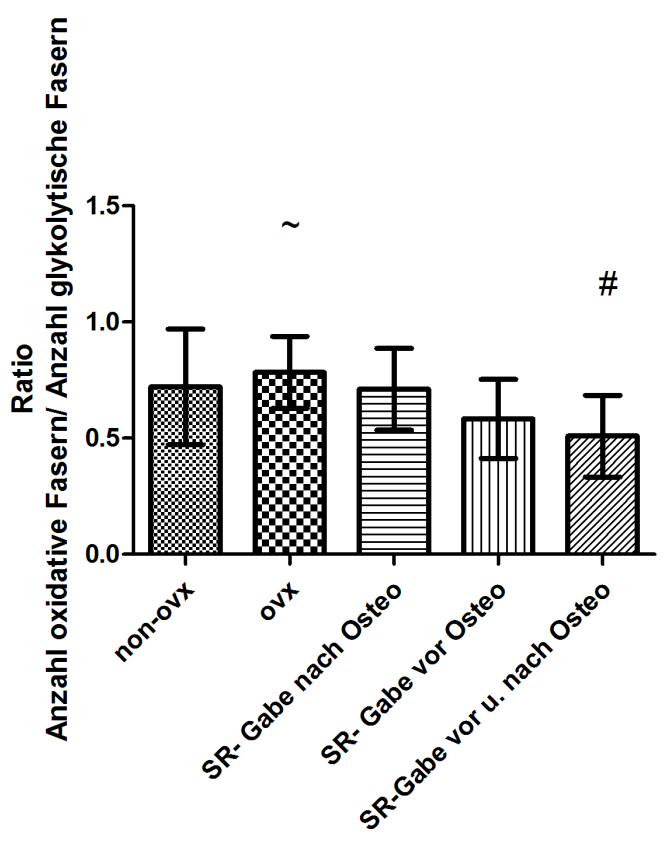

Abbildung 3.17: M. longissimus Ratio aus oxidativen und glykogenolytischen Zellen

(non-ovx: nicht ovariektomierte Kontrollgruppe, ovx: ovariektomierte Tiere, SR nach Osteo: Strontiumsubstitution nach Osteotomie, SR vor Osteo: Strontiumsubstitution vor Osteotomie, SR vor u. nach: Strontiumsubstitution vor und nach Osteotomie, : signifikant erhöht gegen mit \# gekennzeichnete Gruppe)

Es zeigte sich das Verhältnis aus oxidativen und glykolytischen Zellen im Vergleich zur ovarektomierten Gruppe bei den Ratten die Strontiumranelat vor und nach der Osteotomie erhielten signifikant vermindert (Abb. 3.17, Tab. 3.20).

Tabelle 3.20: M. longissimus Ratio aus der Anzahl der oxidativen und glykolytischen Zellen [-]

\begin{tabular}{|c|c|c|c|c|c|}
\hline Gruppe & $\begin{array}{ll}\text { Anzahl } & \text { der } \\
\text { Tiere [-] } & \\
\end{array}$ & Minimum & Maximum & Mittelwert & Standardabweichung \\
\hline non-ovx & 11 & 0,3265 & 1,125 & 0,7203 & 0,2487 \\
\hline ovx $\sim$ & 11 & 0,5652 & 0,9813 & 0,7828 & 0,1547 \\
\hline $\begin{array}{l}\text { SR nach Os- } \\
\text { teo }\end{array}$ & 9 & 0,4857 & 1,110 & 0,7105 & 0,1760 \\
\hline SR vor Osteo & 9 & 0,2671 & 0,7692 & 0,5831 & 0,1700 \\
\hline $\begin{array}{l}\text { SR vor u. } \\
\text { nach Osteo } \\
\#\end{array}$ & 9 & 0,3043 & 0,8689 & 0,5088 & 0,1752 \\
\hline
\end{tabular}


Prozentualer Anteil der glykolytischen Fasern

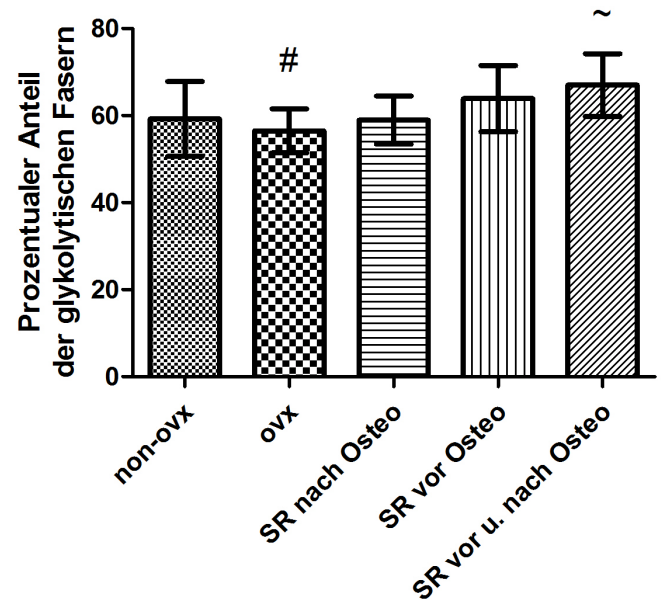

Abbildung 3.18: M. longissimus Prozentualer Anteil der glykolytischen Fasern

(non-ovx: nicht ovariektomierte Kontrollgruppe, ovx: ovariektomierte Tiere, SR nach Osteo: Strontiumsubstitution nach Osteotomie, SR vor Osteo: Strontiumsubstitution vor Osteotomie, SR vor u. nach: Strontiumsubstitution vor und nach Osteotomie, : signifikant erhöht gegen mit \# gekennzeichnete Gruppe)

Es zeigte sich der Anteil an glykolytischen Fasern bei den Ratten die Strontiumranelat vor und nach der Osteotomie erhielten im Vergleich zur ovarektomierten Gruppe signifikant erhöht (Abb. 3.18, Tab. 3.21).

Tabelle 3.21: M. longissimus Prozentualer Anteil der glykolytischen Fasern [\%]

\begin{tabular}{|c|c|c|c|c|c|}
\hline Gruppe & $\begin{array}{ll}\text { Anzahl } & \text { der } \\
\text { Tiere [-] } & \\
\end{array}$ & Minimum & Maximum & Mittelwert & Standardabweichung \\
\hline non-ovx & 11 & 47,06 & 75,38 & 59,25 & 8,580 \\
\hline ovx \# & 11 & 50,47 & 63,89 & 56,49 & 5,077 \\
\hline $\begin{array}{l}\text { SR nach Os- } \\
\text { teo }\end{array}$ & 9 & 47,39 & 67,31 & 58,96 & 5,527 \\
\hline $\mathrm{SR}$ vor Osteo & 9 & 56,52 & 78,92 & 63,89 & 7,622 \\
\hline $\begin{array}{l}\text { SR vor u. } \\
\text { nach Osteo }\end{array}$ & 9 & 53,51 & 76,67 & 67,02 & 7,215 \\
\hline
\end{tabular}

: signifikant erhöht gegen mit \# gekennzeichnete Gruppe 
Prozentualer Anteil der oxidativen Fasern

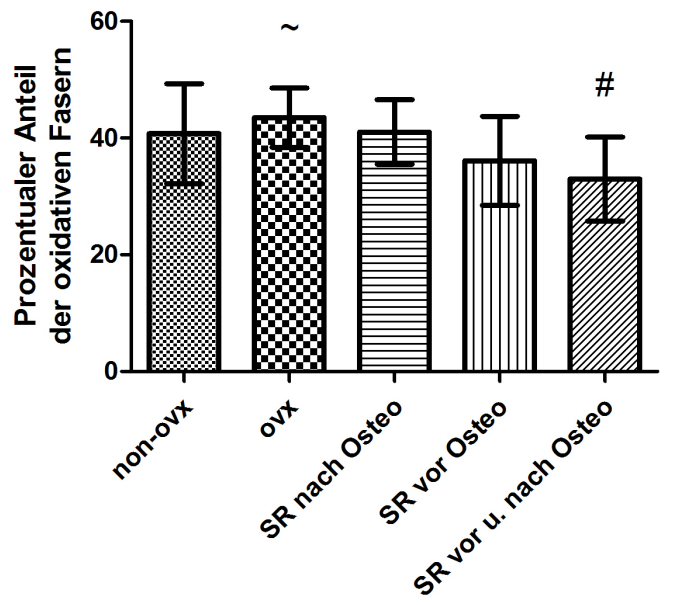

Abbildung 3.19: M. longissimus Prozentualer Anteil der oxidativen Fasern (non-ovx: nicht ovariektomierte Kontrollgruppe, ovx: ovariektomierte Tiere, SR nach Osteo: Strontiumsubstitution nach Osteotomie, SR vor Osteo: Strontiumsubstitution vor Osteotomie, SR vor u. nach: Strontiumsubstitution vor und nach Osteotomie, : signifikant erhöht gegen mit \# gekennzeichnete Gruppe)

Es zeigte sich korrespondierend der Anteil an oxidativen Fasern bei den Ratten die Strontiumranelat vor und nach der Osteotomie erhielten im Vergleich zur ovarektomierten Gruppe signifikant vermindert (Abb. 3.19, Tab. 3.22).

Tabelle 3.22: M. longissimus Prozentualer Anteil der oxidativen Fasern [\%]

\begin{tabular}{|c|c|c|c|c|c|}
\hline Gruppe & $\begin{array}{ll}\text { Anzahl } & \text { der } \\
\text { Tiere [-] } & \\
\end{array}$ & Minimum & Maximum & Mittelwert & Standardabweichung \\
\hline non-ovx & 11 & 24,62 & 52,94 & 40,75 & 8,580 \\
\hline ovx $~ ~$ & 11 & 36,11 & 49,53 & 43,51 & 5,077 \\
\hline $\begin{array}{l}\text { SR nach Os- } \\
\text { teo }\end{array}$ & 9 & 32,69 & 52,61 & 41,04 & 5,527 \\
\hline SR vor Osteo & 9 & 21,08 & 43,48 & 36,11 & 7,622 \\
\hline $\begin{array}{llr}\text { SR } & \text { vor } u . \\
\text { nach } & \text { Osteo } \\
\# & \end{array}$ & 9 & 23,33 & 46,49 & 3,298 & 7,215 \\
\hline
\end{tabular}




\subsubsection{M. soleus}

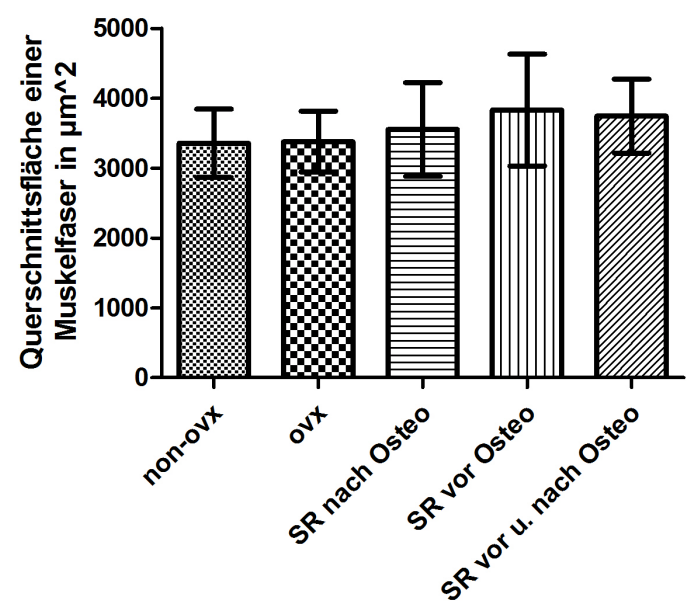
Abbildung 3.20: M. soleus-Querschnittsfläche der Muskelfasern (non-ovx: nicht ovariekto- mierte Kontrollgruppe, ovx: ovariektomierte Tiere, SR nach Osteo: Strontiumsubsti- tution nach Osteotomie, SR vor Osteo: Strontiumsubstitu- tion vor Osteotomie, SR vor u. nach: Strontiumsubstitution vor und nach Osteotomie)

Es zeigten sich keine signifikanten Unterschiede in der Querschnittsfläche der Muskelfasern beim M. soleus (Abb. 3.20, Tab. 3.23).

Tabelle 3.23: M. soleus-Querschnittsfläche der Muskelfasern $\left[\mu m^{2}\right]$

\begin{tabular}{|c|c|c|c|c|c|}
\hline Gruppe & $\begin{array}{ll}\text { Anzahl der } \\
\text { Tiere [-] }\end{array}$ & Minimum & Maximum & Mittelwert & Standardabweichung \\
\hline non-ovx & 12 & 2386 & 3999 & 3356 & 489,2 \\
\hline ovx & 11 & 2827 & 4388 & 3379 & 436,7 \\
\hline $\begin{array}{l}\text { SR nach Os- } \\
\text { teo }\end{array}$ & 9 & 2865 & 5039 & 3551 & 670,5 \\
\hline SR vor Osteo & 9 & 3057 & 5456 & 3832 & 801,5 \\
\hline $\begin{array}{l}\text { SR vor u. } \\
\text { nach Osteo }\end{array}$ & 10 & 2908 & 4737 & 3745 & 529,0 \\
\hline
\end{tabular}


3 Ergebnisse

\subsection{Zusammenfassung der signifikanten Ergebnisse}

Tabelle 3.24: Zusammenfassung der signifikanten Ergebnisse

\begin{tabular}{|c|c|c|c|}
\hline Färbung & Muskel & $\begin{array}{l}\text { Welche Ergebnisse } \\
\text { waren signifikant }\end{array}$ & Welche Gruppe \\
\hline Kapillarfärbung & M. longissimus & $\begin{array}{l}\text { Ratio aus Anzahl } \\
\text { Kapillaren/ Anzahl } \\
\text { Fasern }\end{array}$ & ovx erhöht gegen SR vor Osteo \\
\hline Kapillarfärbung & M. soleus & $\begin{array}{l}\text { Ratio aus Anzahl } \\
\text { Kapillaren/ Anzahl } \\
\text { Fasern }\end{array}$ & $\begin{array}{l}\text { SR vor Osteo, SR nach Osteo, SR vor } \\
\text { u. nach Osteo erhöht gegen non- ovx }\end{array}$ \\
\hline ATPasefärbung & M. gastrocnemius & $\begin{array}{l}\text { Querschnittsfläche } \\
\text { der glykogenolyti- } \\
\text { schen Fasern }\end{array}$ & $\begin{array}{l}\text { ovx, SR nach Osteo, SR vor u. nach Os- } \\
\text { teo erhöht gegen non-ovx }\end{array}$ \\
\hline ATPasefärbung & M. gastrocnemius & $\begin{array}{l}\text { Größenverhältnis } \\
\text { aus oxidativen und } \\
\text { glykogenolytischen } \\
\text { Zellen }\end{array}$ & $\begin{array}{l}\text { non-ovx erhöht gegen ovx, SR vor u. } \\
\text { nach Osteo }\end{array}$ \\
\hline ATPasefärbung & M. longissimus & $\begin{array}{l}\text { Ratio aus oxidati- } \\
\text { ven und glykogeno- } \\
\text { lytischen Zellen }\end{array}$ & ovx erhöht gegen SR vor u. nach Osteo \\
\hline
\end{tabular}

Tabelle 3.24 listet noch einmal die signifikanten Ergebnisse auf. 


\section{Diskussion}

Strontiumranelat ist in Deutschland- trotz des erhöhten Risikos von tiefen Beinvenenthrombosen und des gehäuften Auftretens von kardiovaskulären Ereignissen- als Medikament zur Osteoporosetherapie bei Kontraindikationen für andere Osteoporosemedikamente zugelassen. Von Strontiumranelat ist bekannt, dass es als einziges aktuell zugelassenes Medikament sowohl den Abbau von Knochen hemmt als auch die Proliferation von Osteoblasten stimuliert (Bonnelye et al. 2008), wobei über die Wirkung von Strontiumranelat auf das Muskelgewebe kaum Informationen vorliegen. Die Intention der vorliegenden Dissertationsarbeit war es, die Auswirkung von Strontiumranelatgaben zu verschiedenen Zeitpunkten auf die Muskulatur von ovarektomierten und osteotomierten Ratten zu untersuchen. Als Kontrollgruppen dienten eine nicht-ovariektomierte osteotomierte Gruppe (non-ovx) und eine ovarektomierte osteotomierte Gruppe (ovx). Nach Abschluss der Versuche wurden der M. gastrocnemius, M. longissimus und M. soleus aller Versuchstiere analysiert. Es wurde die Anzahl an Zellen, Kapillaren und das Verhältnis von Kapillaren zu Zellen bestimmt. Des Weiteren wurden der Muskelfaserquerschnitt und das Verhältnis von glykogenolytischen zu oxidativen Muskelfaserzellen untersucht. In einer weiteren Dissertation der Arbeitsgruppe wurde der Einfluss von Strontiumranelat auf die Frakturheilung bei metaphysären Frakturen untersucht (Weidemann 2014). Es wurden in dieser Dissertation die antiosteoporotischen Effekte des Strontiumranelat bestätigt und festgestellt, dass Strontiumranelat keine negativen Auswirkung auf die Frakturheilung hat, wobei der antiosteoporotische Effekt bei der Gruppe, die Strontiumranelat über den längsten Zeitraum erhielt, am ausgeprägtesten war. 


\subsection{Die ovarektomierte Ratte als Tiermodell}

In den durchgeführten Versuchen wurde die ovarektomierte Ratte als Modell für Osteoporose und Sarkopenie genutzt. Es handelt sich um ein etabliertes Modell für die Osteoporose, wobei neben der sicheren Reproduktion des Krankheitsbildes und ähnlichen pathophysiologischen Mechanismen auch wirtschaftliche sowie rechtliche Aspekte eine Rolle spielen. Auch bei der Ratte überwiegt nach der Ovarektomie im Remodeling die Knochenresorption, wobei Frakturen als Folge der Osteoporose weder bei der Ratte (Miller und Wronski 1993) noch in anderen Tiermodellen, mit Ausnahme des Affen, beschrieben sind (Frost und Jee 1992). Folglich kann das Vorliegen der Osteoporose nur über die verminderte Knochendichte bewiesen werden. Eine verminderte Knochendichte bei Ratten nach der Ovarektomie wurde bereits nach 14 Tagen festgestellt, wobei nach 100 Tagen eine Stabilisierung auf niedrigem Niveau festgestellt wurde (Wronski et al. 1988). Im Bereich des Schenkelhalses und der lumbalen Wirbelsäule liegt nach 30 (Wronski et al. 1989) bzw. 60 Tagen (Li et al. 1997) bereits eine deutlich verminderte Knochendichte vor. Der Versuchszeitraum ist somit als hinreichend lang anzusehen. Als Kontrolle für die erfolgreiche Ovarektomie eignen sich die reduzierten Uterusgewichte der ovarektomierten Tiere. Ratten erreichen die peakbone-mass im Alter von etwa zehn Monaten (Lelovas et al. 2008), somit ist sie bei nicht-adulten Ratten reduziert, was wiederum den Gegebenheiten bei der postmenopausalen Osteoporose bei Menschen entspricht. Der positive Effekt von antiosteoporotischen Medikamenten wurde bei der Ratte bestätigt, eine analoge Wirkung von Bisphosphonaten, Calcitonin, körperlicher Aktivität, Östrogen, Parathormon, Tamoxifen ist beschrieben (Kalu 1991), ebenso wurden die antiosteoporotischen Effekte von Strontiumranelat bei Ratten belegt (Peng et al. 2014; Bain et al. 2009). Anders als beim Menschen findet bei Ratten weder ein Remodeling über die Haverssysteme im Knochen (Bellino 2000) statt noch reagieren sie mit einer verminderten Knochendichte auf erhöhte Glukokortikoidspiegel (Li et al. 1996). Für spezielle Fragestellungen wie Hormonersatztherapie (Kessler et al. 2015) sowie für die letzten Schritte in der Entwicklung von Medikamenten zur Osteoporosetherapie wird der Affe als Tiermodell bevorzugt (Smith et al. 2009).

Anders als bei der Genese der Osteoporose und der Sarkopenie des Menschen, nehmen die ovarektomierten Ratten sowohl an Gewicht als auch an Muskulatur zu. Ratten erreichen die Geschlechtsreife im Mittel im Alter von etwa 2,5 Monaten, wobei das Skelett der Ratten etwa 
ab einem Alter von 10 Monaten als adult gilt (Jee und Yao 2001). Die Gewichtszunahme bei allen Versuchstieren ist somit auf das Wachstum der Tiere zurückzuführen. Das signifikant erhöhte Gewicht der ovarektomierten Ratten im Vergleich zu der Kontrollgruppe ab der dritten Versuchswoche ist nicht überraschend, da ovarektomierte Tiere sowohl schneller an Gewicht als auch an Muskulatur zunehmen, wobei eine signifikant erhöhte Nahrungsaufnahme nicht unbedingt notwendig erscheint (McCormick et al. 2004). Dies deckt sich auch mit der nur temporär signifikant differierenden Nahrungsaufnahme der Versuchstiere, sodass die Strontiumsubstitution keinen permamenten Einfluss auf die Nahrungsaufnahme im diesem Versuch hatte. Der Zuwachs an Muskulatur ist mutmaßlich auf eine gesteigerte Proteinsynthese aufgrund des reduzierten Östradiols zurückzuführen (Toth et al. 2001, Richard 1986).

Mit der Zunahme an Muskelmasse liegt bei den Tieren definitionsgemäß keine analoge Veränderung entsprechend der Sarkopenie des Menschen vor. Eine mögliche Veränderung im Sinne einer reduzierten Kraftentwicklung wurde in dieser Dissertation nicht untersucht. Für die Erforschung der Sarkopenie werden als Tiermodell üblichweise alte Ratten benutzt, die dann auch dem sarkopenen Menschen isomorphe Veränderungen der Muskulatur zeigen. Eine Abnahme des Körpergewichts und der Futteraufnahme nach der Osteotomie ist bereits in Vorversuchen auffällig gewesen (Komrakova et al. 2009) und mutmaßlich im Rahmen von postoperativen Schmerzen zu erklären. Das Strontiumranelat wurde den entsprechenden Versuchsgruppen als Futterzusatz oral verabreicht, wobei die mittlere mit der Nahrung aufgenommene Dosis $654 \mathrm{mg} / \mathrm{kg} / \mathrm{Tag}$ betrug. Die antiosteoporotische Wirkung von Strontiumranelat hat sich Vorversuchen bereits ab einer Dosis von $625 \mathrm{mg} / \mathrm{kg} / \mathrm{Tag}$ gezeigt (Bain et al. 2009).

\subsection{Diskussion der Ergebnisse der Kapillar-Färbung}

Beim M. gastrocnemius zeigten sich in der Kapillar-Färbung keine signifikanten Abweichungen. Sowohl die Anzahl der Muskelfasern als auch die Anzahl an Kapillaren waren in der non-ovx Gruppe verglichen mit sämtlichen ovarektomierten Tieren erhöht. In der Literatur wird diese Tendenz auf den Wegfall der modulierenden Östrogenwirkung bei den ovarektomierten Tieren zurückgeführt, der zu größeren Muskelfasern (Haizlip et al. 2015) sowie einer gesteigerten Kapillardichte bei ovarektomierten sowie ovarektomierten und mit Strontium behandelten Ratten 
führt (Komrakova et al. 2009, Komrakova et al. 2016). Als Muskel der unteren Extremität wären sarkopenische Veränderung der Muskulatur, sofern sie aufgetreten wären, bei diesem Muskel am ehesten zu beobachten gewesen. Bei Menschen wird üblicherweise nicht der M. gastrocnemius, sondern der Vastus lateralis des M. quadriceps femoris histologisch untersucht, da dieser für Biopsien einfacher zugänglich ist.

Beim M. longissimus bestand sowohl in der Kapillaranzahl als auch in der Muskelfaseranzahl kein signifikanter Unterschied. Die Anzahl an Kapillaren war bei der ovx-Gruppe am höchsten und die Faseranzahl nicht entsprechend stark gesteigert, so dass der Quotient aus Kapillaranzahl und Faseranzahl bei der oxv-Gruppe signifikant gegenüber der Gruppe, die Strontiumranelat vor der Osteotomie erhielt, erhöht war. Eine erhöhte Vaskularisierung ist bei ovarektomierten Ratten vorbekannt (Komrakova et al. 2016), ein Effekt von Strontium auf die Kapillardichte wurde beim M. longissimus bisher nicht beschrieben. Geht man davon aus, dass alle ovarektomierten Tiere, also die Gruppen ovx, SR vor und nach Osteotomie, SR vor Osteomie und SR nach Osteomie, gleichartige Veränderungen der Muskulatur aufgrund der Ovarektomie zeigen, so könnte die verminderte Vaskularisierung ein negativer Effekt von Strontiumranelat sein. Hier muss allerdings in Betracht gezogen werden, dass die Absolutanzahl an Kapillaren und Muskelfaserzellen nicht signifikant verändert waren. Unter dem Aspekt der Sarkopenie wären beim M. longissmus als Muskel des Rückens keine Veränderungen zu erwarten gewesen.

Beim M. soleus war die Ratio aus Kapillaren und Zellen bei der nicht-ovarektomierten Gruppe gegenüber den Gruppen, die Strontium während des Versuchs erhielten, signifikant vermindert. Da der M. soleus wie der M. gastrocnemius ein Muskel der unteren Extremität ist und in Vorversuchen eine erhöhte Vaskularisierung beim M. gastrocnemius beschrieben wurde, ist es naheliegend dieses Ergebnis im Rahmen einer erhöhten Vaskularisierung der ovarektomierten Tiere gegenüber der nicht-ovarektomierten Gruppe zu interpretieren. Die Anzahl an Kapillaren der ovarektomierten Tiere gegenüber den nicht-ovarektomierten Tieren war nicht vermindert und die Anzahl an Kapillaren bei den nichtovarektomierten Tieren am niedrigsten. Die Faseranzahl wiederum war bei den ovarektomierten Tieren, mit Ausnahme der Gruppe, die Strontiumranelat vor und nach der Osteotomie erhielt, niedriger, was wiederum zu einem größeren Muskelfaserquerschnitt passt. Bei anderen Versuchen zeigte sich kein Unterschied in der Kapillardichte beim M. soleus (Komrakova et al. 2016). 


\subsection{Diskussion der Ergebnisse der ATPase-Färbung}

Bei M. gastrocnemius zeigten sich bei der Querschnittsfläche der glykogenolytischen Muskelfasern signifikante Abweichungen. Die Querschnittsfläche der non-ovx Gruppe ist signifikant gegenüber der ovx, der SR vor Osteotomie und der SR vor und nach Osteotomie Gruppe vermindert. Diese Ergebnisse passen zu einem größeren glykogenolytischen Muskelfaserquerschnitt bei ovarektomierten Tieren und sprechen für eine Nebenwirkung der Ovarektomie, da auch die ovxGruppe betroffen ist. Gegen eine Wirkung der Strontiumranelatgabe spricht des Weiteren, dass die Gruppe die Strontium am längsten erhalten hat, die Gruppe SR vor und nach Osteotomie, der ovx-Gruppe analoge Veränderungen zeigt. Die Gruppe SR vor Osteotomie zeigt im Mittel auch größere Muskelfaserzellen, auch wenn die Veränderungen zur non-ovx-Gruppe nicht signifikant sind. Die Querschnittsfläche der oxidativen Fasern zeigt keine signifikanten Abweichungen, wobei tendenziell die Fasern der ovarektomierten Tiergruppen größer sind. Das Größenverhältnis aus oxidativen und glykogenolytischen Zellen ist bei der non-ovx-Gruppe signifikant gegenüber der ovx und der SR-vor-und-nach Osteotomie Gruppe erhöht. Diese Ergebnisse sprechen für im Verhältnis größere glykogenolytische Muskelfasern bei den ovarektomierten Tieren. Eine Größenzunahme der glykogenolytischen Muskelfasern bei gleichbleibender Größe der oxidativen Fasern ist als Östrogenmangeleffekt vorbekannt (Kobori und Yamamuro 1989). Auch hier zeigen die ovx-Gruppe sowie die Gruppe SR vor und nach Osteotomie gleichartige Veränderungen.

Beim M. longissimus bestand in der Anzahl der glykolytischen und der oxidativen Muskelfasern kein signifikanter Unterschied. Es zeigte sich allerdings in der Verteilung von glykogenolytischen und oxidativen Muskelfaserzellen signifikante Abweichungen zwischen der ovx-Gruppe und der Gruppe SR vor und nach Osteotomie. Bei der Gruppe SR vor und nach Osteotomie überwiegt die Anzahl an glykogenolytischen Fasern und bei der ovx-Gruppe die Anzahl der oxidativen Muskelfaserzellen. Entsprechend ist der der Quotient aus oxidativen und glykolytischen Muskelfaserzellen bei der Gruppe SR vor und nach Osteotomie gegenüber der ovx-Gruppe signifikant vermindert, dieses Überwiegen der glykolytischen Fasern würde eigentlich zu der Pathophysiologie des Östrogenmangels, bei der eine Umwandlung von oxidativen hin zu glykolytischen Fasern beschrieben ist, passen (Haizlip et al. 2015). Hier zeigt sich allerdings eine Abweichung zwischen Gruppen, die beide ovarektomiert worden sind. Normalerweise würde man das unterschiedliche 


\section{Diskussion}

Verteilungsmuster der Muskelfaserzellen auf unterschiedliche Belastungen und damit als funktionelle Anpassung interpretieren. Da die Tiere allerdings unter gleichen Bedingungen gehalten worden sind, ist dies unwahrscheinlich. Vielmehr ist hier von einer Wirkung von Strontiumranelat auf die Muskulatur der Ratte auszugehen. Interessanterweise zeigt sich hier eine gegensätzliche Verteilung zwischen der Gruppe ovx und SR vor und nach Osteotomie, die beim M. Gastrocnemius gleichartige Veränderungen aufweisen.

Beim M. soleus fanden sich bei der Größe der Muskelfasern keine signifikanten Abweichungen, wobei die Fasern der SR-Gruppen tendenziell größer waren, dieses Ergebnis ist deckungsgleich mit bisherigen Versuchen (Suzuki und Yamamuro 1985). 


\section{Schlussfolgerung}

Die Muskulatur der osteopenen Ratte war auf Veränderungen im Sinne einer Sarkopenie oder Veränderungen bedingt durch die Ovarektomie, die gegensätzlich zur Sarkopenie sind, zu untersuchen. Des Weiteren bestand die Möglichkeit, dass Strontiumranelat unbekannte oder keine Effekte auf die Muskulatur hat.

Die meisten Effekte, die Strontiumranelats auf die Muskulatur der osteopenen Ratte in diesem Versuch zeigte, lassen sich als Folge des Östrogenmangels aufgrund der Ovarektomie interpretieren, allerdings mit der Ausnahme des Verteilungsmusters von glykogenolytischen und oxidativen Fasern beim M. Longissimus.

Im Falle des M. longissimus verminderte das Strontiumranelat die Vaskularisierung pro Muskelfaser, während es im Falle des M. soleus zu einer erhöhten Vaskularisierung pro Muskelfaser führte. Eine mögliche Erklärung für diesen differierenden Einfluss könnte die hohe Vaskularisierung bei der ovx-Gruppe sein, die sogar den Grad der Vaskularisierung der non-ovx Gruppe übertraf. Zudem ist zu bedenken, dass sich in der Absolutanzahl an Kapillaren und Muskelfasern keine signifikanten Abweichungen fanden. Da sowohl der M. soleus als auch der M. longissims primär der Aufrechterhaltung der Körperhaltung, während der M. gastrocnemius primär der Bewegung dient (Shorey et al. 1993, Flisinski et al. 2014), lässt sich der differierende Einfluss des Strontiumranelats nicht unter funktionellen Aspekten deuten.

Die Querschnittsflächen der Muskelfaserzellen der SR-Gruppen waren im Vergleich zu den nicht ovarektomierten Tieren signifikant erhöht, dieser Effekt könnte aber auch dem Östrogenmangel aufgrund der Ovarektomie und nicht der Strontiumranelatgabe geschuldet sein. Dafür spricht, dass die ovx-Gruppe ebenfalls signifikant größere Muskelfaserzellen als die non-ovx Gruppe aufwies.

Das Verteilungsmuster der oxidativen und glykogenolytischen Muskelfaserzellen bei M. lon- 
gissimus weist signifikante Abweichungen zwischen der ovx-Gruppe und der SR vor und nach Strontiumranelatgabe, mit einem Überwiegen der glykogenolytischen Muskelfaserzellen bei der Gruppe die Strontium erhielt. Dies ist vor allen Dingen interessant, da sonst sich bei den sonstigen signifikanten Abweichungen gleichartige Veränderungen in beiden Gruppen gezeigt haben. Hier ist von einer Wirkung des Strontiumranelats auf die Muskulatur auszugehen, deren Rolle allerdings unklar bleibt. In dieser Arbeit konnte kein negativer Einfluss der Strontiumranelatgabe auf die Muskulatur festgestellt werden, sodass es vor dem Hintergrund, dass das Strontiumranelat die Knochendichte bei dem längsten Verabreichungszeitraum am stärksten erhöhte, ohne negative Effekte auf die Frakturheilung zu haben, sich die Langzeitgabe empfiehlt. Für weitere Versuche empfiehlt sich neben der Erfassung der rein morphologischen Parameter der Muskulatur auch eine Funktionsprüfung der Muskeln, insbesondere in Hinblick auf die durch den Mangel an Östrogen vergrößerte Muskulatur bei Ratten. So ließe sich vielleicht auch eruieren, ob die hypertrophierte und teilweise hyperplastische Muskulatur, abgesehen von einer verminderten Regeneration (Haizlip et al. 2015), dysfunktional ist oder die Muskulatur zur einer körpergewichtskorrigierten, physiologischen Kraftentwicklung in der Lage ist. Für die Zukunft der klinischen Osteoporoseforschung beim Menschen ist aufgrund der überragenden Bedeutung der Muskulatur für die Integrität der Knochen eine stärke Fokussierung auf diese wünschenswert, wobei beachtet werden muss, dass die Veränderungen der Muskulatur möglicherweise nur eine Folge der neuralen Degeneration sind und die morphologischen Veränderungen der Muskulatur damit nur ein Epiphänomen wären (Pannérec et al. 2016). Möchte man explizit sarkopenische und osteoporotische Veänderungen bei der Ratte als Tiermodell gemeinsam untersuchen, so muss man auf ältere Versuchstiere (mindestens 18 Monate), als in diesem Versuch verwendet wurden, zurückgreifen. 


\section{Abbildungsverzeichnis}

2.1 M.gastrocnemius Kapillar-Färbung . . . . . . . . . . . . . . . . . . . . . 41

2.2 M.longissimus Kapillar-Färbung . . . . . . . . . . . . . . . . . . . . . 42

2.3 M.soleus Kapillar-Färbung . . . . . . . . . . . . . . . . . . . . . . . . . . . . 42

2.4 M. gastrocnemicus ATPase-Färbung . . . . . . . . . . . . . . . . . . . 44

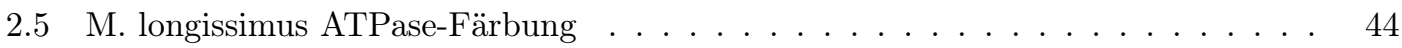

2.6 M. soleus ATPase- Färbung . . . . . . . . . . . . . . . . . . . . . . 45

$3.1 \quad$ M. gastrocnemius-Kapillaranzahl . . . . . . . . . . . . . . . . 50

$3.2 \quad$ M. gastrocnemius-Faseranzahl . . . . . . . . . . . . . . . . . 51

3.3 M. gastrocnemius Ratio Anzahl Kapillaren/Anzahl Fasern . . . . . . . . . . . . . 52

3.4 M. longissimus-Kapillaranzahl . . . . . . . . . . . . . . . . . . . 53

3.5 M. longissimus- Muskelfaseranzahl _. . . . . . . . . . . . . . . . . . . 54

3.6 M. longissimus Ratio Anzahl Kapillaren/ Anzahl Fasern . . . . . . . . . . . . . . 55

3.7 M. soleus-Anzahl Kapillaren . . . . . . . . . . . . . . . . . . . . . . . . . . . 56

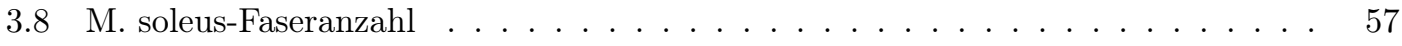

3.9 M. soleus Ratio Anzahl Kapillaren/Anzahl Fasern . . . . . . . . . . . . . . . 58

3.10 M. gastrocnemius Fläche der glykogenolytischen Fasern _ . . . . . . . . . . . 59

3.11 M. gastrocnemius Fläche der oxidativen Zellen . . . . . . . . . . . . . . . 60

3.12 M. gastrocnemius Ratio Anzahl Oxidativ/ Anzahl Glykogen . . . . . . . . . . . . 61

3.13 M. longissimus Querschnittsfläche der glykogenolytischen Fasern . . . . . . . . 62

3.14 M. longissimus Querschnittsfläche der oxidativen Fasern . . . . . . . . . . . . . 63

3.15 M. longissimus Anzahl der glykogenlytischen Fasern . . . . . . . . . . . . . . . 64

3.16 M. longissimus Anzahl der oxidativen Fasern f . . . . . . . . . . . . . . . 65 


\section{Abbildungsverzeichnis}

3.17 M. longissimus Ratio aus oxidativen und glykogenolytischen Zellen . . . . . . . 66

3.18 M. longissimus Prozentualer Anteil der glykolytischen Fasern . . . . . . . . . . 67

3.19 M. longissimus Prozentualer Anteil der oxidativen Fasern . . . . . . . . . . . 68

3.20 M. soleus- Querschnittsfläche der Muskelfasern . . . . . . . . . . . . . . . . 69 


\section{Tabellenverzeichnis}

1.1 Ursachen der lokalisierten Osteoporose . . . . . . . . . . . . . . . . . . . . . . 19

1.2 Ursachen der sekundären Osteoporose . . . . . . . . . . . . . . . . . . . . . . 20

1.3 Therapieindikationen in Abhängigkeit vom T-Score . . . . . . . . . . . . . . . 25

2.1 Verteilung der Versuchstiere . . . . . . . . . . . . . . . . . . . . . 32

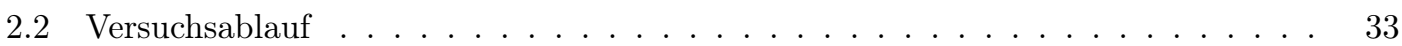

3.1 Uterusgewichte der Tiere $[\mathrm{g}] \ldots \ldots$. . . . . . . . . . . . . . . 47

3.2 Gewichtsentwicklung der Versuchstiere im Verlauf $[\mathrm{g}]$. . . . . . . . . . . . . . 48

3.3 Futteraufnahme der Tiere im Verlauf $[\mathrm{g}] \ldots$. . . . . . . . . . . . . . . . . . . 49

3.4 M. gastrocnemius-Kapillaranzahl $\left[1 / 0,985 \mathrm{~mm}^{2}\right] \ldots \ldots \ldots$. . . . . . . . . . 50

3.5 M. gastronemius-Faseranzahl $\left[1 / 0,985 \mathrm{~mm}^{2}\right] \ldots \ldots \ldots$. . . . . . . . . . . . 51

3.6 M. gastrocnemius Ratio Anzahl Kapillaren/Anzahl Fasern [-] . . . . . . . . . . . 52

3.7 M. longissimus-Kapillaranzahl $\left[1 / 0,985 \mathrm{~mm}^{2}\right] \ldots \ldots \ldots$

3.8 M. longissimus-Muskelfaseranzahl $\left[1 / 0,985 \mathrm{~mm}^{2}\right] \ldots \ldots$. . . . . . . . . . . . 54

3.9 M. longissimus Ratio Anzahl Kapillaren/Anzahl Zellen [-] . . . . . . . . . . . . . 55

3.10 M. soleus-Kapillaranzahl $\left[1 / 0,985 \mathrm{~mm}^{2}\right] \ldots \ldots \ldots$. . . . . . . . . . . 56

3.11 M. soleus-Faseranzahl $\left[1 / 0,985 \mathrm{~mm}^{2}\right] \ldots \ldots \ldots \ldots$. . . . . . . . . . . 57

3.12 M. soleus Ratio Anzahl Kapillaren/Anzahl Fasern [-] . . . . . . . . . . . . . . . 58

3.13 M. gastrocnemius Querschnittsfläche der glykogenolytischen Fasern $\left[\mathrm{\mu m}^{2}\right]$. . . . 59

3.14 M. gastronemius Fläche der oxidativen Zellen $\left[\mu m^{2}\right] \ldots \ldots$. . . . . . . . . . . . 60

3.15 M. gastronemius Größenverhältnis aus oxidativen und glykogenolytischen Zellen [-] 61

3.16 M. longissimus Querschnittsfläche der glykogenolytischen Fasern $\left[\mu m^{2}\right]$. . . . . 62

3.17 M. longissimus Querschnittsfläche der oxidativen Fasern $\left[\mu m^{2}\right] \ldots \ldots$ 


\section{Tabellenverzeichnis}

3.18 M. longissimus Anzahl der glykogenolytischen Fasern $\left[1 / 0,985 \mathrm{~mm}^{2}\right]$. . . . . . 64

3.19 M. longissimus Anzahl der oxidativen Fasern $\left[1 / 0,985 \mathrm{~mm}^{2}\right]$. . . . . . . . . . 65

3.20 M. longissimus Ratio aus der Anzahl der oxidativen und glykolytischen Zellen [-] 66

3.21 M. longissimus Prozentualer Anteil der glykolytischen Fasern [\%] . . . . . . . . . 67

3.22 M. longissimus Prozentualer Anteil der oxidativen Fasern [\%] . . . . . . . . . . . 68

3.23 M. soleus-Querschnittsfläche der Muskelfasern $\left[\mu m^{2}\right] \ldots \ldots$. . . . . . . . . . . 69

3.24 Zusammenfassung der signifikanten Ergebnisse . . . . . . . . . . . . . . 70 


\section{Literaturverzeichnis}

Altun M, Besche HC, Overkleeft HS, Piccirillo R, Edelmann MJ, Kessler BM, Goldberg AL, Ulfhake B (2010): Muscle wasting in aged, sarcopenic rats is associated with enhanced activity of the ubiquitin proteasome pathway. J Biol Chem 285, 39597-39608

Aloia JF, McGowan DM, Vaswani AN, Ross P, Cohn SH (1991): Relationship of menopause to skeletal and muscle mass. Am J Clin Nutr $\underline{53}, 1378-1383$

Andersen P (1975): Capillary density in skeletal muscle of man. Acta Physiol Scand 95, 203-205

Bain SD, Jerome C, Shen V, Dupin-Roger I, Ammann P (2009): Strontium ranelate improves bone strength in ovariectomized rat by positively influencing bone resistance determinants. Osteoporos Int $\underline{20}, 1417-1428$

Ballak SB, Degens H, de Haan A, Jaspers RT (2014): Aging related changes in determinants of muscle force generating capacity: a comparison of muscle aging in men and male rodents. Ageing Res Rev 14, 43-55

Bartl R: Osteoporose: Prävention, Diagnostik, Therapie. 4. Auflage; Thieme, Stuttgart 2010

Bea JW, Zhao Q, Cauley JA, LaCroix AZ, Bassford T, Lewis CE, Jackson RD, Tylavsky FA, Chen Z (2011): Effect of hormone therapy on lean body mass, falls, and fractures: 6-year results from the Women's Health Initiative hormone trials. Menopause $\underline{18}, 44-52$

Bellino FL (2000): Nonprimate Animal Models of Menopause: Workshop Report. Menopause $\underline{7}$, $14-24$

Black DM, Thompson DE, Bauer DC, Ensrud K, Musliner T, Hochberg MC, Nevitt MC, Suryawanshi S, Cummings SR (2000): Fracture Risk Reduction with Alendronate in Women with Osteoporosis: The Fracture Intervention Trial. J Clin Endocrinol Metab 모, 4118-4124 


\section{Literaturverzeichnis}

Black DM, Schwartz AV, Ensrud KE, Cauley JA, Levis S, Quandt SA, Satterfield S, Wallace RB, Bauer DC, Palermo L, et al. (2006): Effects of continuing or stopping alendronate after 5 years of treatment: The fracture intervention trial long-term extension (flex): a randomized trial. JAMA $\underline{296}, 2927-2938$

Black DM, Delmas PD, Eastell R, Reid IR, Boonen S, Cauley JA, Cosman F, Lakatos P, Leung PC, Man Z, et al. (2007): Once-Yearly Zoledronic Acid for Treatment of Postmenopausal Osteoporosis. N Engl J Med $\underline{356}, 1809-1822$

Black DM, Reid IR, Boonen S, Bucci-Rechtweg C, Cauley JA, Cosman F, Cummings SR, Hue TF, Lippuner K, Lakatos P, et al. (2012): The effect of 3 versus 6 years of Zoledronic acid treatment of osteoporosis: A randomized extension to the HORIZON-Pivotal Fracture Trial (PFT). J Bone Miner Res $\underline{27}, 243-254$

Bobba RS, Beattie K, Parkinson B, Kumbhare D, Adachi JD (2006): Tolerability of different dosing regimens of bisphosphonates for the treatment of osteoporosis and malignant bone disease. Drug Saf $\underline{29}, 1133-1152$

Bolland MJ, Grey A (2014): A comparison of adverse event and fracture efficacy data for strontium ranelate in regulatory documents and the publication record. BMJ Open $\underline{4}$ Ve005787

Bone HG, Hosking D, Devogelaer J-P, Tucci JR, Emkey RD, Tonino RP, Rodriguez-Portales JA, Downs RW, Gupta J, Santora AC, Liberman UA (2004): Ten Years' Experience with Alendronate for Osteoporosis in Postmenopausal Women. N Engl J Med 풍, 1189-1199

Bonnelye E, Chabadel A, Saltel F, Jurdic P (2008): Dual effect of strontium ranelate: stimulation of osteoblast differentiation and inhibition of osteoclast formation and resorption in vitro. Bone $\underline{42}, 129-138$

Brodal P, Ingjer F, Hermansen L (1977): Capillary supply of skeletal muscle fibers in untrained and endurance-trained men. Am J Physiol 232, H705-H712

Cao L, Morley JE (2016): Sarcopenia Is Recognized as an Independent Condition by an International Classification of Disease, Tenth Revision, Clinical Modification (ICD-10-CM) Code. J Am Med Dir Assoc 17, 675-677 


\section{Literaturverzeichnis}

Chan OYA, van Houwelingen AH, Gussekloo J, Blom JW, den Elzen WPJ (2014): Comparison of quadriceps strength and handgrip strength in their association with health outcomes in older adults in primary care. Age $\underline{36} 9714$

Chesnut CH, Silverman S, Andriano K, Genant H, Gimona A, Harris S, Kiel D, LeBoff M, Maricic M, Miller P, et al. (2000): A randomized trial of nasal spray salmon calcitonin in postmenopausal women with established osteoporosis: the prevent recurrence of osteoporotic fractures study. PROOF Study Group. Am J Med 109, 267-276

Clynes MA, Edwards MH, Buehring B, Dennison EM, Binkley N, Cooper C (2015): Definitions of Sarcopenia: Associations with Previous Falls and Fracture in a Population Sample. Calcif Tissue Int $\underline{97}, 445-452$

Cruz-Jentoft AJ, Baeyens JP, Bauer JM, Boirie Y, Cederholm T, Landi F, Martin FC, Michel J-P, Rolland Y, Schneider SM, et al. (2010): Sarcopenia: European consensus on definition and diagnosis. Age Ageing $\underline{39}, 412-423$

Cruz-Jentoft AJ, Landi F, Schneider SM, Zúñiga C, Arai H, Boirie Y, Chen L-K, Fielding RA, Martin FC, Michel J-P, et al. (2014): Prevalence of and interventions for sarcopenia in ageing adults: a systematic review. Report of the International Sarcopenia Initiative (EWGSOP and IWGS). Age Ageing $\underline{43}, 748-759$

Cummings SR, Melton LJ (2002): Epidemiology and outcomes of osteoporotic fractures. Lancet $\underline{359}, 1761-1767$

Dam T-T, Peters KW, Fragala M, Cawthon PM, Harris TB, McLean R, Shardell M, Alley DE, Kenny A, Ferrucci L, et al. (2014): An Evidence-Based Comparison of Operational Criteria for the Presence of Sarcopenia. J Gerontol A Biol Sci Med Sci $\underline{69}, 584-590$

Dempster DW, Cosman F, Parisien M, Shen V, Lindsay R (1993): Anabolic Actions of Parathyroid Hormone on Bone. Endocr Rev 14, 690-709

Dinenno FA, Seals DR, DeSouza CA, Tanaka H (2001): Age-related decreases in basal limb blood flow in humans: time course, determinants and habitual exercise effects. J Physiol $\underline{531}, 573-579$ Drenckhahn D: Benninghoff, Drenckhahn, Anatomie: Makroskopische Anatomie, Histologie, Em- 


\section{Literaturverzeichnis}

bryologie, Zellbiologie. Band 1: Zelle, Gewebe, Entwicklung, Skelett- und ... Verdauungssystem, Harn- und Genitalsystem. 17. Auflage; Urban \& Fischer Verlag/Elsevier, München 2008

DVO-Leitlinie (2014): Prophylaxe, Diagnostik und Therapie der Osteoporose bei Männern ab dem 60. Lebensjahr und bei postmenopausalen Frauen. Leitline des Dachvebands der Deutschsprachigen Wissenschaftlichen Osteologischen Gesellschaften e.V. Version 1a

Ettinger B, Black DM, Mitlak BH, Knickerbocker RK, Nickelsen T, Genant HK, Christiansen C, Delmas PD, Zanchetta JR, Stakkestad J, et al. (1999): Reduction of vertebral fracture risk in postmenopausal women with osteoporosis treated with raloxifene: Results from a 3-year randomized clinical trial. JAMA $282,637-645$

Fielding RA, Vellas B, Evans WJ, Bhasin S, Morley JE, Newman AB, Abellan van Kan G, Andrieu S, Bauer J, Breuille D, et al. (2011): Sarcopenia: An Undiagnosed Condition in Older Adults. Current Consensus Definition: Prevalence, Etiology, and Consequences (2011) J Am Med Dir Assoc 12, 249-256

Flisinski M, Brymora A, Elminowska-Wenda G, Bogucka J, Walasik K, Stefanska A, Strozecki P, Manitius J (2014): Morphometric analysis of muscle fibre types in rat locomotor and postural skeletal muscles in different stages of chronic kidney disease. J Physiol Pharmacol Off J Pol Physiol Soc $\underline{65}, 567-576$

Frontera WR, Reid KF, Phillips EM, Krivickas LS, Hughes VA, Roubenoff R, Fielding RA (2008): Muscle fiber size and function in elderly humans: a longitudinal study. J Appl Physiol $\underline{105}, 637-642$

Frost HM (2001): From Wolff's law to the Utah paradigm: Insights about bone physiology and its clinical applications. Anat Rec $\underline{262}, 398-41$

Frost HM, Jee WS (1992): On the rat model of human osteopenias and osteoporoses. Bone Miner $\underline{18}, 227-236$

Giannoulis MG, Martin FC, Nair KS, Umpleby AM, Sonksen P (2012): Hormone Replacement Therapy and Physical Function in Healthy Older Men. Time to Talk Hormones? Endocr Rev $\underline{33}$, $314-377$ 


\section{Literaturverzeichnis}

Goodpaster BH, Park SW, Harris TB, Kritchevsky SB, Nevitt M, Schwartz AV, Simonsick EM, Tylavsky FA, Visser M, Newman AB (2006): The loss of skeletal muscle strength, mass, and quality in older adults: the health, aging and body composition study. J Gerontol A Biol Sci Med Sci $\underline{61}, 1059-1064$

Haizlip KM, Harrison BC, Leinwand LA (2015): Sex-Based Differences in Skeletal Muscle Kinetics and Fiber-Type Composition. Physiology $\underline{30}, 30-39$

Häussler B, Gothe H, Göl D, Glaeske G, Pientka L, Felsenberg D (2007): Epidemiology, treatment and costs of osteoporosis in Germany-the BoneEVA Study. Osteoporos Int 18, 77-84

He H, Liu Y, Tian Q, Papasian CJ, Hu T, Deng H-W (2015): Relationship of sarcopenia and body composition with osteoporosis. Osteoporos Int $\underline{27}, 473-482$

Hong B, Chen M, Hu X (2013): Influence of injection of Chinese botulinum toxin type A on the histomorphology and myosin heavy chain composition of rat gastrocnemius muscles. J Zhejiang Univ Sci B $\underline{14}, 983-992$

Horák V (1983): A successive histochemical staining for succinate dehydrogenase and „reversed- "ATPase in a single section for the skeletal muscle fibre typing. Histochemistry $\underline{78}, 545-553$

Hyytiäinen HK, Mykkänen AK, Hielm-Björkman AK, Stubbs NC, McGowan CM (2014): Muscle fibre type distribution of the thoracolumbar and hindlimb regions of horses: relating fibre type and functional role. Acta Vet Scand $\underline{56}, 8$

Ibebunjo C, Chick JM, Kendall T, Eash JK, Li C, Zhang Y, Vickers C, Wu Z, Clarke BA, Shi J, et al. (2013): Genomic and proteomic profiling reveals reduced mitochondrial function and disruption of the neuromuscular junction driving rat sarcopenia. Mol Cell Biol $\underline{33}, 194-212$

Janssen I, Heymsfield SB, Wang ZM, Ross R (2000): Skeletal muscle mass and distribution in 468 men and women aged 18-88 yr. J Appl Physiol (1985)모, 81-88

Jee WS, Yao W (2001): Overview: animal models of osteopenia and osteoporosis. J Musculoskelet Neuronal Interact $\underline{1}, 193-207$

Junqueira LCU, Carneiro J, Gratzl M: Histologie. 6.Auflage; Springer, Heidelberg 2005 


\section{Literaturverzeichnis}

Kaji H (2013): Linkage between muscle and bone: common catabolic signals resulting in osteoporosis and sarcopenia. Curr Opin Clin Nutr Metab Care 16, 272-277

Kalu DN (1991): The ovariectomized rat model of postmenopausal bone loss. Bone Miner $\underline{15}$, $175-191$

Kanis JA, Johnell O (2005): Requirements for DXA for the management of osteoporosis in Europe. Osteoporos Int $\underline{16}, 229-238$

Kaufman J-M, Audran M, Bianchi G, Braga V, Diaz-Curiel M, Francis RM, Goemaere S, Josse R, Palacios S, Ringe JD, et al. (2013): Efficacy and safety of strontium ranelate in the treatment of osteoporosis in men. J Clin Endocrinol Metab $\underline{98}, 592-601$

Kessler MJ, Wang Q, Cerroni AM, Grynpas MD, Gonzalez Velez OD, Rawlins RG, Ethun KF, Wimsatt JH, Kensler TB, Pritzker KPH (2015): Long-term effects of castration on the skeleton of male rhesus monkeys (Macaca mulatta). Am J Primatol 표, 152-66

Khan M, Couturier A, Kubens JF, Most E, Mooren F-C, Krüger K, Ringseis R, Eder K (2013): Niacin supplementation induces type II to type I muscle fiber transition in skeletal muscle of sheep. Acta Vet Scand $\underline{55}, 85$

Kim S, Won CW, Kim BS, Choi HR, Moon MY (2014): The Association between the Low Muscle Mass and Osteoporosis in Elderly Korean People. J Korean Med Sci $\underline{29}, 995-1000$

Kobori M, Yamamuro T (1989): Effects of gonadectomy and estrogen administration on rat skeletal muscle. Clin Orthop $\underline{243}, 306-311$

Komrakova M, Werner C, Wicke M, Nguyen BT, Sehmisch S, Tezval M, Stuermer KM, Stuermer EK (2009): Effect of daidzein, 4-methylbenzylidene camphor or estrogen on gastrocnemius muscle of osteoporotic rats undergoing tibia healing period. J Endocrinol 201, 253-262

Komrakova M, Hoffmann DB, Nuehnen V, Stueber H, Wassmann M, Wicke M, Tezval M, Stuermer KM, Sehmisch S (2016): The Effect of Vibration Treatments Combined with Teriparatide or Strontium Ranelate on Bone Healing and Muscle in Ovariectomized Rats. Calcif Tissue Int $\underline{99}, 408-422$

Kugelberg E (1976): Adaptive transformation of rat soleus motor units during growth. J Neurol Sci $27,269-289$ 


\section{Literaturverzeichnis}

Laughlin MH (1999): Cardiovascular response to exercise. Am J Physiol 277, S244-259

Leitner MM, Tami AE, Montavon PM, Ito K (2009): Longitudinal as well as age-matched assessments of bone changes in the mature ovariectomized rat model. Lab Anim $\underline{43}, 266-271$

Lelovas PP, Xanthos TT, Thoma SE, Lyritis GP, Dontas IA (2008): The Laboratory Rat as an Animal Model for Osteoporosis Research. Comp Med $\underline{58}, 424-430$

Lexell J, Henriksson-Larsén K, Winblad B, Sjöström M (1983): Distribution of different fiber types in human skeletal muscles: effects of aging studied in whole muscle cross sections. Muscle Nerve $\underline{6}, 588-595$

Lexell J, Taylor CC, Sjöström M (1988): What is the cause of the ageing atrophy? Total number, size and proportion of different fiber types studied in whole vastus lateralis muscle from 15- to 83-year-old men. J Neurol Sci $\underline{84}, 275-294$

Li M, Shen Y, Halloran BP, Baumann BD, Miller K, Wronski TJ (1996): Skeletal response to corticosteroid deficiency and excess in growing male rats. Bone $\underline{19}, 81-88$

Li M, Shen Y, Wronski TJ (1997): Time course of femoral neck osteopenia in ovariectomized rats. Bone $\underline{20}, 55-61$

Lüllmann-Rauch R, Paulsen F: Taschenlehrbuch Histologie. 4., vollständig überarbeitete Auflage; Thieme, Stuttgart; New York, NY 2012

Martel GF, Roth SM, Ivey FM, Lemmer JT, Tracy BL, Hurlbut DE, Metter EJ, Hurley BF, Rogers MA (2006): Age and sex affect human muscle fibre adaptations to heavy-resistance strength training. Exp Physiol 91, 457-464

Martino S, Cauley JA, Barrett-Connor E, Powles TJ, Mershon J, Disch D, Secrest RJ, Cummings SR, CORE Investigators (2004): Continuing outcomes relevant to Evista: breast cancer incidence in postmenopausal osteoporotic women in a randomized trial of raloxifene. J Natl Cancer Inst $\underline{96}, 1751-1761$

Matsubara K, Harada H, Ando N, Watada S, Obara H, Matsumoto K, Kitagawa Y (2012): Estrogen deficiency attenuates neovascularization in a murine model of hindlimb ischemia. $\mathrm{J}$ Surg Res $\underline{178}, 1022-1028$ 


\section{Literaturverzeichnis}

McCormick KM, Burns KL, Piccone CM, Gosselin LE, Brazeau GA (2004): Effects of ovariectomy and estrogen on skeletal muscle function in growing rats. J Muscle Res Cell Motil 25, 21-27 Meunier PJ, Reginster JY (2003): Design and methodology of the phase 3 trials for the clinical development of strontium ranelate in the treatment of women with postmenopausal osteoporosis. Osteoporos Int $\underline{14}$ Suppl 3, 66-76

Meunier PJ, Roux C, Seeman E, Ortolani S, Badurski JE, Spector TD, Cannata J, Balogh A, Lemmel E-M, Pors-Nielsen S, et al. (2004): The effects of strontium ranelate on the risk of vertebral fracture in women with postmenopausal osteoporosis. N Engl J Med 350, 459-468

Meunier PJ, Roux C, Ortolani S, Diaz-Curiel M, Compston J, Marquis P, Cormier C, Isaia G, Badurski J, Wark JD, et al. (2009): Effects of long-term strontium ranelate treatment on vertebral fracture risk in postmenopausal women with osteoporosis. Osteoporos Int $\underline{20}, 1663-1673$

Miller SC, Wronski TJ (1993): Long-term osteopenic changes in cancellous bone structure in ovariectomized rats. Anat Rec $\underline{236}, 433-441$

Mitchell SJ, Scheibye-Knudsen M, Longo DL, de Cabo R (2015): Animal models of aging research: implications for human aging and age-related diseases. Annu Rev Anim Biosci $\underline{3}$, 283-303

Moran AL, Warren GL, Lowe DA (2006): Removal of ovarian hormones from mature mice detrimentally affects muscle contractile function and myosin structural distribution. J Appl Physiol $1985 \underline{100}, 548-559$

Morley JE (2012): Anorexia of aging: a true geriatric syndrome. J Nutr Health Aging 16, 422-425

Morley JE, Baumgartner RN, Roubenoff R, Mayer J, Nair KS (2001): Sarcopenia. J Lab Clin Med $\underline{137}, 231-243$

Nederveen JP, Joanisse S, Snijders T, Ivankovic V, Baker SK, Phillips SM, Parise G (2016): Skeletal muscle satellite cells are located at a closer proximity to capillaries in healthy young compared with older men. J Cachexia Sarcopenia Muscle ㅍ, 547-554

Neer RM, Arnaud CD, Zanchetta JR, Prince R, Gaich GA, Reginster JY, Hodsman AB, Eriksen EF, Ish- Shalom S, Genant HK, et al. (2001): Effect of parathyroid hormone (1-34) on fractures and bone mineral density in postmenopausal women with osteoporosis. N Engl J Med $\underline{344}, 1434-$ 1441 


\section{Literaturverzeichnis}

NIH Consensus Development Panel on Osteoporosis Prevention, Diagnosis, and Therapy (2001): OSteoporosis prevention, diagnosis, and therapy. JAMA $\underline{285}, 785-795$

Nilwik R, Snijders T, Leenders M, Groen BBL, van Kranenburg J, Verdijk LB, van Loon LJC (2013): The decline in skeletal muscle mass with aging is mainly attributed to a reduction in type II muscle fiber size. Exp Gerontol $\underline{48}, 492-498$

Özkaya N, Nordin M, Goldsheyder D, Leger D: Fundamentals of Biomechanics: Equilibrium, Motion, and Deformation. 3. Auflage, Springer, New York 2012

Pannérec A, Springer M, Migliavacca E, Ireland A, Piasecki M, Karaz S, Jacot G, Métairon S, Danenberg E, Raymond F, et al. (2016): A robust neuromuscular system protects rat and human skeletal muscle from sarcopenia. Aging $\underline{8}, 712-728$

Pazianas M, Miller P, Blumentals WA, Bernal M, Kothawala P (2007): A review of the literature on osteonecrosis of the jaw in patients with osteoporosis treated with oral bisphosphonates: prevalence, risk factors, and clinical characteristics. Clin Ther $\underline{29}, 1548-1558$

Peng S, Liu XS, Huang S, Pan H, Zhen W, Zhou G, Luk KDK, Guo XE, Lu WW (2014): Intervention timing of strontium treatment on estrogen depletion-induced osteoporosis in rats: bone microstructure and mechanics. J Orthop Res $\underline{32}$, 477-484

Powles TJ, Hickish T, Kanis JA, Tidy A, Ashley S (1996): Effect of tamoxifen on bone mineral density measured by dual-energy x-ray absorptiometry in healthy premenopausal and postmenopausal women. J Clin Oncol $\underline{14}, 78-84$

Proctor DN, Sinning WE, Walro JM, Sieck GC, Lemon PW (1995): Oxidative capacity of human muscle fiber types: effects of age and training status. J Appl Physiol 표, 2033-2038

Rantanen T, Volpato S, Ferrucci L, Heikkinen E, Fried LP, Guralnik JM (2003): Handgrip strength and cause-specific and total mortality in older disabled women: exploring the mechanism. J Am Geriatr Soc ㅁ1, 636-641

Reginster JY, Seeman E, De Vernejoul MC, Adami S, Compston J, Phenekos C, Devogelaer JP, Curiel MD, Sawicki A, Goemaere S, et al. (2005): Strontium ranelate reduces the risk of nonvertebral fractures in postmenopausal women with osteoporosis: Treatment of Peripheral Osteoporosis (TROPOS) study. J Clin Endocrinol Metab 무, 2816-2822 


\section{Literaturverzeichnis}

Reginster J-Y, Felsenberg D, Boonen S, Diez-Perez A, Rizzoli R, Brandi M-L, Spector TD, Brixen K, Goemaere S, Cormier C, et al. (2008): Effects of long-term strontium ranelate treatment on the risk of nonvertebral and vertebral fractures in postmenopausal osteoporosis: Results of a five-year, randomized, placebo-controlled trial. Arthritis Rheum $\underline{58}, 1687-1695$

Richard D (1986): Effects of ovarian hormones on energy balance and brown adipose tissue thermogenesis. Am J Physiol 250, R245-R249

Riggs BL, Melton LJ (1995): The worldwide problem of osteoporosis: insights afforded by epidemiology. Bone $\underline{17}, 505 \mathrm{~S}-511 \mathrm{~S}$

Rosenberg IH (1997): Sarcopenia: origins and clinical relevance. J Nutr 127, 990S-991S

Russell RGG, Watts NB, Ebetino FH, Rogers MJ (2008): Mechanisms of action of bisphosphonates: similarities and differences and their potential influence on clinical efficacy. Osteoporos Int $\underline{19}, 733-759$

Sahin G, Duce MN, Milcan A, Bagis S, Cimen OB, Cimen B, Erdogan C (2002): Bone mineral density and grip strength in postmenopausal Turkish women with osteoporosis: site specific or systemic? Int J Fertil Womens Med $\underline{47}, 236-239$

Saita Y, Ishijima M, Kaneko K (2015): Atypical femoral fractures and bisphosphonate use: current evidence and clinical implications. Ther Adv Chronic Dis $\underline{6}, 185-193$

Saltin B (1988): Capacity of blood flow delivery to exercising skeletal muscle in humans. Am J Cardiol $\underline{62}, 30 \mathrm{E}-35 \mathrm{E}$

Saul D, Harlass B, Ahrabi A, Kosinsky RL, Hoffmann DB, Wassmann M, Wigger R, Böker KO, Sehmisch S, Komrakova M (2017): Effect of Strontium Ranelate on the Muscle and Vertebrae of Ovariectomized Rats. Calcif Tissue Int 102, 705-719

Sayer AA, Robinson SM, Patel HP, Shavlakadze T, Cooper C, Grounds MD (2013): New horizons in the pathogenesis, diagnosis and management of sarcopenia. Age Ageing $\underline{42}, 145-150$

Schiessl H, Frost HM, Jee WSS (1998): Estrogen and Bone-Muscle Strength and Mass Relationships. Bone $\underline{22}, 1-6$

Schoenau E (2005): From mechanostat theory to development of the Functional Muscle-BoneUnit. J Musculoskelet Neuronal Interact $\underline{5}, 232-238$ 


\section{Literaturverzeichnis}

Sengupta P (2013): The Laboratory Rat: Relating Its Age With Human's. Int J Prev Med $\underline{4}$, $624-630$

Sengupta S, Arshad M, Sharma S, Dubey M, Singh MM (2005): Attainment of peak bone mass and bone turnover rate in relation to estrous cycle, pregnancy and lactation in colony-bred Sprague-Dawley rats: suitability for studies on pathophysiology of bone and therapeutic measures for its management. J Steroid Biochem Mol Biol $\underline{94}, 421-429$

Shorey CD, Everitt AV, Armstrong RA, Manning LA (1993): Morphometric analysis of the muscle fibres of the soleus muscle of the ageing rat: long-term effect of hypophysectomy and food restriction. Gerontology $\underline{39}, 80-92$

Silva AM, Shen W, Heo M, Gallagher D, Wang Z, Sardinha LB, Heymsfield SB (2010): EthnicityRelated Skeletal Muscle Differences Across the Lifespan. Am J Hum Biol Off J Hum Biol Counc $\underline{22}, 76-82$

Snijders T, Verdijk LB, van Loon LJC (2009): The impact of sarcopenia and exercise training on skeletal muscle satellite cells. Ageing Res Rev $\underline{8}, 328-338$

Snijders T, Nederveen JP, Joanisse S, Leenders M, Verdijk LB, van Loon LJC, Parise G (2017): Muscle fibre capillarization is a critical factor in muscle fibre hypertrophy during resistance exercise training in older men. J Cachexia Sarcopenia Muscle $\underline{8}, 267-276$

Smith SY, Jolette J, Turner CH (2009): Skeletal health: primate model of postmenopausal osteoporosis. Am J Primatol $\underline{71}, 752-765$

Sorensen OH, Crawford GM, Mulder H, Hosking DJ, Gennari C, Mellstrom D, Pack S, Wenderoth D, Cooper C, Reginster J-Y (2003): Long-term efficacy of risedronate: a 5-year placebo- controlled clinical experience. Bone $\underline{32}, 120-126$

Sousa-Santos AR, Amaral TF (2017): Differences in handgrip strength protocols to identify sarcopenia and frailty - a systematic review. BMC Geriatr $\underline{17}, 238$

Suzuki S, Yamamuro T (1985): Long-term effects of estrogen on rat skeletal muscle. Exp Neurol 87, 291-299

Tasić-Dimov D, Dimov I (2007): Muscle fiber types and fiber morphometry in the soleus muscle of the rat. Facta Univ Ser Med Biol Serbia 


\section{Literaturverzeichnis}

Thompson DD, Simmons HA, Pirie CM, Ke HZ (1995): FDA Guidelines and animal models for osteoporosis. Bone 17, 125S-133S

Tieland M, Trouwborst I, Clark BC Skeletal muscle performance and ageing. J Cachexia Sarcopenia Muscle $\underline{9}, 3-19$

Timmerman KL, Lee JL, Dreyer HC, Dhanani S, Glynn EL, Fry CS, Drummond MJ, SheffieldMoore M, Rasmussen BB, Volpi E (2010): Insulin Stimulates Human Skeletal Muscle Protein Synthesis via an Indirect Mechanism Involving Endothelial-Dependent Vasodilation and Mammalian Target of Rapamycin Complex 1 Signaling. J Clin Endocrinol Metab 모, 3848-3857

Toth MJ, Poehlman ET, Matthews DE, Tchernof A, MacCoss MJ (2001): Effects of estradiol and progesterone on body composition, protein synthesis, and lipoprotein lipase in rats. Am J Physiol 280, E496-E501

Tzeng H-E, Muo C-H, Chen H-T, Hwang W-L, Hsu H-C, Tsai C-H (2015): Tamoxifen use reduces the risk of osteoporotic fractures in women with breast cancer in Asia: a nationwide populationbased cohort study. BMC Musculoskelet Disord $\underline{16} 123$

Verdijk LB, Koopman R, Schaart G, Meijer K, Savelberg HHCM, van Loon LJC (2007): Satellite cell content is specifically reduced in type II skeletal muscle fibers in the elderly. Am J Physiol Endocrinol Metab 292, E151-157

Verdijk LB, Snijders T, Holloway TM, VAN Kranenburg J, VAN Loon LJC (2016): Resistance Training Increases Skeletal Muscle Capillarization in Healthy Older Men. Med Sci Sports Exerc $\underline{48}, 2157-2164$

Wall BT, Dirks ML, Snijders T, Senden JMG, Dolmans J, van Loon LJC (2014): Substantial skeletal muscle loss occurs during only 5 days of disuse. Acta Physiol Oxf Engl 210, 600-611

Weidemann A: Der Einfluss von Strontiumranelat auf die metaphysäre Frakturheilung osteopener Ratten. Med. Diss. Göttingen 2013

Wolff J: Das Gesetz der Transformation der Knochen. Pro Business, Berlin 2010 (Reprint der Ausgabe Hirschwald, Berlin 1892)

Writing Group for the Women's Health Initiative Investigators (2002): Risks and benefits of 


\section{Literaturverzeichnis}

estrogen plus progestin in healthy postmenopausal women: Principal results from the women's health initiative randomized controlled trial. JAMA $288,321-333$

Wronski TJ, Cintrón M, Dann LM (1988): Temporal relationship between bone loss and increased bone turnover in ovariectomized rats. Calcif Tissue Int $\underline{43}, 179-183$

Wronski TJ, Dann LM, Horner SL (1989): Time course of vertebral osteopenia in ovariectomized rats. Bone $\underline{10}, 295-301$

Yorke A, Kane AE, Hancock Friesen CL, Howlett SE, O'Blenes S (2017): Development of a Rat Clinical Frailty Index. J Gerontol A Biol Sci Med Sci $\underline{72}, 897-903$ 


\section{Danksagung}

Zunächst gilt mein Dank Prof. Dr. med. em. Klaus Michael Stürmer sowie Prof. Dr. Wolfgang Lehmann als Direktoren für die Ermöglichung des Projekts und an die Elsbeth-Bonhoff Stiftung für die Unterstüzung des Projekts. Mein besonderer Dank gilt Ramona Castro-Machguth, Annette Witt sowie Ruth Wigger für die Unterstützung in technischen Dingen, die Motivation und die lange Ausdauer. Mein ganz besonderer Dank gilt Frau Dr. rer. nat. Komrakova. 